\title{
Plasma-Assisted Atomic Layer Deposition: Basics, Opportunities, and Challenges
}

H. B. Profijt, S. E. Potts, M. C. M. van de Sanden, and W. M. M. Kessels

Citation: Journal of Vacuum Science \& Technology A: Vacuum, Surfaces, and Films 29, 050801 (2011); doi: 10.1116/1.3609974

View online: http://dx.doi.org/10.1116/1.3609974

View Table of Contents: http://avs.scitation.org/toc/jva/29/5

Published by the American Vacuum Society

\section{Articles you may be interested in}

Surface chemistry of atomic layer deposition: A case study for the trimethylaluminum/water process Journal of Vacuum Science \& Technology A: Vacuum, Surfaces, and Films 97, 121301121301 (2005); $10.1063 / 1.1940727$

Crystallinity of inorganic films grown by atomic layer deposition: Overview and general trends Journal of Vacuum Science \& Technology A: Vacuum, Surfaces, and Films 113, 021301021301 (2013); $10.1063 / 1.4757907$

Atomic layer deposition of metal and nitride thin films: Current research efforts and applications for semiconductor device processing Journal of Vacuum Science \& Technology A: Vacuum, Surfaces, and Films 21, (2016); 10.1116/1.1622676

Review Article: Recommended reading list of early publications on atomic layer deposition-Outcome of the "Virtual Project on the History of ALD"

Journal of Vacuum Science \& Technology A: Vacuum, Surfaces, and Films 35, 010801010801 (2016); $10.1116 / 1.4971389$

Overview of atomic layer etching in the semiconductor industry Journal of Vacuum Science \& Technology A: Vacuum, Surfaces, and Films 33, 020802020802 (2015); $10.1116 / 1.4913379$

Plasma-enhanced atomic layer deposition of Ta and Ti for interconnect diffusion barriers Journal of Vacuum Science \& Technology A: Vacuum, Surfaces, and Films 18, (2016); 10.1116/1.1305809

\section{HDEN}

\section{Instruments for Advanced Science}
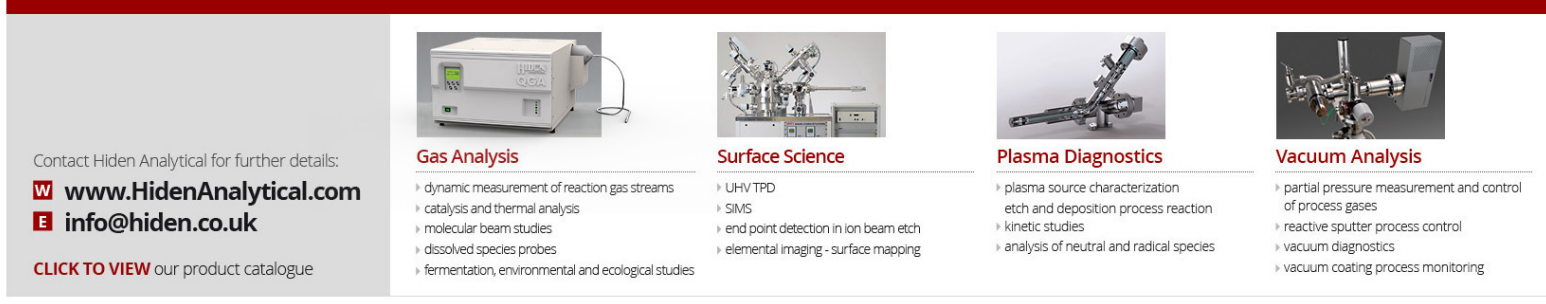


\title{
REVIEW ARTICLE
}

\section{Plasma-Assisted Atomic Layer Deposition: Basics, Opportunities, and Challenges}

\author{
H. B. Profijt, S. E. Potts, M. C. M. van de Sanden, and W. M. M. Kessels ${ }^{a)}$ \\ Department of Applied Physics, Eindhoven University of Technology, P.O. Box 513, 5600 MB Eindhoven, \\ The Netherlands
}

(Received 22 February 2011; accepted 19 June 2011; published 18 August 2011)

\begin{abstract}
Plasma-assisted atomic layer deposition (ALD) is an energy-enhanced method for the synthesis of ultra-thin films with $\AA$-level resolution in which a plasma is employed during one step of the cyclic deposition process. The use of plasma species as reactants allows for more freedom in processing conditions and for a wider range of material properties compared with the conventional thermallydriven ALD method. Due to the continuous miniaturization in the microelectronics industry and the increasing relevance of ultra-thin films in many other applications, the deposition method has rapidly gained popularity in recent years, as is apparent from the increased number of articles published on the topic and plasma-assisted ALD reactors installed. To address the main differences between plasma-assisted ALD and thermal ALD, some basic aspects related to processing plasmas are presented in this review article. The plasma species and their role in the surface chemistry are addressed and different equipment configurations, including radical-enhanced ALD, direct plasma ALD, and remote plasma ALD, are described. The benefits and challenges provided by the use of a plasma step are presented and it is shown that the use of a plasma leads to a wider choice in material properties, substrate temperature, choice of precursors, and processing conditions, but that the processing can also be compromised by reduced film conformality and plasma damage. Finally, several reported emerging applications of plasma-assisted ALD are reviewed. It is expected that the merits offered by plasma-assisted ALD will further increase the interest of equipment manufacturers for developing industrial-scale deposition configurations such that the method will find its use in several manufacturing applications. (C) 2011 American Vacuum Society.
\end{abstract}

[DOI: 10.1116/1.3609974]

\section{INTRODUCTION}

Atomic layer deposition (ALD) is a vapor-phase deposition technique in which ultra-thin films are typically synthesized sub-monolayer by sub-monolayer by repeating two subsequently executed half-cycles. ${ }^{1-10}$ See Fig. 1 for a schematic illustration of an ALD cycle. ALD offers atomic layer precision of the growth, because the reaction of the species dosed during the two half-cycles is self-limiting. As a consequence, when sufficient precursor and reactant species are dosed, the ALD film growth is not flux-dependent, as is the case with deposition techniques such as chemical vapor deposition (CVD) and physical vapor deposition (PVD). The growth rate with respect to ALD is expressed as the growth per cycle (GPC), which is typically in the range of $0.05-0.1$ $\mathrm{nm}$ per cycle. In order to ensure that only ALD surface reactions take place and not CVD-like reactions, which can appear when precursor and reactant are present in the reactor at the same time, a purge step is executed after each halfcycle to remove the residual precursor or reactant species. The total duration of a cycle is the sum of the precursor dos-

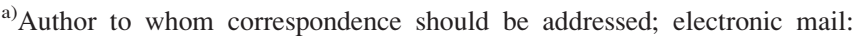
w.m.m.kessels@tue.nl
}

ing time, the precursor purge time, the reactant dose time and the reactant purge time. Consequently, the duration of one cycle cannot only be shortened by optimizing the dosing times, but also by optimizing the purge times. During ALD, the reactant is typically a gas, such as $\mathrm{O}_{2}$, or a vapor, such as $\mathrm{H}_{2} \mathrm{O}$, and the surface reactions are thermally-driven by slightly elevated substrate temperatures (typically 150-350 $\left.{ }^{\circ} \mathrm{C}\right)$. Therefore, the method is also referred to as thermal ALD. Besides the atomic control over the film thickness, the self-limiting half-cycles in ALD facilitate uniform deposition over large substrates and conformal deposition in structures of high aspect ratio, as long as the dosing and purge times are sufficiently long.

The first ALD research was conducted in the 1960s and 1970s in the former USSR and Finland, and the deposition method was patented in 1977 by Suntola. ${ }^{11}$ For a more extensive review on the history of ALD, the reader is referred to Puurunen et al. ${ }^{7}$ In the mid-1990s, the semiconductor industry became interested in ALD because a deposition method with atomic control over the film thickness and the ability to deposit films conformally on nonplanar substrates was needed. Since then, the semiconductor industry has been the key driver of the field of ALD. ${ }^{12}$ In 2007, Intel introduced its first $45 \mathrm{~nm}$ microprocessor containing Hf- 

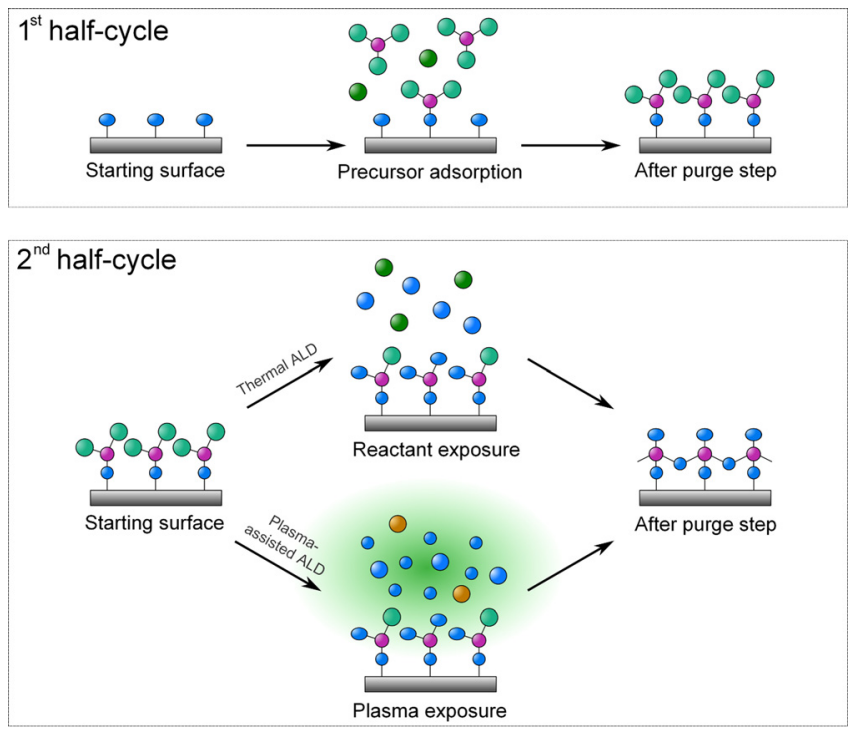

FIG. 1. (Color online) Schematic representation of thermal ALD and plasma-assisted ALD. During the co-reactant step of the cycle (the $2^{\text {nd }}$ halfcycle), the surface is exposed to a reactant gas or vapor such as $\mathrm{NH}_{3}$ or $\mathrm{H}_{2} \mathrm{O}$, or to species generated by a plasma.

based gate dielectric layers fabricated by ALD. It is expected that, starting from the $22 \mathrm{~nm}$ technology node, ALD will be used in several key process steps. ${ }^{13,14}$

Plasma-assisted ALD is an energy-enhanced ALD method that is rapidly gaining in popularity. ${ }^{15}$ In plasmaassisted ALD, also referred to as plasma enhanced ALD (PEALD), plasma ALD and, in some cases, radicalenhanced ALD, the surface is exposed to the species generated by a plasma during the reactant step. This process is also illustrated in Fig. 1. Typical plasmas used during plasma-assisted ALD are those generated in $\mathrm{O}_{2}, \mathrm{~N}_{2}$ and $\mathrm{H}_{2}$ reactant gases or combinations thereof. Such plasmas can replace ligand-exchange reactions typical of $\mathrm{H}_{2} \mathrm{O}$ or $\mathrm{NH}_{3}$, and they can be employed to deposit metal oxides, metal nitrides and metal films. Moreover, plasmas generated in gases or vapors such as $\mathrm{NH}_{3}$ and $\mathrm{H}_{2} \mathrm{O}$ have been reported, for which there can also be a combination of plasma and thermal ALD surface reactions taking place at the same time.

Plasma-assisted ALD offers several merits for the deposition of ultra-thin films over thermal ALD and other vaporphase deposition techniques. The high reactivity of the plasma species on the deposition surface during the plasmaassisted ALD process allows for more freedom in processing conditions and for a wider range of material properties. These ideas will be addressed in detail later in this review article and are the primary reason why the interest in plasmaassisted ALD has increased rapidly in recent years. This interest has also been catalyzed by the many new applications of ALD that are emerging in and outside the semiconductor industry. Several non-semiconductor applications have set new requirements for the ALD parameter space, which cannot always be satisfied easily by a pure thermally-driven ALD process.

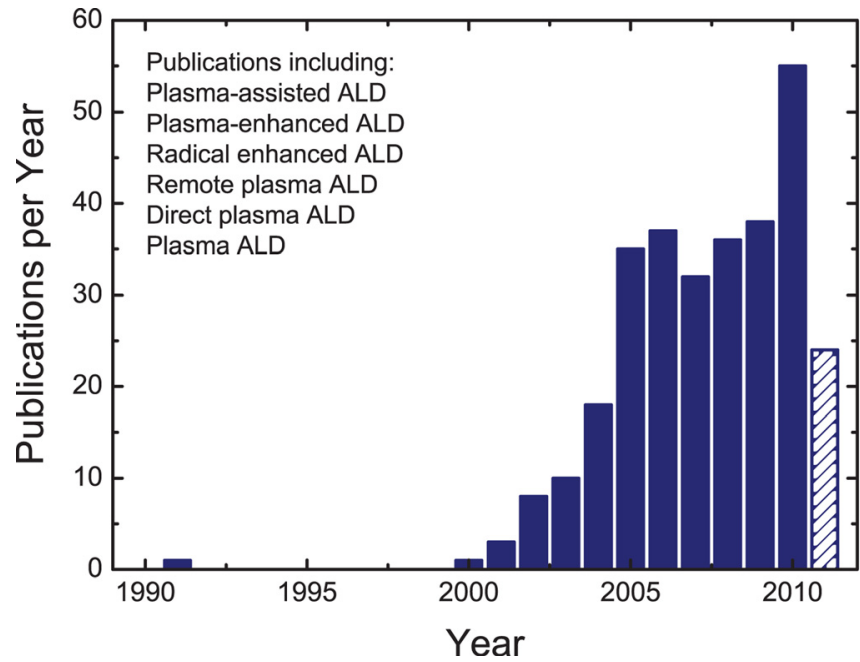

FIG. 2. (Color online) Number of publications per year on the subject of plasma-assisted ALD, between 1991 and 2011 (status May 31, 2011). The search was run in published abstracts using Web of Science ${ }^{\circledR}$ (Ref. 23). The search terms included "plasma-assisted ALD," "plasma-enhanced ALD," "radical enhanced ALD," "remote plasma ALD," "direct plasma ALD," and "plasma ALD." The first report of a plasma-assisted ALD process by De Keijser and Van Opdorp (Philips Research Laboratories, Eindhoven), published in 1991, is also included.

The increasing popularity of plasma-assisted ALD is manifested by the increasing number of recent publications about the topic (see Fig. 2), and the large set of thin film materials that have been synthesized by the method (see Table I). Such is the interest and demand in the field that the number of ALD equipment manufacturers providing dedicated plasma-assisted ALD tools has increased significantly in the recent years. Currently (status May 2011), companies such as ASM (Emerald (2005) and Stellar (2006)), ${ }^{16}$ Oxford Instruments (FlexAL (2006) and OpAL (2008)), ${ }^{17}$ Beneq (TFS 200 (2009)), ${ }^{18}$ Cambridge NanoTech (Fiji (2009)), ${ }^{19}$ Applied Materials (Applied Endura iLB (2010)), ${ }^{20}$ Tokyo Electron Limited (TELINDY PLUS IRad SA (2011)), ${ }^{21}$ and Picosun (SUNALE (2011)) ${ }^{22}$ provide tools for plasmaassisted ALD.

The first case of plasma-assisted ALD was reported in 1991, when De Keijser and Van Opdorp of the Philips Research Laboratories in Eindhoven, the Netherlands, published a paper on atomic layer epitaxy (ALE) of GaAs using $\mathrm{H}$ radicals. ${ }^{111}$ The hydrogen radicals were generated in a remote microwave-induced plasma and transported to the deposition surface through a quartz tube (see Fig. 3). The atomic hydrogen was used to drive the surface reactions after $\mathrm{GaMe}_{3}$ and $\mathrm{AsH}_{3}$ pulsing at substrate temperatures below $500{ }^{\circ} \mathrm{C}$, which is close to the onset temperature for the thermal decomposition of $\mathrm{GaMe}_{3}$. Subsequently, the method remained unexplored until the end of the 1990s, when the semiconductor industry became interested in ALD as mentioned earlier. Sherman filed a patent on the method in $1996,{ }^{298}$ after which Rossnagel and co-workers reported on plasma-assisted ALD of Ta and Ti metal films in $2000 .{ }^{206} \mathrm{In}$ the latter case, the anticipated application of the technique was the deposition of $\mathrm{Cu}$ diffusion barriers in advanced 
TABLE I. Overview of the materials deposited by plasma-assisted ALD. The material, the precursor, the plasma gas (only the reactant gas, not the carrier gas), the reactor type (" $r e$ " is radical-enhanced, " $d$ " is direct-plasma ALD, " $r$ " is remote plasma ALD, and "_-" is not specified) and the references are given for processes reported up to May 31, 2011. The search was run in published abstracts using Web of Science ${ }^{\circledR}$ (Ref. 23). acac $=$ acetylacetonate, amd $=N, N^{\prime}$-diisopropylacetamidinate, $\quad \operatorname{cod}=1,4$-cyclooctadiene, $\mathrm{Cp}=\eta^{5}$-cyclopentadienyl, $\quad \mathrm{Cp}^{*}=\eta^{5}$-pentamethylcyclopentadienyl, $\quad \mathrm{Cp}{ }^{\mathrm{Et}}=\eta^{5}$-ethylcyclopentadienyl, $\mathrm{Cp}{ }^{i \mathrm{Pr}}=\eta^{5}$ isopropylcyclopentadienyl, $\quad \mathrm{Cp}^{\mathrm{Me}}=\eta^{5}$-methylcyclopentadienyl, $\quad$ dmamb $=1$-dimethylamino-2-methyl-2-butanolate, $\quad \mathrm{dme}=$ dimethoxyethane, $\mathrm{Et}=\mathrm{ethyl}$, fod $=6,6,7,7,8,8,8$-heptafluoro-2,2-dimethyl-3,5-octanedionate, hfac =1,1,1,5,5,5-hexafluoroacetylacetonate, ${ }^{i} \mathrm{Pr}=\mathrm{isopropyl}, \mathrm{Me}=\mathrm{methyl}, \mathrm{mp}=3$-methyl-3pentoxyl, ${ }^{n} \mathrm{Bu}=$ butyl, $\mathrm{Ph}=$ phenyl, ${ }^{t} \mathrm{Bu}=$ tertiary butyl, thd $=2,2,6,6$-tetramethyl-3,5-heptanedionate, ${ }^{t} \mathrm{Pn}=$ tertiarypentyl, vtmos $=$ vinyltrimethoxylsilane.

\begin{tabular}{|c|c|c|c|c|}
\hline Material & Precursor & Plasma & Reactor & Refs. \\
\hline \multirow[t]{2}{*}{$\mathrm{Ag}$} & $\mathrm{Ag}\left(\mathrm{O}_{2} \mathrm{C}^{t} \mathrm{Bu}\right)\left(\mathrm{PEt}_{3}\right)$ & $\mathrm{H}_{2}$ & re & 24 \\
\hline & $\mathrm{Ag}\left(\mathrm{O}_{2} \mathrm{C}^{t} \mathrm{Bu}\right)\left(\mathrm{P}^{n} \mathrm{Bu}_{3}\right)$ & $\mathrm{H}_{2}$ & re & 24 \\
\hline $\mathrm{Al}$ & $\mathrm{AlH}_{3}\left(\mathrm{NEtMe}_{2}\right)$ & $\mathrm{H}_{2}$ & $d$ & 25,26 \\
\hline \multirow[t]{6}{*}{$\mathrm{Al}_{2} \mathrm{O}_{3}$} & $\mathrm{AlH}_{3}\left(\mathrm{MeNC}_{4} \mathrm{H}_{4}\right)$ & $\mathrm{O}_{2}$ & $d$ & 27 \\
\hline & $\mathrm{AlMe}_{2}\left(\mathrm{O}^{i} \mathrm{Pr}\right)$ & $\mathrm{O}_{2}$ & - & 28 \\
\hline & $\mathrm{AlMe}_{3}$ & $\mathrm{O}_{2}$ & $d, r, r e,-$ & $28-67$ \\
\hline & & $\mathrm{CO}_{2}$ & - & 68 \\
\hline & & $\mathrm{N}_{2} / \mathrm{O}_{2}$ & $d,-$ & $32,69-72$ \\
\hline & & $\mathrm{N}_{2} \mathrm{O}$ & $d$ & 73 \\
\hline \multirow[t]{3}{*}{ AlN } & $\mathrm{AlCl}_{3}$ & $\mathrm{NH}_{3} / \mathrm{H}_{2}$ & $d$ & 74,75 \\
\hline & $\mathrm{AlMe}_{3}$ & $\mathrm{NH}_{3}$ & $d, r$ & $42,76,77$ \\
\hline & & $\mathrm{H}_{2} / \mathrm{N}_{2}$ & $r$ & 78 \\
\hline $\mathrm{AlO}_{x} \mathrm{~N}_{y}$ & $\mathrm{AlMe}_{3}$ & $\mathrm{O}_{2} / \mathrm{N}_{2}$ & $d$ & $30,38,79$ \\
\hline \multirow[t]{2}{*}{$\mathrm{AlSi}_{x} \mathrm{O}_{y}$} & $\mathrm{AlMe}_{3}$ and $\mathrm{Si}(\mathrm{OEt})_{4}$ & $\mathrm{O}_{2} / \mathrm{N}_{2}$ & $d$ & 80 \\
\hline & & $\mathrm{O}_{2}$ & - & 81 \\
\hline \multirow[t]{2}{*}{$\mathrm{AlTi}_{x} \mathrm{O}_{y}$} & $\mathrm{AlMe}_{3}$ and $\mathrm{Ti}\left(\mathrm{O}^{i} \mathrm{Pr}\right)_{4}$ & $\mathrm{O}_{2}$ & $d$ & $82-85$ \\
\hline & & $\mathrm{N}_{2} \mathrm{O}$ & $d$ & 85 \\
\hline \multirow[t]{8}{*}{$\mathrm{Co}$} & $\mathrm{Co}(\mathrm{amd})_{2}$ & $\mathrm{NH}_{3}$ & $d$ & 86 \\
\hline & $\mathrm{Co}(\mathrm{Cp})(\mathrm{amd})$ & $\mathrm{NH}_{3}$ & $d$ & 87 \\
\hline & $\mathrm{Co}_{2}(\mathrm{CO})_{8}$ & $\mathrm{H}_{2}$ & $r$ & 88 \\
\hline & & $\mathrm{H}_{2} / \mathrm{N}_{2}$ & $r$ & 89 \\
\hline & $\mathrm{CoCp}_{2}$ & $\mathrm{NH}_{3}$ & $r$ & 90,91 \\
\hline & $\mathrm{CoCp}(\mathrm{CO})_{2}$ & $\mathrm{H}_{2}$ & $r$ & 92,93 \\
\hline & & $\mathrm{H}_{2} / \mathrm{N}_{2}$ & $r$ & 89 \\
\hline & & $\mathrm{NH}_{3}$ & $r$ & 90 \\
\hline $\mathrm{Co}_{3} \mathrm{O}_{4}$ & $\mathrm{CoCp}_{2}$ & $\mathrm{O}_{2}$ & $r$ & 94 \\
\hline $\mathrm{CoSi}_{2}$ & $\mathrm{CoCp}_{2}$ & $\mathrm{NH}_{3}$ and $\mathrm{SiH}_{4}$ & $d$ & 95,96 \\
\hline \multirow[t]{4}{*}{$\mathrm{Cu}$} & $\mathrm{Cu}(\mathrm{acac})_{2}$ & $\mathrm{H}_{2}$ & $d$, re & $97-100$ \\
\hline & $\mathrm{Cu}(\mathrm{hfac})(\mathrm{vtmos})$ & $\mathrm{H}_{2}$ & - & 101 \\
\hline & $\mathrm{Cu}(\text { thd })_{2}$ & $\mathrm{H}_{2}$ & $r$ & 102 \\
\hline & $\mathrm{Cu}\left(\eta^{2}-\mathrm{OC}(\mathrm{Et})(\mathrm{Me}) \mathrm{CH}_{2} \mathrm{NMe}_{2}\right)$ & $\mathrm{H}_{2}$ & - & 103 \\
\hline $\mathrm{Er}_{2} \mathrm{O}_{3}$ & $\operatorname{Er}(\text { thd })_{3}$ & $\mathrm{O}_{2}$ & re & 104 \\
\hline $\mathrm{Ga}_{2} \mathrm{O}_{3}$ & {$\left[\mathrm{Ga}(\mathrm{Me})_{2} \mathrm{NH}_{2}\right]_{3}$} & $\mathrm{O}_{2}$ & $d$ & $105-110$ \\
\hline GaAs & $\mathrm{GaMe}_{3}$ and $\mathrm{AsH}_{3}$ & $\mathrm{H}_{2}$ & re & 111 \\
\hline $\mathrm{GaTi}_{x} \mathrm{O}_{y}$ & {$\left[\mathrm{Ga}(\mathrm{Me})_{2} \mathrm{NH}_{2}\right]_{3}$ and $\mathrm{Ti}\left(\mathrm{NMe}_{2}\right)_{4}$} & $\mathrm{O}_{2}$ & $d$ & $105,107,108,112$ \\
\hline \multirow[t]{2}{*}{$\mathrm{GeSb}_{x} \mathrm{Te}_{y}$} & $\mathrm{Ge}\left(\mathrm{NMe}_{2}\right)_{4}$ and $\mathrm{Sb}\left(\mathrm{NMe}_{2}\right)_{4}$ and $\mathrm{Te}^{i} \mathrm{Pr}_{2}$ & $\mathrm{H}_{2}$ & $d$ & 113 \\
\hline & $\mathrm{Ge}^{i} \mathrm{Bu}_{4}$ and $\mathrm{Sb}^{i} \operatorname{Pr}_{3}$ and $\mathrm{Te}^{i} \operatorname{Pr}_{2}$ & $\mathrm{H}_{2}$ & $d$ & 114 \\
\hline \multirow[t]{3}{*}{$\mathrm{HfN}$} & $\mathrm{Hf}\left(\mathrm{NMe}_{2}\right)_{4}$ & $\mathrm{H}_{2}$ & $d$ & $115-117$ \\
\hline & & $\mathrm{H}_{2} / \mathrm{N}_{2}$ & $d$ & 117 \\
\hline & & $\mathrm{N}_{2}$ & $d, r$ & 117,118 \\
\hline \multirow[t]{8}{*}{$\mathrm{HfO}_{2}$} & $\mathrm{Hf}\left(\mathrm{NEt}_{2}\right)_{4}$ & $\mathrm{O}_{2}$ & $d, r,-$ & $119-133$ \\
\hline & & $\mathrm{N}_{2} \mathrm{O}$ & $d,-$ & 126,134 \\
\hline & $\mathrm{Hf}(\mathrm{NEtMe})_{4}$ & $\mathrm{O}_{2}$ & $d, r, r e$ & $33,34,135-139$ \\
\hline & $\mathrm{Hf}\left(\mathrm{NMe}_{2}\right)_{4}$ & $\mathrm{O}_{2}$ & $d, r,-$ & $116,140-142$ \\
\hline & & $\mathrm{O}_{2} / \mathrm{N}_{2}$ & $r$ & 143 \\
\hline & $\mathrm{Hf}(\mathrm{OH})_{3} \mathrm{NH}_{2}$ & $\mathrm{O}_{2}$ & - & 144 \\
\hline & $\mathrm{Hf}(\mathrm{mp})_{4}$ & $\mathrm{O}_{2}$ & $r$ & 127 \\
\hline & $\mathrm{Hf}\left(\mathrm{O}^{t} \mathrm{Bu}\right)_{4}$ & $\mathrm{O}_{2}$ & re & 145 \\
\hline $\mathrm{HfAl}_{x} \mathrm{O}_{y}$ & $\mathrm{Al}(\mathrm{Me})_{3}$ and $\mathrm{Hf}(\mathrm{NEtMe})_{4}$ & $\mathrm{O}_{2}$ & $d$ & 33,34 \\
\hline \multirow[t]{2}{*}{$\mathrm{HfO}_{x} \mathrm{~N}_{y}$} & $\mathrm{Hf}\left(\mathrm{NMe}_{2}\right)_{4}$ & $\mathrm{O}_{2} / \mathrm{N}_{2}$ & $r$ & $140,143,146$ \\
\hline & $\mathrm{Hf}\left(\mathrm{NEt}_{2}\right)_{4}$ & $\mathrm{O}_{2} / \mathrm{N}_{2}$ & $r$ & 147 \\
\hline \multirow[t]{2}{*}{$\mathrm{HfSi}_{x} \mathrm{O}_{y}$} & $\mathrm{Hf}(\mathrm{NEtMe})_{4}$ and $\mathrm{Si}\left(\mathrm{NMe}_{2}\right)_{3} \mathrm{H}$ & $\mathrm{O}_{2}$ & $r$ & 147 \\
\hline & $\mathrm{Hf}\left(\mathrm{O}^{t} \mathrm{Bu}\right)_{4}$ and $\mathrm{Si}(\mathrm{OEt})_{4}$ & $\mathrm{O}_{2}$ & $r e$ & 148 \\
\hline
\end{tabular}


TABLE I. Continued.

\begin{tabular}{|c|c|c|c|c|}
\hline Material & Precursor & Plasma & Reactor & Refs. \\
\hline $\mathrm{Ir}$ & $\operatorname{Ir}\left(\mathrm{Cp}^{\mathrm{Et}}\right)(\mathrm{COD})$ & $\mathrm{NH}_{3}$ & $d,-$ & 149,150 \\
\hline \multirow[t]{2}{*}{$\mathrm{La}_{2} \mathrm{O}_{3}$} & $\mathrm{La}\left(\mathrm{Cp}^{\mathrm{Et}}\right)_{3}$ & $\mathrm{O}_{3}$ & re & 151,152 \\
\hline & $\mathrm{La}\left(\mathrm{Cp}^{i \mathrm{Pr}}\right)_{3}$ & $\mathrm{O}_{2}$ & $r$,re & $53,139,153,154$ \\
\hline $\mathrm{LaHf}_{x} \mathrm{O}_{y}$ & $\mathrm{La}\left(\mathrm{Cp}^{i \mathrm{Pr}}\right)_{3}$ and $\mathrm{Hf}(\mathrm{NEtMe})_{4}$ & $\mathrm{O}_{2}$ & re & 139,155 \\
\hline $\mathrm{NbN}$ & $\mathrm{Nb}\left(\mathrm{N}^{t} \mathrm{Bu}\right)(\mathrm{NEtMe})_{3}$ & $\mathrm{H}_{2}, \mathrm{H}_{2} / \mathrm{N}_{2}, \mathrm{NH}_{3}$ & $r$ & 156,157 \\
\hline \multirow[t]{3}{*}{$\mathrm{Ni}$} & $\mathrm{Ni}(\mathrm{dmamb})_{2}$ & $\mathrm{NH}_{3}, \mathrm{H}_{2}$ & $d$ & 158 \\
\hline & "Bis-Ni(II)" & $\mathrm{H}_{2}$ & - & 159 \\
\hline & $\mathrm{Ni}\left(\mathrm{Cp}^{\mathrm{Et}}\right)_{2}$ & $\mathrm{H}_{2}$ & - & 160 \\
\hline $\mathrm{NiSi}_{2}$ & $\mathrm{Ni}(\mathrm{dmamb})_{2}$ & $\mathrm{NH}_{3} / \mathrm{SiH}_{4}$ & $d$ & 95 \\
\hline \multirow[t]{2}{*}{$\mathrm{Pd}$} & $\mathrm{Pd}(\mathrm{hfac})_{2}$ & $\mathrm{H}_{2}$ & $r$ & 161,162 \\
\hline & $\mathrm{Pd}(\mathrm{hfac})_{2}$ & $\mathrm{H}_{2} / \mathrm{N}_{2}$ & $r$ & 163 \\
\hline $\mathrm{Pt}$ & $\mathrm{Pt}\left(\mathrm{Cp}^{\mathrm{Me}}\right) \mathrm{Me}_{3}$ & $\mathrm{O}_{2}$ & $r$ & 164 \\
\hline $\mathrm{PtO}_{2}$ & $\mathrm{Pt}\left(\mathrm{Cp}^{\mathrm{Me}}\right) \mathrm{Me}_{3}$ & $\mathrm{O}_{2}$ & $r$ & 164 \\
\hline \multirow[t]{6}{*}{$\mathrm{Ru}$} & $\mathrm{Ru}\left(\mathrm{Cp}^{\mathrm{Et}}\right)_{2}$ & $\mathrm{NH}_{3}$ & $d, r,-$ & $165-174$ \\
\hline & & $\mathrm{H}_{2} / \mathrm{N}_{2}$ & $d,-$ & $175-178$ \\
\hline & $\mathrm{RuCp}(\mathrm{CO})_{2} \mathrm{Et}$ & $\mathrm{O}_{2}$ & $r$ & 179 \\
\hline & $\mathrm{Ru}(\mathrm{Cp})_{2}$ & $\mathrm{NH}_{3}$ & - & 173 \\
\hline & $\mathrm{Ru}\left(\mathrm{Cp}^{\mathrm{Et}}\right)\left(\mathrm{NC}_{4} \mathrm{H}_{4}\right)$ & $\mathrm{NH}_{3}$ & $d,-$ & 180,181 \\
\hline & $\mathrm{Ru}\left(1-{ }^{i} \mathrm{Pr}-4-\mathrm{MeC}_{6} \mathrm{H}_{4}\right)\left(1,3-\mathrm{C}_{6} \mathrm{H}_{8}\right)$ & $\mathrm{NH}_{3}$ & $d$ & 182,183 \\
\hline \multirow[t]{6}{*}{$\mathrm{SiO}_{2}$} & $\mathrm{SiH}_{4}$ & $\mathrm{~N}_{2} \mathrm{O}$ & - & 184 \\
\hline & $\mathrm{SiH}_{2}\left(\mathrm{NEt}_{2}\right)_{2}$ & $\mathrm{O}_{2}$ & $d$ & 185 \\
\hline & $\mathrm{SiH}_{3} \mathrm{NH}_{2}$ & $\mathrm{O}_{2}$ & $d$ & 186 \\
\hline & $\mathrm{Si}\left(\mathrm{NMe}_{2}\right)_{4}$ and $\mathrm{Si}\left(\mathrm{NMe}_{2}\right)_{3} \mathrm{Cl}($ mix $)$ & $\mathrm{O}_{2} / \mathrm{N}_{2}$ & $d$ & 187 \\
\hline & $\mathrm{Si}(\mathrm{OEt})_{4}$ & $\mathrm{O}_{2}$ & $r$ & 188 \\
\hline & {$\left[\mathrm{SiMe}_{2} \mathrm{O}-\right]_{4}$} & $\mathrm{O}_{2}$ & - & 189 \\
\hline $\mathrm{SiN}_{x}$ & $\mathrm{SiH}\left(\mathrm{N}^{i} \mathrm{PrH}\right)_{3}$ & $\mathrm{NH}_{3}$ & $d$ & 182 \\
\hline $\mathrm{SnO}_{2}$ & $\mathrm{Sn}\left(\mathrm{O}_{2} \mathrm{CMe}\right)_{2}\left({ }^{n} \mathrm{Bu}\right)_{2}$ & $\mathrm{O}_{2}$ & - & 190-194 \\
\hline \multirow[t]{3}{*}{$\mathrm{SrO}$} & $\mathrm{Sr}\left(\mathrm{C}_{5} \mathrm{H}_{2}{ }^{i} \mathrm{Pr}_{3}\right)_{2}(\mathrm{dme})$ & $\mathrm{O}_{2}$ & $r$ & 195 \\
\hline & $\mathrm{Sr}\left(\mathrm{C}_{11} \mathrm{H}_{19} \mathrm{O}_{2}\right)_{2}$ & $\mathrm{O}_{2}$ & - & $196-198$ \\
\hline & $\mathrm{Sr}(\text { thd })_{2}$ & $\mathrm{O}_{2}$ & $d$ & 199 \\
\hline \multirow[t]{2}{*}{$\mathrm{SrTaO}_{6}$} & $\mathrm{Sr}\left[\mathrm{Ta}(\mathrm{OEt})_{5}\left(\mathrm{OCH}_{2} \mathrm{CH}_{2} \mathrm{NMe}_{2}\right)\right]_{2}$ & $\mathrm{O}_{2}$ & $d$ & 200 \\
\hline & $\mathrm{Sr}\left[\mathrm{Ta}(\mathrm{OEt})_{5}\left(\mathrm{OCH}_{2} \mathrm{CH}_{2} \mathrm{OMe}\right)\right]_{2}$ & $\mathrm{O}_{2}$ & $d$ & 201,202 \\
\hline \multirow[t]{2}{*}{$\mathrm{SrTiO}_{3}$} & $\operatorname{Sr}(\text { thd })_{2}$ and $\operatorname{Ti}\left(\mathrm{O}^{i} \operatorname{Pr}\right)_{4}$ & $\mathrm{O}_{2}$ & $d$ & $196-198$ \\
\hline & $\mathrm{Ti}\left(\mathrm{Cp}^{*}\right)(\mathrm{OMe})_{3}$ and $\mathrm{Sr}\left(\mathrm{C}_{5} \mathrm{H}_{2}{ }^{i} \mathrm{Pr}_{3}\right)_{2}(\mathrm{dme})$ & $\mathrm{O}_{2}$ & $r$ & 195 \\
\hline $\mathrm{SrBi}_{x} \mathrm{Ta}_{y}$ & $\begin{array}{c}\mathrm{Sr}\left[\mathrm{Ta}(\mathrm{OEt})_{5}\left(\mathrm{OCH}_{2} \mathrm{CH}_{2} \mathrm{OMe}\right)\right]_{2} \\
\text { and } \mathrm{BiPh}_{3}(\operatorname{mix})\end{array}$ & $\mathrm{O}_{2}$ & $d$ & 202,203 \\
\hline $\mathrm{Ta}$ & $\mathrm{TaCl}_{5}$ & $\mathrm{H}_{2}$ & $r$ & 204-206 \\
\hline \multirow[t]{3}{*}{$\mathrm{TaO}_{x}$} & $\mathrm{Ta}\left(\mathrm{NMe}_{2}\right)_{5}$ & $\mathrm{O}_{2}$ & $r$ & $56,207-209$ \\
\hline & & $\mathrm{O}_{2} / \mathrm{N}_{2}$ & $r$ & 209 \\
\hline & $\mathrm{Ta}(\mathrm{OEt})_{5}$ & $\mathrm{O}_{2}$ & $r e,-$ & 210,211 \\
\hline \multirow[t]{5}{*}{$\mathrm{TaC}_{x} \mathrm{~N}_{y}$} & $\mathrm{Ta}\left(\mathrm{N}^{t} \mathrm{Bu}\right)\left(\mathrm{NEt}_{2}\right)_{3}$ & $\mathrm{H}_{2}$ & $d$ & 212,213 \\
\hline & & $\mathrm{NH}_{3}$ & $d$ & 214 \\
\hline & & $\mathrm{CH}_{4} / \mathrm{H}_{2}$ & $d$ & 215 \\
\hline & $\mathrm{Ta}\left(\mathrm{N}^{t} \mathrm{Pn}\right)\left(\mathrm{NMe}_{2}\right)_{3}$ & $\mathrm{H}_{2}$ & $d$ & 216 \\
\hline & $\mathrm{Ta}\left(\mathrm{NMe}_{2}\right)_{5}$ & $\mathrm{H}_{2}$ & $r$ & 217 \\
\hline \multirow[t]{11}{*}{$\mathrm{TaN}_{x}$} & $\mathrm{TaCl}_{5}$ & $\mathrm{H}_{2} / \mathrm{N}_{2}$ & $r,-$ & $218-220$ \\
\hline & $\mathrm{TaF}_{5}$ & $\mathrm{H}_{2} / \mathrm{N}_{2}$ & $d$ & 221 \\
\hline & $\mathrm{Ta}\left(\mathrm{NMe}_{2}\right)_{5}$ & $\mathrm{H}_{2}$ & $r,-$ & $207,222-224$ \\
\hline & & $\mathrm{N}_{2}$ & $r$ & 225 \\
\hline & & $\mathrm{H}_{2} / \mathrm{N}_{2}$ & $r$ & 223,226 \\
\hline & & $\mathrm{NH}_{3}$ & $r,-$ & $174,223,225$ \\
\hline & $\mathrm{Ta}\left(\mathrm{N}^{t} \mathrm{Bu}\right)\left(\mathrm{NEt}_{2}\right)_{3}$ & $\mathrm{H}_{2}$ & $d, r$ & 227-229 \\
\hline & & $\mathrm{NH}_{3}$ & - & 181 \\
\hline & $\mathrm{Ta}\left(\mathrm{N}^{t} \mathrm{Bu}\right)(\mathrm{NEtMe})_{3}$ & $\mathrm{H}_{2}$ & - & 230 \\
\hline & $\mathrm{Ta}\left(\mathrm{N}^{i} \mathrm{Pr}\right)(\mathrm{NEtMe})_{3}$ & $\mathrm{H}_{2} / \mathrm{N}_{2}$ & $r$ & 231 \\
\hline & $\mathrm{Ta}\left(\mathrm{N}^{t} \mathrm{Pn}\right)\left(\mathrm{NMe}_{2}\right)_{3}$ & $\mathrm{H}_{2}$ & - & 175 \\
\hline $\mathrm{Ti}$ & $\mathrm{TiCl}_{4}$ & $\mathrm{H}_{2}$ & $r$ & 206,232 \\
\hline \multirow[t]{2}{*}{$\operatorname{TiN}_{x}$} & $\mathrm{TiCl}_{4}$ & $\mathrm{H}_{2} / \mathrm{N}_{2}$ & $d, r$ & $31,51,136,222,233-238$ \\
\hline & & $\mathrm{H}_{2}, \mathrm{D}_{2}$ & re & 239 \\
\hline
\end{tabular}


TABLE I. Continued.

\begin{tabular}{|c|c|c|c|c|}
\hline Material & Precursor & Plasma & Reactor & Refs. \\
\hline & $\mathrm{Ti}\left(\mathrm{NMe}_{2}\right)_{4}$ & $\mathrm{H}_{2}$ & $d$ & 240 \\
\hline & & $\mathrm{N}_{2}$ & $r,-$ & 177,241 \\
\hline & & $\mathrm{H}_{2} / \mathrm{N}_{2}$ & - & 176 \\
\hline & & $\mathrm{H}_{2}, \mathrm{~N}_{2}, \mathrm{H}_{2} / \mathrm{N}_{2}$ & $d, r$ & 242,243 \\
\hline & & $\mathrm{H}_{2}, \mathrm{~N}_{2}, \mathrm{NH}_{3}$ & $r$ & 244 \\
\hline & & $\mathrm{NH}_{3}$ & $r$ & 171,245 \\
\hline \multirow{10}{*}{$\mathrm{TiO}_{2}$} & $\mathrm{TiCl}_{4}$ & $\mathrm{O}_{2}$ & $r$ & 246,247 \\
\hline & $\mathrm{Ti}\left(\mathrm{Cp}^{\mathrm{Me}}\right)\left(\mathrm{O}^{i} \mathrm{Pr}\right)_{3}$ & $\mathrm{O}_{2}$ & $r$ & 56 \\
\hline & $\mathrm{Ti}(\mathrm{Cp} *)(\mathrm{OMe})_{3}$ & $\mathrm{O}_{2}$ & $r$ & 56 \\
\hline & $\mathrm{Ti}\left(\mathrm{Cp}^{\mathrm{Me}}\right)\left(\mathrm{NMe}_{2}\right)_{3}$ & $\mathrm{O}_{2}$ & $r$ & 248 \\
\hline & $\mathrm{Ti}\left(\mathrm{NMe}_{2}\right)_{4}$ & $\mathrm{O}_{2}$ & $d, r,-$ & $112,142,208,249-257$ \\
\hline & & $\mathrm{H}_{2} \mathrm{O}$ & $r$ & 254 \\
\hline & $\operatorname{Ti}\left(\mathrm{O}^{i} \operatorname{Pr}\right)_{4}$ & $\mathrm{O}_{2}$ & $d, r, r e,-$ & $56,79,85,137,149,254,258-265$ \\
\hline & & $\mathrm{N}_{2} \mathrm{O}$ & $d$ & 85,259 \\
\hline & & $\mathrm{O}_{2} / \mathrm{N}_{2}$ & $d,-$ & 79,266 \\
\hline & & $\mathrm{H}_{2} \mathrm{O}$ & $r$ & 254 \\
\hline $\mathrm{TiO}_{x} \mathrm{~N}_{y}$ & $\mathrm{AlMe}_{3}$ & $\mathrm{O}_{2} / \mathrm{N}_{2}$ & $d$ & 79 \\
\hline \multirow{2}{*}{$\mathrm{TiAl}_{x} \mathrm{~N}_{y}$} & $\mathrm{TiCl}_{4}$ and $\mathrm{AlCl}_{3}$ & $\mathrm{H}_{2} / \mathrm{N}_{2}, \mathrm{NH}_{3} / \mathrm{H}_{2}$ & $d$ & 267 \\
\hline & $\mathrm{Ti}\left(\mathrm{NMe}_{2}\right)_{4}$ and $\mathrm{AlMe}_{3}$ & $\mathrm{H}_{2}, \mathrm{NH}_{3}$ & $d$ & 268 \\
\hline $\operatorname{TiSi}_{x} \mathrm{~N}_{y}$ & $\mathrm{TiCl}_{4}$ and $\mathrm{SiH}_{4}$ & $\mathrm{H}_{2} / \mathrm{N}_{2}$ & $d$ & 269 \\
\hline $\mathrm{TiSi}_{x} \mathrm{O}_{y}$ & $\mathrm{Ti}\left(\mathrm{O}^{i} \mathrm{Pr}\right)_{4}$ and $\mathrm{Si}(\mathrm{OEt})_{4}$ & $\mathrm{O}_{2}$ & $d$ & 270 \\
\hline $\mathrm{V}_{x} \mathrm{O}_{y}$ & $\mathrm{VO}\left(\mathrm{O}^{i} \mathrm{Pr}\right)_{3}$ & $\mathrm{O}_{2}, \mathrm{H}_{2} \mathrm{O}$ & $r$ & 271 \\
\hline $\mathrm{WC}_{x}$ & $\mathrm{~W}\left(\mathrm{~N}^{t} \mathrm{Bu}\right)_{2}\left(\mathrm{NMe}_{2}\right)_{2}$ & $\mathrm{H}_{2} / \mathrm{N}_{2}$ & $d$ & 272 \\
\hline $\mathrm{WN}_{x}$ & $\mathrm{WF}_{6}$ & $\mathrm{NH}_{3}$ & $d, r$ & 273,274 \\
\hline \multirow[t]{2}{*}{$\mathrm{WC}_{x} \mathrm{~N}_{y}$} & $\mathrm{~W}\left(\mathrm{Cp}^{\mathrm{Et}}\right)(\mathrm{CO})_{2}(\mathrm{NO})$ & $\mathrm{H}_{2}$ & $d$ & 180 \\
\hline & $\mathrm{WF}_{6}$ & $\mathrm{~N}_{2} / \mathrm{NH}_{3} \& \mathrm{CH}_{4}$ & $d$ & 273 \\
\hline $\mathrm{Y}_{2} \mathrm{O}_{3}$ & $\mathrm{Y}(\text { thd })_{3}$ & $\mathrm{O}_{2}$ & re & 104,275 \\
\hline $\mathrm{Y}_{2} \mathrm{O}_{3}: \mathrm{Er}$ & $\mathrm{Y}(\text { thd })_{3}$ and $\operatorname{Er}(\text { thd })_{3}$ & $\mathrm{O}_{2}$ & re & 276-279 \\
\hline \multirow[t]{3}{*}{$\mathrm{ZnO}$} & $\mathrm{ZnEt}_{2}$ & $\mathrm{O}_{2}$ & $d, r,-$ & $37,280-283$ \\
\hline & & $\mathrm{N}_{2} \mathrm{O}$ & $d$ & $284-286$ \\
\hline & $\mathrm{ZnMe}_{2}$ & $\mathrm{O}_{2}$ & $d$ & 287,288 \\
\hline \multirow[t]{5}{*}{$\mathrm{ZrO}_{2}$} & $\mathrm{Zr}\left(\mathrm{NEt}_{2}\right)_{4}$ & $\mathrm{O}_{2}$ & $r,-$ & 289,290 \\
\hline & $\mathrm{Zr}(\mathrm{NEtMe})_{4}$ & $\mathrm{O}_{2}$ & $d$ & 291,292 \\
\hline & & $\mathrm{O}_{2} / \mathrm{N}_{2}$ & $d$ & $266,291-293$ \\
\hline & $\mathrm{Zr}\left(\mathrm{O}^{t} \mathrm{Bu}\right)_{4}$ & $\mathrm{O}_{2}$ & $r e,-$ & $145,290,294$ \\
\hline & & $\mathrm{H}_{2}$ & - & 295 \\
\hline \multirow[t]{2}{*}{$\mathrm{ZrN}$} & $\mathrm{Zr}\left(\mathrm{NEt}_{2}\right)_{4}$ & $\mathrm{~N}_{2}$ & $r$ & 296 \\
\hline & $\mathrm{ZrCp}_{2}\left(\mathrm{NMe}_{2}\right)_{2}, \mathrm{ZrCp}_{2}\left(\eta^{2}-\mathrm{MeNCH}_{2} \mathrm{CH}_{2} \mathrm{NMe}\right)$ & $\mathrm{H}_{2} / \mathrm{N}_{2}, \mathrm{~N}_{2}, \mathrm{NH}_{3}, \mathrm{O}_{2}$ & $r$ & 297 \\
\hline
\end{tabular}

interconnect technology, a field already very familiar with the merits and robustness of plasma-assisted processes through the broadly-applied PVD technique of sputtering. Afterwards, the number of materials, processes and applications of plasma-assisted ALD has diversified and grown rapidly.

In this article, different plasma-assisted ALD configurations will be described and the merits offered by the technique will be discussed. Also, the challenges that plasma-assisted ALD faces will be addressed, both in terms of limitations inherent to the use of a plasma-based process and in terms of the scale-up of the technique for industrial applications. Subsequently, the potential of plasma-assisted ALD will be illustrated by addressing some application areas of ultra-thin films. Next, an outlook will be given for the research and wide scale applicability of the plasma-assisted ALD method. However, to begin with, the next section will briefly cover some plasma basics for the typical plasma operating conditions employed during plasma-assisted ALD.

\section{PLASMA BASICS}

A plasma is a collection of free, charged particles, among other gas-phase species, which is, on average, electrically neutral. ${ }^{299,300}$ This so-called quasi-neutrality means that at macroscopic length scales (typically $>1 \mathrm{~mm}$ ) the electron density is equal to the ion density, i.e. $n_{e}=n_{i}$, under the assumption that negative ions can be neglected. In most plasma configurations, plasmas are created by electrical fields which lead to acceleration and heating of the electrons. These hot electrons are able to ionize gas-phase species through electron-induced collisions and, as such, they can compensate for electron-loss collisions and consequently sustain the plasma. Typically, the average electron temperature (a measure for the kinetic electron energy), $T_{e}$, is $\sim 3.5 \times 10^{4} \mathrm{~K}$ (approximately $3 \mathrm{eV}$ ) while the gas temperature remains low $\left(T_{\text {gas }}=300-500 \mathrm{~K}\right)$. This results in nonequilibrium conditions, caused by the relatively low gas pressure that is typically employed in processing plasmas, 


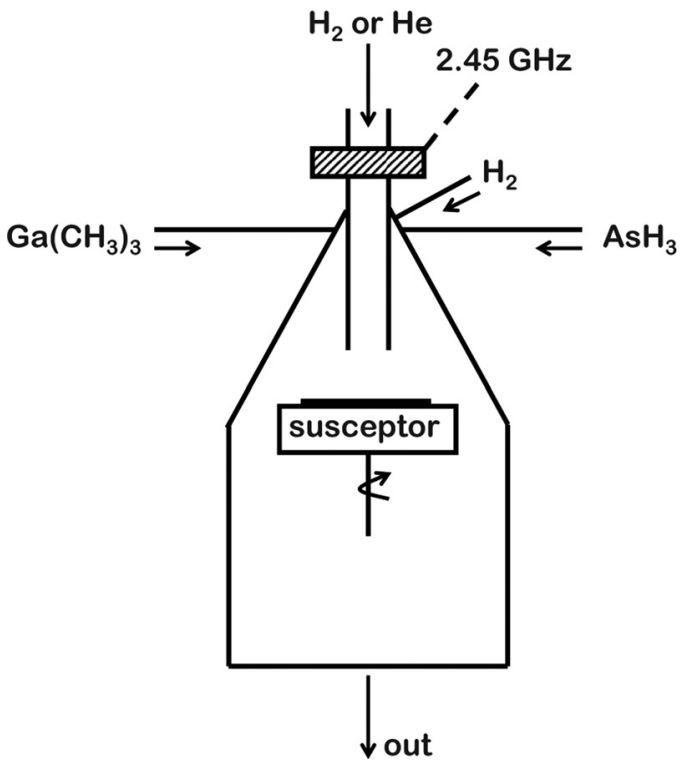

FIG. 3. Reactor layout as used in the first plasma-assisted ALD experiments (Philips Research Laboratories, Eindhoven) reported in the literature Ref. 111. An $\mathrm{H}_{2}$ plasma was generated by means of a remote microwave-induced plasma source in a quartz tube. The $\mathrm{H}$ radicals assisted in the atomic layer epitaxy (ALE) process of GaAs. Reprinted from M. de Keijser and C. van Opdorp, Appl. Phys. Lett. 58, 1188 (1991). Copyright 1991, American Institute of Physics.

which, therefore, belong to the class of so-called "cold" plasmas. The electrons in the high-energy tail of the energy distribution are not only able to ionize species, but they can also dissociate and excite the reactant gas through electronimpact collisions. This leads to the formation of reactive atomic and molecular neutrals (typically referred to as "plasma radicals"), ions, and photons. Subsequently, these species can undergo additional gas-phase reactions and they can induce surface reactions when they arrive at deposition or reactor surfaces.

Although the charged particles play a central role in sustaining the plasma, the fractional ionization or "ionization degree" of processing plasmas is very low, typically within the range $10^{-6}-10^{-3}$. This means that the fluxes of electrons and ions to the deposition surface are much lower than the flux of the plasma radicals. Therefore, in many cases, the surface chemistry is ruled by the interaction of the plasma radicals with the surface species. However, the energy of the ions, $E_{\mathrm{ion}}$, arriving at the surface can be much higher than the ion or electron temperature, as ions are accelerated within a thin positive space-charge layer, the "plasma sheath," at the boundary between the plasma and the substrate. This plasma sheath develops because the electron thermal velocity is much higher than the ion thermal velocity. To make the net current to the substrate zero, an electrical field develops between the plasma and the substrate, which retards the electrons and accelerates the ions. Therefore an electropositive plasma is (time-averaged) always at a positive potential relative to any surface in contact with it. In the rudimentary case of a floating substrate, the difference between the plasma potential, $V_{p}$, and the substrate potential, $V_{f}$, is generally given by

$$
V_{P}-V_{f}=\frac{T_{e}}{2 e}+\frac{T_{e}}{2 e} \ln \left(\frac{m_{i}}{2 \pi m_{e}}\right)
$$

where $T_{e}$ is the electron energy in $\mathrm{eV}$, and $m_{e}$ and $m_{i}$ are the electron and ion mass, respectively. This means that $V_{p}-V_{f}$ is typically a few multiples of $T_{e}$. The energy gained by the ions in the plasma sheath, and consequently whether "ion bombardment" can take place or not, also depends on the collisional mean free path of the ions and the thickness of the plasma sheath. At relatively low pressures, the ion mean free path is larger than the plasma sheath thickness, such that the ions can be accelerated over the full sheath (i.e. the plasma sheath is collisionless) and consequently $E_{\text {ion }}=e\left(V_{p}-V_{f}\right)$.

For typical processing plasmas, the potential over the plasma sheath is $<50 \mathrm{~V}$, however, depending on the plasma gas, the reactor geometry and substrate stage configuration (symmetry or asymmetry of the electrodes, grounding or biasing of electrode/substrate stage, etc.), this potential can also be as high as a few hundreds of Volts. Examples of energy distributions for ions arriving at substrates for $\mathrm{O}_{2}$, $\mathrm{N}_{2}$, and $\mathrm{H}_{2}$ plasmas under specific ALD conditions in a reactor equipped with an inductively-coupled plasma are given in Fig. 4. At higher pressures, however, the plasma sheath becomes collisional and the net energy gained by the ions is much smaller as a result. Also note that the ions in the plasma sheath are accelerated in the direction perpendicular to the (local) surface. This means that the flux of the ions to the surface is anisotropic with the ions having an angle of incidence around the normal to the surface.

The key properties of the plasma step, executed during the synthesis of thin film materials by plasma-assisted ALD, are

(1) The reactive species are created in the gas-phase, which means that a relatively high reactivity can be provided to the deposition surface (almost) independently of the

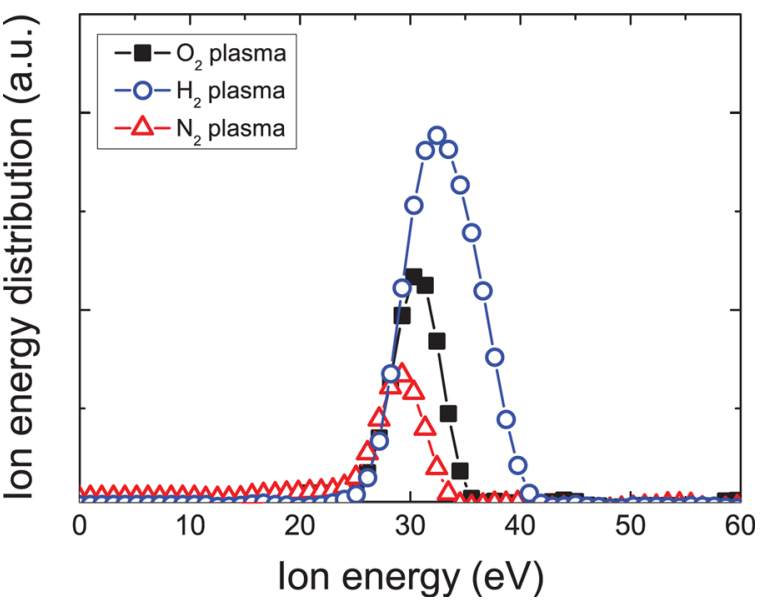

FIG. 4. (Color online) Ion energy distribution as measured by a retarding field energy analyzer (RFEA) in $\mathrm{O}_{2}, \mathrm{H}_{2}$ and $\mathrm{N}_{2}$ plasmas (operating pressure: 8 mTorr; plasma power: $100 \mathrm{~W}$ ) used for remote plasma-assisted ALD. The RFEA was positioned at the substrate stage. Measurements were performed in the home-built ALD-I reactor installed at Eindhoven University of Technology. Due to non-ideal effects such as capacitive coupling, the ion energies measured are higher than those measured in the Oxford Instruments FlexAL reactor, which are reported elsewhere (Ref. 303). 
substrate conditions (e.g. substrate temperature and substrate materials). The reactivity of the plasma can also be "selective" (e.g. in terms of reactive species produced) by tuning its properties and composition by carefully choosing the plasma operating conditions (gases, flows, power, pressure, etc.).

(2) Typically the plasma supplies a relatively low heat flux to the surface, despite its high reactivity. The reason is that, for cold plasmas, only the electrons are heated significantly and not the other gas-phase species. Furthermore, plasma exposure takes place only during a part of the cycle (typically only for a few seconds) which does not allow the plasma to extensively heat the substrate.

(3) Through ion bombardment, additional energy can be provided to the deposition surface. This energy is locally dissipated by the surface species and can enhance surface reaction rates and processes such as surface diffusion. Possible ion-surface interactions are depicted in Fig. 5 for typical ranges of ion energy and ion flux towards the substrate, corresponding to various plasma-assisted techniques. Moreover, the presence and level of ion bombardment can be controlled through the plasma operating conditions (mainly the gas pressure) as well as by the choice of plasma configuration and substrate (stage) conditions (e.g. grounded substrate, stage size and substrate bias).

These key properties can be summarized by the phrase: plasmas can deliver a high, diverse but selective reactivity to a surface without heat, and can therefore access a parameter space in materials processing, which is not easily accessible with strictly chemical methods. ${ }^{299,300}$

Other key differences between plasma-assisted ALD and thermal ALD include.

(1) Electron-impact collisions, as well as other reactions, which lead to the excitation of atoms and molecules. This excitation can be electronic for atoms and electronic, vibrational, and rotational for molecules. When

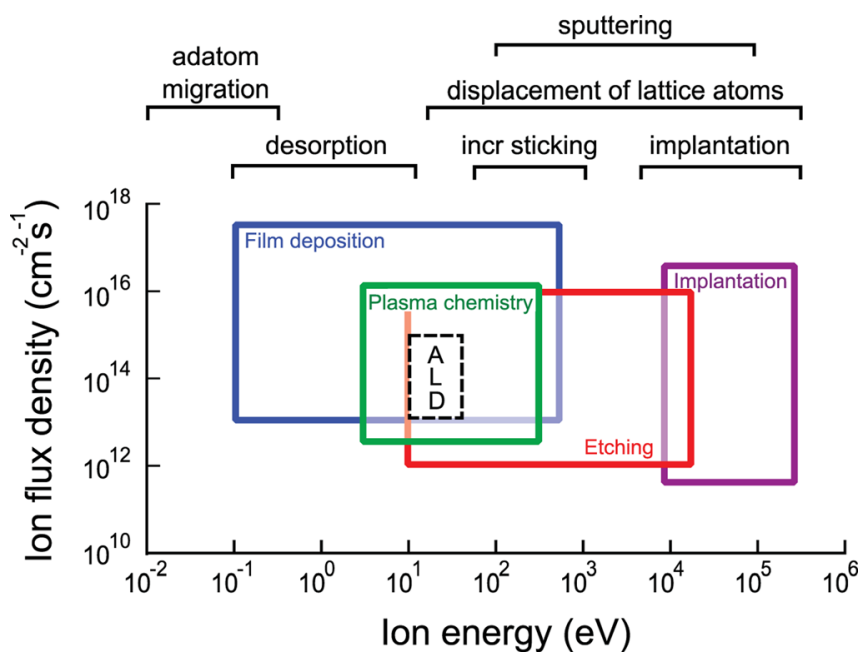

FIG. 5. (Color online) Ion-surface interactions during plasma processes with respect to ion flux and ion energy (Ref. 345). The typical operating windows for remote plasma ALD and other plasma-based processes are indicated. Reprinted with permission from T. Tagaki, J. Vac. Sci. Technol. A 2, 382 (1984). Copyright 1984 American Vacuum Society. electronically excited states return to the ground state, they emit their energy as electromagnetic radiation, which can be measured using optical emission spectroscopy (OES). ${ }^{42,46,47,52,119,137,138,148,223,237,271,289,301-303}$ This excitation process accounts for the vacuum ultraviolet (VUV) to visible emission by the plasma as shown in the OES spectra of $\mathrm{O}_{2}, \mathrm{H}_{2}$, and $\mathrm{N}_{2}$ plasmas in Figs. 6(a)-6(c), for example. The emission in the visible region gives the plasma its characteristic color (as illustrated by the insets of Figs. 6(a)-6(c)) and, therefore, its spectral fingerprint
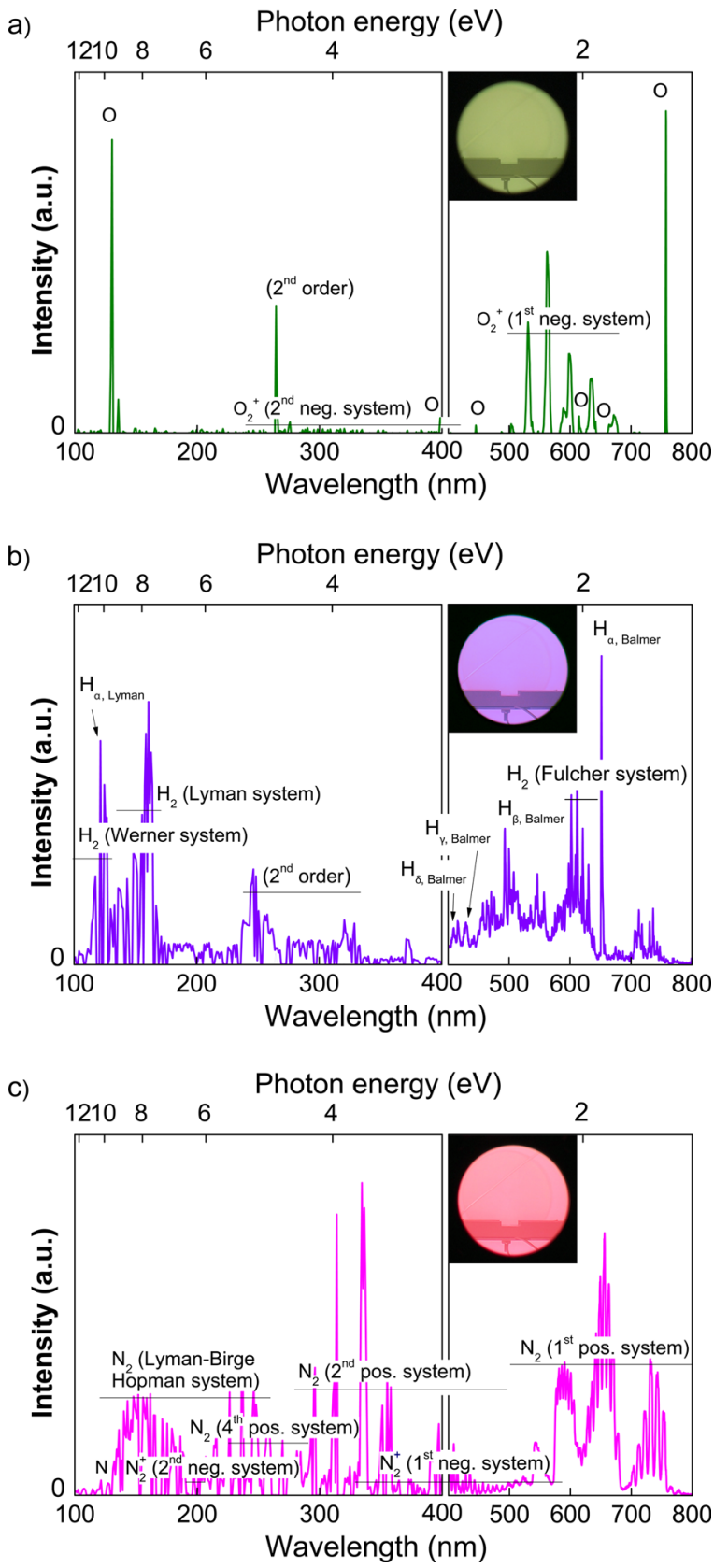

FIG. 6. (Color online) Optical emission spectra of plasma radiation in (a) an $\mathrm{O}_{2}$ plasma, (b) an $\mathrm{H}_{2}$ plasma, and (c) a $\mathrm{N}_{2}$ plasma as used for plasma-assisted ALD (operating pressure: 8 mTorr; plasma power: $100 \mathrm{~W}$ ). The emission in the (vacuum) ultraviolet region was measured by means of a VUV monochromator and the emission in the visible by a simple spectrometer (Refs. 302, 303). Emission peaks were identified using the literature (Refs. 373-377). The insets show photographs of the corresponding plasmas. 
can be easily used to extract information about the species present in the plasma as well as about the chemical and physical processes occurring both within the plasma and at the surface. Measuring the visible emission of the plasma also provides many opportunities for plasmaassisted ALD in terms of process monitoring and optimization. $^{302}$ The emission in the ultraviolet can, however, also be sufficiently energetic to influence and induce (unfavorable) processes at surfaces or within thin films (see Sec. V). ${ }^{303}$

(2) Creation of reactant species from the reactant gas during the plasma step, which are mainly radicals. Apart from the ALD surface reactions, these radicals can also undergo additional reactions at the surface, even at saturated surface sites. For example, radicals can recombine on wall (and deposition) surfaces to form nonreactive molecules that desorb back into the plasma. The probability of such recombination reactions, the so-called surface recombination probability, $r$, can be as small as $10^{-6}$ and as high as 1 (see Table II). ${ }^{304}$ The value of $r$ has a direct impact on the density of the radicals in the plasma as it defines the surface loss term for the radicals. Moreover, a relatively high $r$ can also significantly reduce the flux of radicals in trenches or other high-aspectratio features on the substrate, for which the radicals have to undergo multiple wall collisions to reach deep inside the structures (see Sec. V).

(3) The presence of a multitude of gas-phase and surface species, which makes it not possible to identify single reac-

TABLE II. Overview of recombination loss probabilities, $r$, for $\mathrm{H}, \mathrm{N}$ and $\mathrm{O}$ radicals on the surfaces of various materials (Ref. 304). Accuracies in the values are indicated where available. The data are taken from Refs. 305310 .

\begin{tabular}{|c|c|c|}
\hline Radical & Surface & $r$ \\
\hline \multirow[t]{11}{*}{$\mathrm{H}$} & $\mathrm{SiO}_{2}$ & $0.00004 \pm 0.00003$ \\
\hline & $\mathrm{Al}_{2} \mathrm{O}_{3}$ & $0.0018 \pm 0.0003$ \\
\hline & Pyrex & $0.0058 \pm 0.0018$ \\
\hline & Stainless steel & $0.032 \pm 0.015$ \\
\hline & $\mathrm{Ti}$ & 0.35 \\
\hline & $\mathrm{Al}$ & 0.29 \\
\hline & $\mathrm{Ni}$ & $0.20 \pm 0.09$ \\
\hline & $\mathrm{Cu}$ & 0.14 \\
\hline & $\mathrm{Au}$ & $0.15 \pm 0.05$ \\
\hline & $\mathrm{Pd}$ & $0.07 \pm 0.015$ \\
\hline & $\mathrm{Pt}$ & 0.03 \\
\hline \multirow[t]{4}{*}{$\mathrm{N}$} & $\mathrm{SiO}_{2}$ & $0.0003 \pm 0.0002$ \\
\hline & Stainless steel & 0.0063 \\
\hline & $\mathrm{Si}$ & 0.0016 \\
\hline & $\mathrm{Al}$ & 0.0018 \\
\hline \multirow[t]{9}{*}{$\mathrm{O}$} & $\mathrm{SiO}_{2}$ & $0.0002 \pm 0.0001$ \\
\hline & Pyrex & 0.000045 \\
\hline & $\mathrm{Al}_{2} \mathrm{O}_{3}$ & 0.0021 \\
\hline & $\mathrm{ZnO}$ & 0.00044 \\
\hline & $\mathrm{Fe}_{2} \mathrm{O}_{3}$ & 0.0052 \\
\hline & $\mathrm{Co}_{3} \mathrm{O}_{4}$ & 0.0049 \\
\hline & $\mathrm{NiO}$ & 0.0089 \\
\hline & $\mathrm{CuO}$ & 0.043 \\
\hline & Stainless steel & $0.070 \pm 0.009$ \\
\hline
\end{tabular}

tant species solely responsible for the surface reactions. For example, when admixing two reactant gases in the plasma, new molecules (and related radicals) can be formed through gas-phase or surface recombination reactions. ${ }^{313}$ Furthermore, volatile products from the ALD reactions can be excited, ionized and dissociated by the plasma when leaving the surface. All of these species can contribute to the ALD surface chemistry adding to its complexity.

To illustrate which species are typically present in a plasma, including their typical density, an overview is given in Table III for an $\mathrm{O}_{2}$ plasma. ${ }^{314}$ Data are given for two operating pressures for an inductively-coupled plasma, as typically employed for remote plasma-assisted ALD described in the next section.

\section{PLASMA-ASSISTED ALD CONFIGURATIONS}

Several equipment configurations exist for assisting an ALD process by means of a plasma step. ${ }^{136}$

\section{A. Radical-enhanced ALD}

In the first configuration, a plasma generator is fitted to a thermal ALD reactor, see Fig. 7(a). Examples of such plasma sources are microwave surfatron systems ${ }^{100}$ and the radiofrequency-driven $\mathrm{R}^{*}$ Evolution (MKS Instruments) ${ }^{315}$ and Litmas RPS (Advanced Energy) ${ }^{316}$ systems, which are also commonly used for plasma-based reactor cleaning. Due to technical constraints on existing ALD reactors, plasma generation typically takes place at a relatively far distance from ALD reaction zone. Consequently, the plasma species have to flow through the reactor tubing between the plasma source and reaction chamber. This allows for many surface collisions, where ions and electrons are lost before reaching the substrate due to their recombination at surfaces. Therefore, the method is typically referred to as "radical-enhanced ALD". The many surface collisions of the plasma species can, however, also significantly reduce the flux of radicals arriving at the substrate. This is especially prominent when the choice of the inner surface of the tubing material is not harmonized with the plasma radicals to reduce surface recombination. For example, $\mathrm{H}$ radicals have a relatively low surface recombination probability on quartz surfaces but a very high recombination probability on most metals (see Table II). In the case of metallic surfaces, very long radical exposure times might be necessary to reach saturation of the reactant step in the ALD cycle.

\section{B. Direct plasma ALD}

The second configuration stems directly from the field of plasma-enhanced chemical vapor deposition (PECVD). In this case, a capacitively-coupled plasma is generated at radio frequency, (RF, typically $13.56 \mathrm{MHz}$ ), between two parallel electrodes in a so-called RF parallel plate or RF diode reactor, see Fig. 7(b). In this case, typically one electrode is powered while the other is grounded and, generally, the substrate is positioned on the grounded electrode. As such, this ALD reactor configuration of is referred to as "direct plasma 
TABLE III. Densities of plasma species in an $\mathrm{O}_{2}$ plasma, as typically used in plasma ALD processes. Data are presented for two different pressures and the electron temperature, $T_{e}$, and energy, $E_{\mathrm{ion}}$, of ions accelerated to the (grounded) substrate are also given. The data have been compiled from the modeling results described in Ref. 314 for an inductively-coupled plasma operated at a source power of $500 \mathrm{~W}$. The excited species $\mathrm{O}^{*}$ and $\mathrm{O}_{2}{ }^{*}$ correspond to the lowest metastable states being $\mathrm{O}\left({ }^{1} \mathrm{D}\right)$ and $\mathrm{O}_{2}\left({ }^{1}{ }^{1} \Delta_{\mathrm{g}}\right)$, respectively. Note that the calculated ion energy is lower than the measured ion energy reported on in Fig. 4 , probably as a result of a different reactor geometry and capacitive-coupling of the plasma between the coil and the grounded reactor wall.

\begin{tabular}{|c|c|c|c|c|c|c|c|c|c|c|}
\hline Pressure (mTorr) & $\mathrm{O}_{2}\left(\mathrm{~cm}^{-3}\right)$ & $\mathrm{O}\left(\mathrm{cm}^{-3}\right)$ & $\mathrm{O}_{2}{ }^{*}\left(\mathrm{~cm}^{-3}\right)$ & $\mathrm{O}^{*}\left(\mathrm{~cm}^{-3}\right)$ & $\mathrm{O}_{2}^{+}\left(\mathrm{cm}^{-3}\right)$ & $\mathrm{O}^{+}\left(\mathrm{cm}^{-3}\right)$ & $\mathrm{O}^{-}\left(\mathrm{cm}^{-3}\right)$ & $n_{e}\left(\mathrm{~cm}^{-3}\right)$ & $T_{e}(\mathrm{eV})$ & $E_{\text {ion }}(\mathrm{eV})$ \\
\hline 10 & $3 \times 10^{14}$ & $7 \times 10^{13}$ & $4 \times 10^{13}$ & $4 \times 10^{12}$ & $5 \times 10^{10}$ & $4 \times 10^{10}$ & $2 \times 10^{10}$ & $7 \times 10^{10}$ & 2.8 & 15.3 \\
\hline 100 & $3 \times 10^{15}$ & $1 \times 10^{14}$ & $3 \times 10^{14}$ & $5 \times 10^{10}$ & $4 \times 10^{10}$ & $1 \times 10^{9}$ & $3 \times 10^{10}$ & $2 \times 10^{10}$ & 2.1 & 10.8 \\
\hline
\end{tabular}

ALD" because the wafer is directly positioned at one of the electrodes which contribute to plasma generation. The gases are introduced into the reactor either through a shower head in the powered electrode ${ }^{228}$ or from the side of the electrodes. ${ }^{199}$ The first is typically referred to as "shower-head type" and the second as "flow-type" (if the pressure is sufficiently high). The ALD reactors provided by ASM (Emerald and Stellar) ${ }^{16}$ and Beneq (TFS 200),${ }^{18}$ for example, can be classified as direct-plasma ALD reactors. Typical operating pressures used during the plasma step in direct plasma ALD are of the order of 1 Torr, ${ }^{200}$ although these also could be $<100$ mTorr for an RF parallel plate reactor. ${ }^{25}$ During direct plasma-assisted ALD, the fluxes of plasma radicals and ions towards the deposition surface can be very high, as the plasma species are created in very close proximity of the substrate surface. In principle, this enables uniform deposition over the full wafer area with short plasma exposure steps. Because of the relatively simple reactor layout and
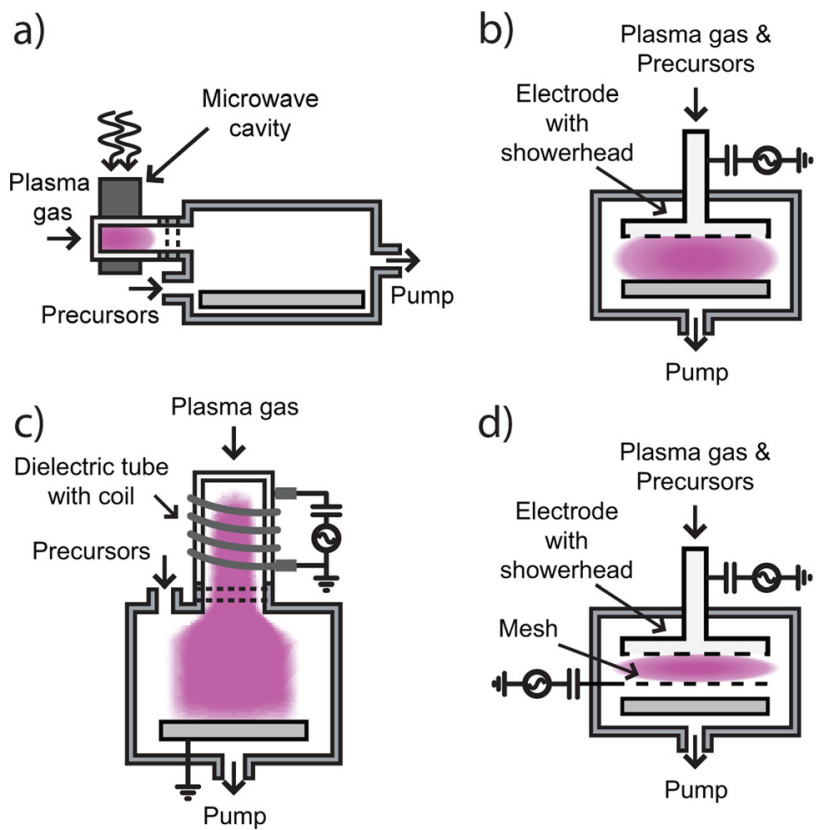

Fig. 7. (Color online) Various reactor configurations for plasma-assisted ALD (Ref. 136): (a) radical-enhanced ALD, (b) direct plasma-assisted ALD, (c) remote plasma ALD, and (d) direct plasma reactor with mesh. The reactor layouts and plasma sources shown serve only as examples. Reprinted with permission from S.B.S. Heil et al., J. Vac. Sci. Technol. A 25, 1357 (2007). Copyright 2007 American Vacuum Society. their proven performance in other plasma processing methods, direct plasmas are extensively used in industrial tools. Depending on the voltage applied to the powered electrode and the operating pressure, the energy of the ions arriving on the substrate can, however, be substantial. In addition, the emission of high energy photons can be significant, possibly leading to plasma damage. The extent of plasma induced damage is, however, determined by the specific implementation of the plasma source and the processing conditions.

\section{Remote plasma ALD}

A third configuration for plasma-assisted ALD equipment can be classified as "remote plasma ALD." In this case, as its name implies, the plasma source is located remotely from the substrate stage such that the substrate is not involved in the generation of the plasma species, see Fig. 7(c). This configuration can be distinguished from radical-enhanced ALD by the fact that the plasma is still present above the deposition surface, i.e. the electron and ion densities have not decreased to zero. ${ }^{237,303}$ The "downstream" plasma can be of the afterglow type (where the local electron temperature is too low to be ionizing) or can still be active (ionizing). The flux of the radicals towards the substrate can therefore be much higher than for radical-enhanced ALD. Moreover, under these circumstances, the plasma and substrate conditions can be varied (relatively) independently of each other, something which is not the case for direct plasma ALD. For example, in direct plasma-assisted ALD a change in substrate temperature affects the gas temperature and consequently the density of gas-phase species and the generation of plasma species. ${ }^{299}$ Therefore, the remote nature of the remote plasma-assisted ALD configuration allows for more control of the plasma's composition and properties than is possible with direct-plasma ALD. The plasma properties can be optimized relatively easily by tuning the operating conditions of the plasma source and the downstream conditions at the position of the substrate. This holds specifically for the presence of ion bombardment and the influence of plasma radiation. ${ }^{303}$ Due to their high degree of flexibility remote plasma ALD reactors are therefore well suited for process design and other R\&D applications.

A variety of plasma sources can be employed for remote plasma-assisted ALD, including microwave plasmas, ${ }^{111}$ electron cyclotron resonance (ECR) plasmas, ${ }^{152}$ and RFdriven inductively-coupled plasmas (ICP). ${ }^{206}$ The latter type, either with a cylindrical or planar coil, is currently the 
most popular and it has proven itself extensively as a plasma source in plasma etching. In the Oxford Instruments FlexAL and OpAL reactors, ${ }^{17}$ a multiturn cylindrical coil surrounds an alumina discharge tube, while in the Cambridge NanoTech Fiji system ${ }^{19}$ the inductor surrounds a quartz tube. The operating pressure for these ICP systems can be as high as 1 Torr (Ref. 229) but, in many cases, pressures $<100$ mTorr are common. ${ }^{206}$ For such low pressures, which are atypical for (thermal) ALD, the reactors are equipped with turbomolecular pumps. In remote plasma systems, the fact that the plasma source and substrate surface are separated also allows for easy use of in situ diagnostic techniques such as spectroscopic ellipsometry. ${ }^{238}$

An alternative approach is provided by Beneq in their TFS 200 system. ${ }^{18}$ Although this is, in principle, a direct ALD reactor employing a capacitively-coupled plasma, a grid can be placed between the two electrodes creating a socalled triode configuration (see Fig. 7(d)). This enables confinement of the plasma between the driven electrode and the grid such that the deposition surface is not in contact with the active plasma. ${ }^{62}$ In essence, this leads to a lower ion energy and flux towards the deposition surface, and lower ion and photon fluxes towards the deposition surface but also to a somewhat reduced radical density.

\section{Developments related to plasma-assisted ALD reactors}

Recently, there have been a number of other developments with respect to the aforementioned reactor configurations. These initiatives mainly aim at obtaining additional control over the production of plasma species and over their interaction with the material surface. In the remote and direct-plasma configurations discussed so far, the substrate is generally placed on a grounded substrate stage. As a result, the potential over the plasma sheath and, consequently, the ion energy is relatively small. However, it is expected that some deposition processes can benefit from enhanced radical production and/or from enhanced ion energies. In that case the nongrounded substrate stage can be biased by a DC, AC, $\mathrm{RF}$, or pulse-shaped signal, or a combination of different signals. ${ }^{317}$ Such methods were inspired by configurations designed for other plasma-assisted material processing techniques such as plasma etching, ion implantation, and deposition by PECVD or PVD. ${ }^{299}$ One configuration recently reported has a capacitively-coupled remote plasma (a direct plasma with a grid), in which a pulsed dc power was applied to the grid. ${ }^{138}$ It was reported that for the resulting negative grid voltage, both the electron temperature and plasma density increased resulting in a higher radical and ion flux to the substrate. It was stated that this improved the electrical properties of $\mathrm{HfO}_{2}$ films, such as the effective oxide thickness and the breakdown voltage. Another embodiment is the application of an RF bias or self-bias voltage to the substrate stage in a remote plasma ICP reactor. ${ }^{318}$ Under properly chosen operating conditions, this leads to an enhanced energy of the ions impinging on the substrate, therefore yielding an additional control over the plasma-surface interaction in which the ion energy can be independently controlled from the ion and radical flux. It is expected that more results from these and other similar approaches will appear in the literature relatively soon.

\section{MERITS OF PLASMA-ASSISTED ALD}

The use of plasma-assisted ALD for ultra-thin film synthesis has several potential advantages, in addition to the benefits provided by the ALD technique itself. These merits can be useful for specific applications of ALD-synthesized thin films.

\section{A. Improved material properties}

It has been reported that, for some materials and applications, plasma-assisted ALD affords better material properties than thermal ALD in terms of, for example, film density, ${ }^{166,167,187,207,214,227,228}$ impurity content, ${ }^{120,162,229,241,245,271,290,294}$ and electronic properties. $^{30,31,50,68,134,135,154,207,208,211,228,229,242,272,290,294,319}$ In most cases, these improved material properties are a result of the high reactivity provided by the plasma, which will be addressed in more detail below. However, more specifically, this improvement can often be attributed to kinetically driven, selective ALD surface reactions, for example, the abstraction of surface halogen atoms by $\mathrm{H}$ radicals and several ion-assisted surface reactions, as illustrated in Fig. 5.

\section{B. Deposition at reduced substrate temperatures}

As high reactivity is delivered to the deposition surface by the plasma species, less thermal energy is required at the substrate to drive the ALD surface chemistry. This means that it is possible to deposit films with equivalent material properties at lower substrate temperatures than for thermal ALD. ${ }^{40,56,65,87,187,233,243,249,254,320}$ The reactivity delivered by the plasma species is not only provided by reactive plasma radicals but is also determined by the kinetic energy of the ions accelerated in the plasma sheath, the surfacerecombination energy of the ions and other species, and the energy flux caused by the plasma radiation.

\section{Increased choice of precursors and materials}

The fact that reactive plasma radicals are delivered to the deposition surface allows for the use of precursors with relatively high thermal and chemical stabilities. A classic example is the ALD of metal oxides from $\beta$-diketonate precursors, such as those with acac (acetylacetonate), ${ }^{97-100} \mathrm{hfac}(1,1,1,5,5,5$-hexafluoroacetylacetonate), ${ }^{101,161,162}$ and thd (2,2,6,6,-tetramethyl3,5-heptanedionato) ${ }^{102,104,275-279}$ ligands. Such precursors require more reactive co-reactants as they show no or low reactivity with $\mathrm{H}_{2} \mathrm{O}$ (in essence, they do not readily undergo hydrolysis reactions). Although the use of $\mathrm{O}_{3}$ could also provide a solution in such cases, plasma-assisted ALD processes can give even more reactivity. The plasma-assisted method can also yield solutions when depositing non-oxidic materials such as metal nitrides and metals. In addition to a wider choice of precursors, plasma-assisted ALD processes also enable the deposition of more material systems, for example, of the elemental metals $\mathrm{Ti}$ 
and Ta (see also Sec. VI A). ${ }^{204-206,232}$ For these metals, no (thermal ALD) reactant is available to reduce the precursor. Furthermore, plasma-assisted ALD allows for a wider choice of substrate materials to be used, particularly those which are temperature-sensitive. ${ }^{35,38,39,54,65,163,187,251,252,256,258,286,320,321}$

\section{Good control of stoichiometry and film composition}

Non-thermally-driven reactions can be induced at the deposition surface due to the nonequilibrium conditions in the plasma, which enables better control of the ALD surface chemistry and of the species incorporated into the film. Therefore, the use of a plasma provides additional variables with which to tune the stoichiometry and composition of the films. These include the operating pressure, ${ }^{205,225,245}$ plasma power, ${ }^{52,62,70,151,152,167,183,213,214,233}$ plasma exposure time, ${ }^{164,183,213,214,221,222,228,236,237,245}$ the admixing of additional gases into the plasma, ${ }^{30,74,215,218}$ and the biasing voltage. ${ }^{138,318}$ It is, for example, relatively straightforward to incorporate $\mathrm{N}$ atoms into oxide thin films by the addition of $\mathrm{N}_{2}$ to a plasma generated in $\mathrm{O}_{2} \cdot{ }^{38,73,128,134,143,146,319}$ Such controlled doping of thin film materials is difficult to achieve with strictly thermally-driven ALD reactions.

\section{E. Increased growth rate}

Cases exist in which the plasma species create a higher density of reactive surface sites due to the high reactivity of the plasma. Consequently, this can lead to higher growth per cycle values. $^{31,32,40,58,60,134,154,187,207,208,229,233,254,259,261,274,294}$ Moreover, the plasma can be switched on and off very rapidly, which enables fast pulsing of the plasma reactant species $^{255,273,274,293,295}$ and reduced purge times (depending on the gas residence time in the reactor). ${ }^{460}$ The latter is especially important for the ALD of metal oxides at low temperatures (room temperature up to $150{ }^{\circ} \mathrm{C}$ ), where purging of $\mathrm{H}_{2} \mathrm{O}$, in the case of thermal ALD, requires excessively long purge times and, therefore, long cycle times. ${ }^{322}$ Shorter cycle times have a significant impact on the net throughput of an ALD reactor. The high plasma reactivity is also beneficial in particular cases where the nucleation delay is shorter for plasma-assisted ALD than for the equivalent thermal ALD process. ${ }^{31,164,166,168,169,173,179,183}$ This aspect also contributes to an increased throughput of ALD reactors.

\section{F. More processing versatility in general}

The availability of a plasma source on an ALD reactor allows for several other in situ treatments of the deposition surface, deposited films, and reactor walls. Plasmas can be used for substrate pretreatment (e.g. oxidation by an $\mathrm{O}_{2}$ plasma ${ }^{69,70,119,122,130,132,149}$ and nitridation by $\mathrm{NH}_{3}$ or $\mathrm{N}_{2}$ plasmas $^{119,129,132}$ ), substrate cleaning, ${ }^{98}$ post-deposition treatments, ${ }^{141,164}$ and reactor wall conditioning and cleaning. ${ }^{240}$ For example, a layer of TiN covering the walls of the reactor can be removed easily by running a F-based plasma such as one generated in $\mathrm{NF}_{3}$ or $\mathrm{SF}_{6}{ }^{136}$

The aforementioned merits of plasma-assisted ALD can be illustrated in more detail by several results that have been reported for various material systems in the recent years.

The first example is the remote plasma-assisted ALD of $\mathrm{Al}_{2} \mathrm{O}_{3}$ from $\mathrm{AlMe}_{3}$ and an $\mathrm{O}_{2}$ plasma, which can be compared to the thermal ALD case with $\mathrm{H}_{2} \mathrm{O}$. For both ALD processes, the dominant reaction products during the precursor dosing step are $\mathrm{CH}_{4}$ molecules. During the subsequent reactant step, however, different reaction products are produced for the thermal and plasma process. For thermal ALD, only $\mathrm{CH}_{4}$ is created, whereas for plasma-assisted ALD, combustion-like reactions take place which result in the production of $\mathrm{CO}_{2}$ and $\mathrm{H}_{2} \mathrm{O}$. In the case where only monofunctional chemisorpion of $\mathrm{AlMe}_{3}$ to the surface is assumed, the suggested dominant surface reactions for plasma-assisted ALD can be written as $46,47,55$

$$
\begin{aligned}
& \text { 1: } \operatorname{AlOH}_{(\text {ads })}+\mathrm{AlMe}_{3(g)} \rightarrow \mathrm{AlOAlMe}_{2(\mathrm{ads})}+\mathrm{CH}_{4(g)}, \\
& \text { 2: } \mathrm{AlMe}_{(\text {ads })}+4 \mathrm{O}_{(g)} \rightarrow \mathrm{AlOH}_{(\text {ads })}+\mathrm{CO}_{2(g)}+\mathrm{H}_{2} \mathrm{O}_{(g)} .
\end{aligned}
$$

The process and material properties of $\mathrm{Al}_{2} \mathrm{O}_{3}$ films deposited by plasma-assisted ALD were compared directly with those for thermal ALD. The results in Fig. 8 show that the $\mathrm{Al}_{2} \mathrm{O}_{3}$ films can be deposited by plasma-assisted ALD at substrate temperatures between 25 and $400{ }^{\circ} \mathrm{C}$. Data are provided for processes carried out in two ALD reactors, ${ }^{323}$ which differ in operating pressure by a factor of $\sim 10$. It is clear that the GPC (growth per cycle) shows no dependence on the plasma operating pressure in this case. ${ }^{323}$ It can also be observed that the GPC increases proportionally with decreasing substrate temperature. Although this effect can partly be attributed to a slightly reduced mass density of the films for temperatures below $150{ }^{\circ} \mathrm{C}$, the change in $\mathrm{GPC}$ is predominantly caused by an increased incorporation of $\mathrm{Al}$ atoms into the film per cycle at lower substrate temperatures. ${ }^{56}$ This number of $\mathrm{Al}$ atoms incorporated is related to a higher

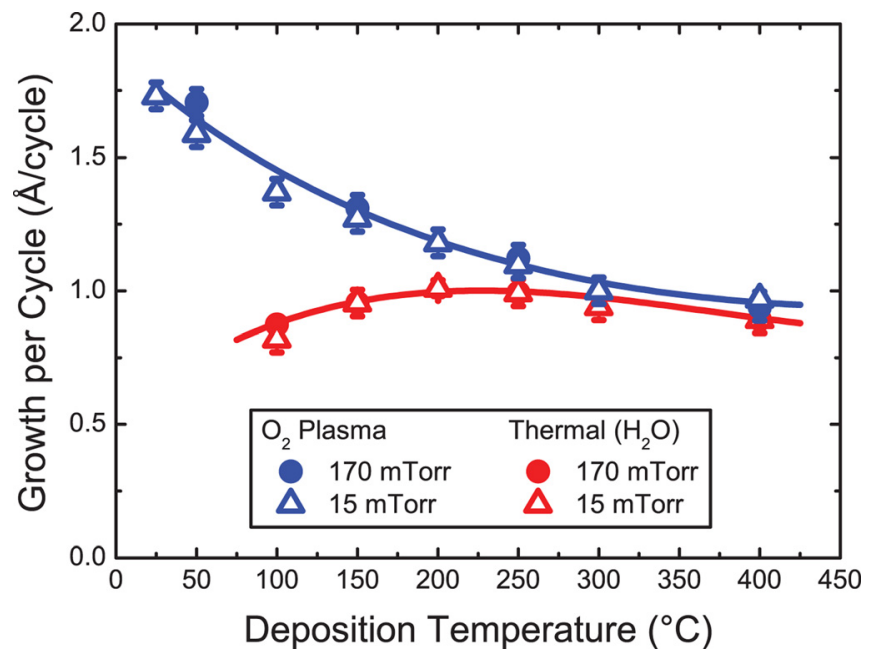

FIG. 8. (Color online) Growth per cycle of $\mathrm{Al}_{2} \mathrm{O}_{3}$ films as a function of the substrate temperature. The films were deposited by plasma-assisted ALD $\left(\mathrm{O}_{2}\right.$ plasma) and thermal ALD $\left(\mathrm{H}_{2} \mathrm{O}\right)$. Two different ALD reactors were used; one operating at $15 \mathrm{mT}$ Torr and the other at 170 mTorr (Refs. 43, 323). From S.E. Potts et al., J. Electrochem. Soc. 157, P66 (2010). Reproduced by permission of ECS-The Electrochemical Society. 
surface density of hydroxyl groups at lower substrate temperatures. This has been confirmed by in situ infrared spectroscopy, which revealed that hydroxyl groups on $\mathrm{Al}_{2} \mathrm{O}_{3}$ surfaces are the dominant adsorption sites for $\mathrm{AlMe}_{3}$ during plasma-assisted ALD. ${ }^{55}$ For the thermal ALD process of $\mathrm{AlMe}_{3}$ and $\mathrm{H}_{2} \mathrm{O}$, the GPC values are comparable but slightly lower than for plasma-assisted ALD at temperatures $>200$ ${ }^{\circ} \mathrm{C}$. However, it is at temperatures $<200{ }^{\circ} \mathrm{C}$ that the main difference is observed, because here the GPC of thermal ALD drops significantly below that for plasma-assisted ALD. The thermal, energy at these temperatures is insufficient to allow for a full reaction of $\mathrm{H}_{2} \mathrm{O}$ with the surface and so, in this case, high hydroxyl surface density cannot be created. Additionally for the thermal ALD process, the purge after the $\mathrm{H}_{2} \mathrm{O}$ dose needs to be increased at low substrate temperatures to avoid parasitic CVD reactions. For temperatures $>200{ }^{\circ} \mathrm{C}$, purge times well below $5 \mathrm{~s}$ are sufficient (optimized industrial ALD reactors even use sub-second purges), whereas at $58{ }^{\circ} \mathrm{C}, 30 \mathrm{~s}$ is required to completely remove residual water. ${ }^{322}$ At room temperature, $\mathrm{Al}_{2} \mathrm{O}_{3}$ films can still be synthesized by thermal ALD, but the purge time required becomes impractically long (up to $180 \mathrm{~s}$ at $33^{\circ} \mathrm{C}$ ). For plasma-assisted ALD, the purge time can be kept relatively short, even at room temperature, in essence, equal to the time used at higher temperatures or only slightly extended. ${ }^{60}$ The structural properties of $\mathrm{Al}_{2} \mathrm{O}_{3}$ thin films are highly comparable for both thermal and plasma-assisted ALD using $\mathrm{AlMe}_{3}$ as a precursor. ${ }^{60,323}$ At lower substrate temperatures the film quality degrades slightly, as evidenced by a reduced mass density, an increased $\mathrm{O} / \mathrm{Al}$ ratio, and a higher $\mathrm{H}$ concentration. ${ }^{60}$ Furthermore, small traces of $\mathrm{C}$ can be found in the films deposited at room temperature. For plasma-assisted ALD the C atoms are mainly incorporated as $\mathrm{CO}_{x}$ groups, the density of which can be reduced by increasing the plasma exposure time. ${ }^{55}$ Despite the somewhat lower material quality of the $\mathrm{Al}_{2} \mathrm{O}_{3}$ deposited at substrate temperatures $<150{ }^{\circ} \mathrm{C}$, these films are considered very attractive for applications which require dense, amorphous and conformal $\mathrm{Al}_{2} \mathrm{O}_{3}$ films deposited at low temperatures. Examples are given in Sec. VI.

The plasma-assisted ALD of $\mathrm{TiO}_{2}$ films from metal-organic precursors and an $\mathrm{O}_{2}$ plasma is another case for which the merits of the plasma-based process can be illustrated. As shown in Fig. 9, $\mathrm{TiO}_{2}$ has also been deposited at low substrate temperatures by this method, using $\mathrm{Ti}\left(\mathrm{O}^{i} \mathrm{Pr}\right)_{4}$, $\mathrm{Ti}\left(\mathrm{Cp}^{\mathrm{Me}}\right)\left(\mathrm{O}^{i} \mathrm{Pr}\right)_{3}, \mathrm{Ti}\left(\mathrm{Cp}^{*}\right)(\mathrm{OMe})_{3}$, and $\mathrm{Ti}\left(\mathrm{Cp}^{\mathrm{Me}}\right)\left(\mathrm{NMe}_{2}\right)_{3}$ as precursors. The films have been deposited at substrate temperatures as low as $25,50,100$, and $100{ }^{\circ} \mathrm{C}$, respectively. ${ }^{56}$ Moreover, the GPC values were marginally affected by the substrate temperature over the full temperature range (up to $300{ }^{\circ} \mathrm{C}$ ). For thermal ALD, with either $\mathrm{H}_{2} \mathrm{O}$ or $\mathrm{O}_{3}$, the situation is quite different. ${ }^{324,325}$ Firstly, the GPC increases with substrate temperature, which indicates that the surface reactions are rate-limited by thermal activation. This holds for $\mathrm{Ti}\left(\mathrm{O}^{i} \mathrm{Pr}\right)_{4}$ with both $\mathrm{H}_{2} \mathrm{O}$ and $\mathrm{O}_{3}$ (see Fig. 9), but also for $\mathrm{Ti}(\mathrm{Cp} *)(\mathrm{OMe})_{3}$ with $\mathrm{O}_{3}$ (not shown). ${ }^{326}$ Furthermore, for all these precursors, the GPC for the thermal process is lower than that for plasma-assisted ALD (except for the case of $\mathrm{Ti}\left(\mathrm{O}^{i} \mathrm{Pr}\right)_{4}$ with $\mathrm{O}_{3}$ at $300{ }^{\circ} \mathrm{C}$, where the high GPC has been

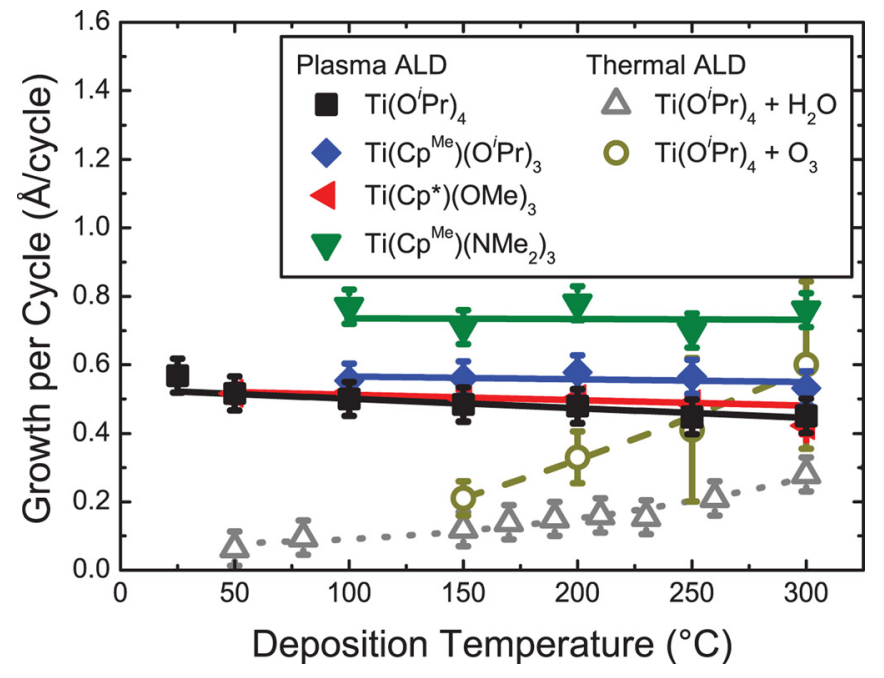

FIG. 9. (Color online) Growth per cycle of $\mathrm{TiO}_{2}$ films as a function of the substrate temperature. Plasma-assisted ALD was carried out using $\mathrm{Ti}\left(\mathrm{O}^{i} \mathrm{Pr}\right)_{4}$, $\mathrm{Ti}\left(\mathrm{Cp}^{\mathrm{Me}}\right)\left(\mathrm{O}^{i} \mathrm{Pr}\right)_{3}, \mathrm{Ti}\left(\mathrm{Cp}^{*}\right)(\mathrm{OMe})_{3}$, and $\mathrm{Ti}\left(\mathrm{Cp}^{\mathrm{Me}}\right)\left(\mathrm{NMe}_{2}\right)_{3}$ as precursors in combination with an $\mathrm{O}_{2}$ plasma (Refs. 56, 248). Data for thermal ALD with $\mathrm{H}_{2} \mathrm{O}$ (Ref. 325) and $\mathrm{O}_{3}$ (Ref. 324) using the widely employed $\mathrm{Ti}\left(\mathrm{O}^{i} \mathrm{Pr}\right)_{4}$ precursor are given for comparison. From S.E. Potts et al., J. Electrochem. Soc. 157, P66 (2010). Reproduced by permission of ECS-The Electrochemical Society.

attributed to thermal decomposition of the precursor $^{324}$ ). This clearly demonstrates that an $\mathrm{O}_{2}$ plasma is not only more reactive than $\mathrm{H}_{2} \mathrm{O}$ but is also more effective than $\mathrm{O}_{3}$, particularly at lower temperatures. In addition, $\mathrm{O}_{2}$ plasmas (and $\mathrm{O}_{3}$ ) allow for the use of Cp-based Ti precursors, which show almost no reactivity against $\mathrm{H}_{2} \mathrm{O}$ in ALD processes. ${ }^{326}$ This exemplifies the fact that a wider range of precursors can be employed for use with plasma-assisted ALD. These relatively stable Cp-based precursors are currently of substantial interest for metal-insulator-metal (MIM) capacitor applications. In such capacitors the use of $\mathrm{SrTiO}_{3}$ is being considered as an ultra-high- $k$ dielectric, e.g. in upcoming technology nodes of DRAM devices. $\mathrm{SrTiO}_{3}$ can be deposited by the combination of $\mathrm{TiO}_{2}$ and $\mathrm{SrO}$ ALD cycles into so-called "supercycles" for which an overlap in temperature window of the two ALD processes is demanded. In order to obtain $\mathrm{SrTiO}_{3}$ dielectric films with the best electrical performance, the highest possible deposition temperature within the shared temperature window should be chosen. ${ }^{195,327}$

The fact that plasma-assisted ALD can lead to improved material properties has also been demonstrated by results on metallic TiN films. ${ }^{233,237}$ The combination of $\mathrm{TiCl}_{4}$ with an $\mathrm{H}_{2} / \mathrm{N}_{2}$ plasma yielded thin TiN films with an excellent resistivity and low impurity levels. These results greatly surpass the material quality achieved with the standard thermal process employing $\mathrm{TiCl}_{4}$ and $\mathrm{NH}_{3} \cdot{ }^{233,237}$ Alternatively, during a thermal ALD process also dimethyl hydrazine $\left(\mathrm{N}_{2} \mathrm{H}_{2} \mathrm{Me}_{2}\right)$ or hydrazine $\left(\mathrm{N}_{2} \mathrm{H}_{4}\right)$ can be used as reactants. These reactants are, however, less common and the results obtained so far are not as good as obtained with a $\mathrm{H}_{2} / \mathrm{N}_{2}$ plasma.

During a plasma-assisted ALD cycle of TiN, the simplified surface reaction scheme can be described as 


$$
\begin{aligned}
& \text { 1. } \mathrm{TiNH}_{(\text {ads })}+\mathrm{TiCl}_{4(g)} \rightarrow \mathrm{TiNTiCl}_{3(\mathrm{ads})}+\mathrm{HCl}_{(g)}, \\
& \text { 2. } \mathrm{TiCl}_{(\text {ads })}+2 \mathrm{H}_{(g)}+\mathrm{N}_{(g)} \rightarrow \mathrm{TiNH}_{(\mathrm{ads})}+\mathrm{HCl}_{(g)} .
\end{aligned}
$$

In terms of acceptable material quality, thermal ALD of TiN is limited to the substrate temperature range of $300-400{ }^{\circ} \mathrm{C}$, while the plasma-assisted ALD process can yield fair material properties down to temperatures as low as $100{ }^{\circ} \mathrm{C}$ as shown in Fig. 10. For thicker films, resistivity values as low as $72 \mu \Omega \mathrm{cm}\left(400{ }^{\circ} \mathrm{C}\right)$ and $209 \mu \Omega \mathrm{cm}\left(100{ }^{\circ} \mathrm{C}\right)$ have been reported, which could be attributed to the low $\mathrm{Cl}$ concentrations of 0.1 and 2.1 at. $\%$, respectively at these temperatures. $^{237}$ This is quite a promising achievement, since TiN has numerous applications, such as an electrode material in metal-insulator-metal (MIM) capacitors and as a metal gate in CMOS devices. ${ }^{328}$

The ability of plasma-assisted ALD to synthesize materials which cannot (or hardly) be deposited by thermal ALD is exemplified by the case of $\mathrm{TaN}_{x}$. Thermal ALD processes using either metal halide or metal-organic precursors in combination with $\mathrm{NH}_{3}$ always yield the highly resistive $\mathrm{Ta}_{3} \mathrm{~N}_{5}$ phase because the reducing power of $\mathrm{NH}_{3}$ is insufficient to reduce the Ta oxidation state from +5 to $+3 .{ }^{329}$ Cubic TaN, can be deposited by thermal ALD when $\mathrm{N}_{2} \mathrm{H}_{4}$ is used as the reactant ${ }^{330}$ or with the help of additional reducing agents such as $\mathrm{AlMe}_{3}$ or elemental Zn. ${ }^{329,331}$ However, these processes employ relatively uncommon reactant gases or additional reducing agent dosing steps, which add significantly more complexity to the deposition process. For plasma ALD processes, it is possible to deposit conductive cubic TaN films from metal-organic precursors using an $\mathrm{H}_{2}$ plasma. $^{223,226}$ This is illustrated in Fig. 11, where the resistivity of TaN films, deposited using $\mathrm{Ta}\left(\mathrm{NMe}_{2}\right)_{5}$ as a precursor, as a function of the $\mathrm{H}_{2}$ plasma exposure time is shown. It is clear that TaN films with resistivity values as low as 380

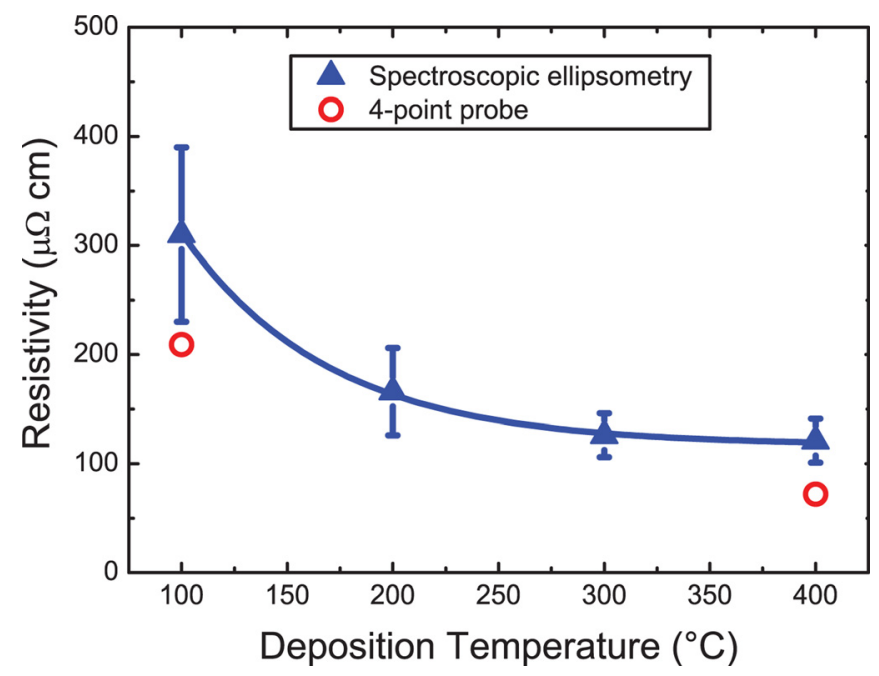

FIG. 10. (Color online) Resistivity (at room temperature) of TiN films obtained at $100-400{ }^{\circ} \mathrm{C}$. The films were deposited by plasma-assisted ALD using $\mathrm{TiCl}_{4}$ in combination with an $\mathrm{H}_{2} / \mathrm{N}_{2}$ plasma. The resistivity was determined by in situ spectroscopic ellipsometry (thin films, $\sim 10 \mathrm{~nm}$ ) and fourpoint probe measurements (thicker films, $>45 \mathrm{~nm}$ ) (Ref. 237). From S.B.S. Heil et al., J. Electrochem. Soc. 153, G956 (2006). Reproduced by permission of ECS-The Electrochemical Society.

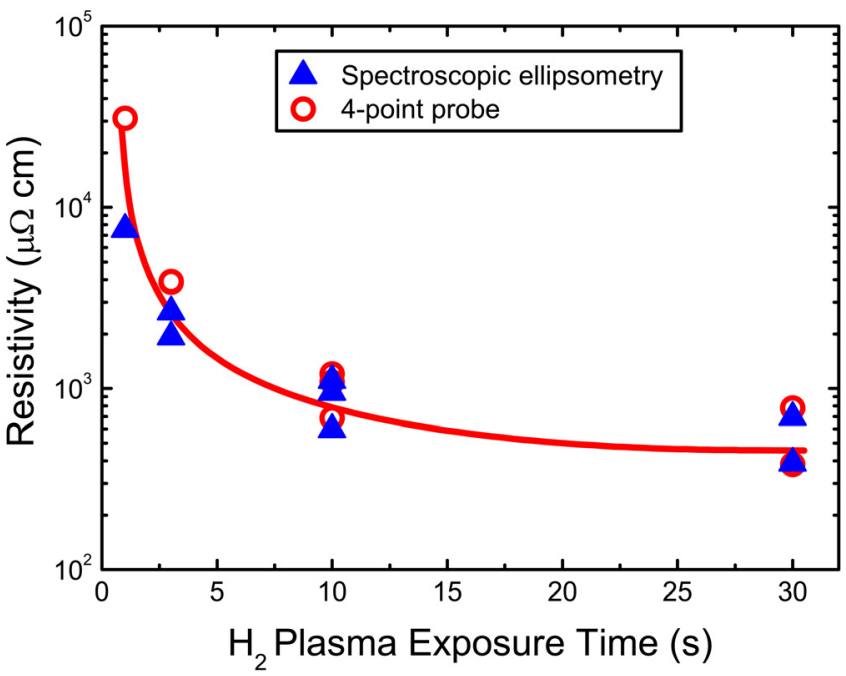

FIG. 11. (Color online) Resistivity (at room temperature) of TaN films as a function of $\mathrm{H}_{2}$ plasma exposure time (Ref. 223). The data were obtained by in situ spectroscopic ellipsometry and four-point probe measurements. Reprinted with permission from E. Langereis et al., J. Appl. Phys. 102, 083517 (2007). Copyright 2007, American Institute of Physics.

$\mu \Omega \mathrm{cm}$ could be obtained for long plasma exposure times. In addition, the aforementioned highly resistive $\mathrm{Ta}_{3} \mathrm{~N}_{5}$ films can also be synthesized by plasma-assisted ALD using the same $\mathrm{Ta}\left(\mathrm{NMe}_{2}\right)_{5}$ precursor, either by admixing a small concentration of $\mathrm{N}_{2}$ into the $\mathrm{H}_{2}$ plasma or by operating the plasma in $\mathrm{NH}_{3}{ }^{223}$ This process also exemplifies that plasmaassisted ALD offers good control over the film stoichiometry.

As another example, the ALD of metal films is considered, in particular the ALD of Pt. Materials from the Ptmetal group, with applications in nanoelectronics (as electrodes) and in catalysis, are among the exceptional cases of elemental metals for which thermal ALD is relatively straightforward. ${ }^{332} \mathrm{Pt}$ can, for example, be deposited by thermal ALD using $\mathrm{Pt}\left(\mathrm{Cp}^{\mathrm{Me}}\right) \mathrm{Me}_{3}$ as a precursor combined with $\mathrm{O}_{2}$ gas. ${ }^{333}$ Assuming that analogous surface reactions to those reported for the thermal ALD process of $\mathrm{Pt}$ take place ${ }^{334}$ it is likely that a reaction mechanism such as the following occurs in the case of plasma-assisted ALD:

$$
\begin{aligned}
& \text { 1. } 2 \mathrm{Pt}\left(\mathrm{Cp}^{\mathrm{Me}}\right) \mathrm{Me}_{3(g)}+3 \mathrm{O}_{(\mathrm{ads})} \rightarrow 2 \mathrm{Pt}\left(\mathrm{Cp}^{\mathrm{Me}}\right) \mathrm{Me}_{2(\mathrm{ads})} \\
& +\mathrm{CH}_{4(g)}+\mathrm{CO}_{2(g)}+\mathrm{H}_{2} \mathrm{O}_{(g)}, \\
& \text { 2. } 2 \mathrm{Pt}\left(\mathrm{Cp}^{\mathrm{Me}}\right) \mathrm{Me}_{2(\mathrm{ads})}+48 \mathrm{O}_{(g)} \rightarrow 2 \mathrm{Pt}_{(s)}+3 \mathrm{O}_{(\text {ads })} \\
& \quad+16 \mathrm{CO}_{2(g)}+13 \mathrm{H}_{2} \mathrm{O}_{(g)} .
\end{aligned}
$$

For ALD of Pt as well as for many other noble metal processes, a relatively long nucleation delay can occur on oxides and other starting surfaces, which is especially prominent when lower operating pressures are employed. However, this nucleation delay can be almost completely eliminated when an $\mathrm{O}_{2}$ plasma is used instead of $\mathrm{O}_{2}$ gas, ${ }^{164}$ as shown in Fig. 12. The plasma-assisted step makes the ALD process and thickness control more reliable, while also reducing the consumption of an expensive Pt precursor. Furthermore, when a 
(seed) layer of $\mathrm{Pt}$ has been deposited by plasma-assisted ALD, the thermal process can be continued without disruption in the thickness increment per cycle (see Fig. 12). Another interesting feature of the plasma-assisted ALD process is that $\mathrm{PtO}_{2}$ films can also be deposited using the same precursor and an $\mathrm{O}_{2}$ plasma, the only difference (compared to the plasma-assisted ALD of Pt) being the plasma exposure time. Pt can be deposited using short plasma exposure times, whereas relatively long plasma exposure times yield $\mathrm{PtO}_{2}$. For the process reported in Fig. 12, these exposure times are 0.5 and $5.0 \mathrm{~s}$, respectively. The GPC for $\mathrm{PtO}_{2}$ is very similar to that for Pt (see Fig. 12) even though the number of Pt atoms per cycle is lower. So far the only thermal ALD process for $\mathrm{PtO}_{x}$ that has been reported was based on a combination of $\mathrm{Pt}(\mathrm{acac})_{2}$ and $\mathrm{O}_{3}$, and was restricted to the small temperature window of $120-130{ }^{\circ} \mathrm{C} .{ }^{335}$

Another material from the Pt-group for which the nucleation delay can be reduced by the plasma-assisted process is $\mathrm{Ru}$. Results obtained using $\mathrm{Ru}\left(\mathrm{Cp}^{\mathrm{Et}}\right)_{2}$ as a precursor and a $\mathrm{NH}_{3}$ plasma as the reactant, for example, are reported in the literature quite extensively. ${ }^{165-176}$ Pure and smooth films with a low resistivity were deposited with substrate-dependent growth rates and nucleation delays ( $\sim 20$ cycles for TiN and almost none for $\mathrm{SiO}_{2}$ ). $\mathrm{NH}_{3}$ gas is not reactive with the precursor and the thermal ALD process does not result in film growth. However, $\mathrm{O}_{2}$ gas can be used for thermal ALD of $\mathrm{Ru}$ and results in growth rates that are up to 4 times higher compared to the plasma-assisted ALD process with $\mathrm{NH}_{3}$ plasma as the reactant. ${ }^{166,173} \mathrm{Ru}$ films were also deposited by employing $\mathrm{O}_{2}$ gas and an $\mathrm{O}_{2}$ plasma as the reactant in deposition processes using $\mathrm{RuCp}(\mathrm{CO})_{2} \mathrm{Et}^{179}$ These processes revealed fairly high growth rates of $\sim 1 \mathrm{~nm} /$ cycle after nucleation delay of $\sim 45$ and $\sim 85$ cycles for plasma-assisted

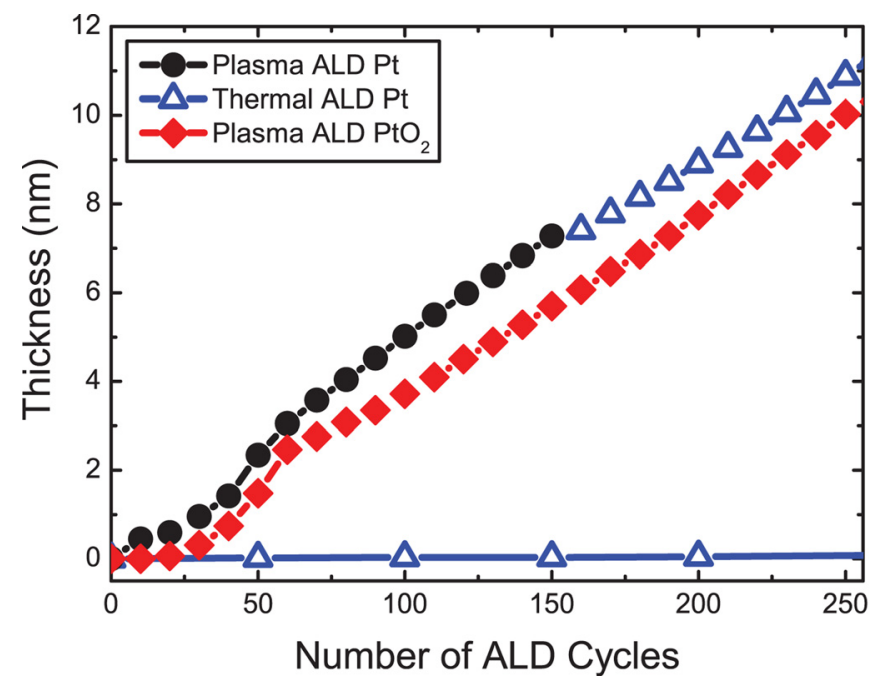

FIG. 12. (Color online) Thickness evolution of $\mathrm{Pt}$ and $\mathrm{PtO}_{2}$ films deposited on an $\mathrm{Al}_{2} \mathrm{O}_{3}$ substrate (Ref. 164). The precursor was $\mathrm{Pt}\left(\mathrm{Cp}{ }^{\mathrm{Me}}\right) \mathrm{Me}_{3}$ and $\mathrm{O}_{2}$ gas or an $\mathrm{O}_{2}$ plasma were used as the oxidants. After 150 cycles, the plasma-assisted ALD process was stopped and film growth was continued using thermal ALD. The plasma exposure time for was $0.5 \mathrm{~s}$ for Pt and $5 \mathrm{~s}$ for $\mathrm{PtO}_{2}$. From H.C.M. Knoops et al., Electrochem. Solid-State Lett. 12, G35 (2009). Reproduced with permission of ECS-The Electrochemical Society.
ALD and thermal ALD, respectively. The surface roughnesses were, however, somewhat higher than for the $\mathrm{NH}_{3}$ plasma process. Besides the nucleation properties and the growth rate, the choice of the reactant can also depend on the other layers in the structure; $\mathrm{O}_{2}$ gas or an $\mathrm{O}_{2}$ plasma can oxidize a surface whereas the use a $\mathrm{NH}_{3}$ plasma could lead to reduction and even nitridation of the surface. ${ }^{175}$

\section{CHALLENGES OF PLASMA-ASSISTED ALD}

Although plasma-assisted ALD can offer several benefits over thermal ALD for selected applications, the method also faces a number of challenges when compared to its thermal counterpart.

One limitation of plasma-assisted ALD that is often highlighted is the reduced conformality or step coverage that can be achieved on nonplanar substrates. These can be substrates with surface structures of high aspect ratio (e.g. wafers with trenches or vias) or substrate materials with very high surface areas (e.g. porous materials and stacked particles). Thermal ALD is known to be the method of choice for depositing conformal thin films on such substrates, as film growth is self-limiting and independent of the precursor flux when the conditions are such that saturation of the ALD (half-) reactions is reached. The difference between plasma-assisted and thermal ALD, in this respect, is that plasma-assisted ALD involves reactive species that not only undergo ALD reactions (as in thermal ALD) but can also react on saturated surface sites. As mentioned in Sec. II, radicals from the plasma can react with other radicals and species residing at the surface, forming nonreactive molecules that desorb back into the plasma. In the case of high-aspect-ratio structures or porous materials, the radicals have to undergo several surface collisions in order to reach deep inside the surface features, which significantly reduces the local flux of the radicals due to the surface recombination. This has only recently been addressed qualitatively by simulations and experimentally. ${ }^{42,304,336,337}$ In many other reports, the impact of the surface recombination of plasma radicals is generalized and the poor conformality of plasma-assisted ALD films is often claimed. However, the conformality achieved by plasmaassisted ALD under certain conditions depends strongly on the value of the recombination probability, $r$, which itself depends on (a) the type of radicals responsible for film growth in a certain plasma-assisted ALD process and (b) the material being deposited (see Table II). Note that the surface temperature can also affect the value of $r$, for example, a significant temperature dependence was reported for oxygen radicals on silica, ${ }^{305}$ whereas the temperature dependence of $\mathrm{H}$ radicals on metals was less prominent. ${ }^{306}$ The influence of the value of $r$ can be illustrated by the results obtained from simple two-dimensional Monte Carlo simulations, in which the evolution of the deposition profile within a trench of high aspect ratio was studied as a function of the incoming radical flux. $^{304,337}$ This was achieved by considering only the plasma exposure step during a single ALD cycle. The information on the deposition profile at the side wall of the trench was derived from the number of ALD growth events as a 
function of the side wall position. For $r>0$, it was found that the deposition profiles showed a minimum thickness at the region just above the bottom of the trench (see Fig. 13(a)) and this minimum was more pronounced for larger values of $r$. The deposition profiles were clearly distinguishable from the cases in which the conformality was reactionlimited or diffusion-limited (see Fig. 13(a)). ${ }^{338}$ Therefore, in addition to these limiting cases (which are also observed for thermal ALD) a new recombination-limited regime was distinguished for the case of plasma-assisted ALD. ${ }^{304}$ In order to achieve conformal deposition while in this recombinationlimited regime, a longer plasma exposure time has to be employed. Compared to the case where $r=0$, the dose required for saturation increases considerably when increas-
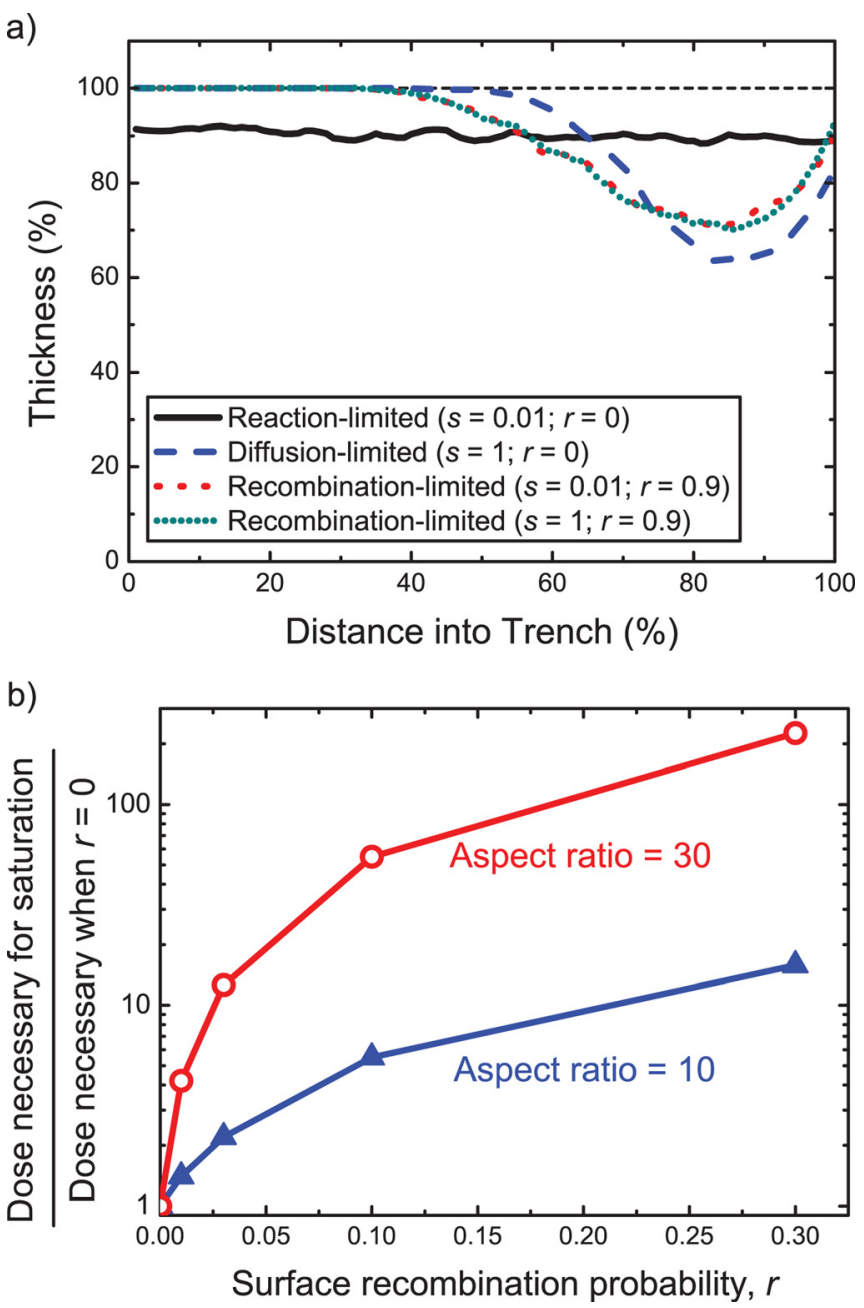

FIG. 13. (Color online) Results from Monte Carlo simulations investigating the influence of surface recombination of radicals during plasma-assisted ALD (Ref. 304). (a) Equivalent thickness profile in a trench of aspect ratio 10 for different deposition regimes, obtained for various combinations of values for the sticking probability, $s$, and surface recombination probability, $r$. The positions within the trench labeled 0 and $100 \%$ correspond to the trench opening and trench bottom, respectively. Note that both recombination-limited cases show almost perfect overlap. (b) The dose required to reach saturation in trenches with aspect ratios of 10 and 30 for nonzero values of $r$. This dose is normalized to the dose required to reach saturation in these trenches when $r=0$. For the simulations $s=0.01$ was assumed. From H.C.M. Knoops et al., J. Electrochem. Soc. 157, G241 (2010). Reproduced with permission of ECS-The Electrochemical Society. ing the value of $r$, especially for high aspect ratios. The latter is illustrated in Fig. 13(b) for aspect ratios of 10 and 30 and for $r$ values ranging from 0.01 to 0.3 . The "sticking" probability of the radicals on unreacted surface sites was assumed to be 0.01 . From the figure it is clear that for the smaller $r$ values and reasonable aspect ratios $(\leq 10)$, conformal deposition can still be achieved relatively easily by increasing the plasma exposure time by, for example, up to 10 times longer than that required for a planar substrate. However, for very high aspect ratios (e.g. $\geq 30$ ) plasma exposure times are necessary that are practically unfeasible. Consequently, because most current applications have reasonable aspect ratios, it can be concluded that in many practical cases, conformal deposition in high-aspect-ratio structures can certainly be achieved by plasma-assisted ALD. This is also confirmed by the results obtained for several metal oxides where the $r$ values of oxygen radicals are known to be relatively low..$^{60,199,200,210,246,339,340}$ For other cases, such as metals, the $r$ values of radicals are relatively high. This makes it very difficult or even impossible to achieve a good conformality, especially for aspect ratios $>10$. Finally, it should be noted that thermal ALD processes can also be subject to surface recombination losses of reactant species. For example, for some materials, $\mathrm{O}_{3}$ also has considerable (nonzero) $r$ values, which generally increase with surface temperature. $^{341,342}$ In this case, conformal film growth might also be recombination-limited. ${ }^{304,341}$

A second limitation of plasma-assisted ALD that can have an important effect on certain applications can be described as plasma-induced damage. During the plasma step of the ALD cycle, the deposition surface is exposed to a multitude of reactive species from the plasma that can also induce undesired surface reactions, including oxidation and nitridation of the top surface layers of the substrate. ${ }^{27,62,175}$ In the case of (enhanced) surface oxidation, the interaction of oxygen atoms with the substrate during the initial ALD cycles can result in a (thicker) interfacial oxide, for example, when metal oxides are deposited on silicon (see also Sec. VI B) ${ }^{343}$ Nitridation can take place when using $\mathrm{N}_{2^{-}}$or $\mathrm{NH}_{3}$ based plasmas to deposit metal nitrides. ${ }^{238}$ Note that nitridation is often also employed on purpose, for example, to increase the stability or the relative permittivity ( $k$-value) of oxides. $^{32,91,119,129,143,209}$ Plasma-induced damage can also manifest itself by the formation of defects inside the material or at the surface onto which the film is deposited. The bombardment of the substrate by energetic ions, accelerated in the plasma sheath, can lead to bond-breaking, displacement of atoms in the surface region and charge accumulation on dielectric layers. ${ }^{344,345}$ Such ion bombardment effects are particularly important during plasma-activated processes, such as reactive ion etching, where the substrate is negatively biased to give the incoming ions kinetic energies of up to several hundreds of $\mathrm{eV} .^{299,300}$ During plasma-assisted ALD the ion energies are typically much lower due to grounding of the substrate stage and/or the high pressures employed (i.e., when the plasma sheath is collisional), meaning that they are typically below the damage threshold (e.g. the atom displacement threshold) and cannot cause 
significant defect creation. However, there is still a significant possibility that ion bombardment may be of influence because the performance of most semiconductor devices, in which the ultra-thin ALD-synthesized films are employed, is strongly affected by their interface properties. The influence of ion bombardment was illustrated by a study in which the material properties of $\mathrm{HfO}_{2}$ films deposited in a remote plasma and a direct plasma reactor were compared. ${ }^{124,125}$ The films deposited in the remote plasma reactor were amorphous, but showed better interface properties than the polycrystalline $\mathrm{HfO}_{2}$ films deposited in the direct plasma reactor (also see Sec. VIb). Consequently, the electrical properties of the films, such as dielectric constant, fixed oxide charge density, and carrier mobility were superior for the remote plasma case. As exemplified by this study, the influence of plasma damage is more likely when the flux of ions is considerable, such as in direct plasma-assisted ALD. Another often neglected, but in many cases even more important, mechanism is defect creation by plasma radiation. As mentioned earlier, a significant amount of ultraviolet (UV) radiation is formed in plasmas, the energy of which can reach up to $10 \mathrm{eV}$ (see Fig. 6). Oxides, such as $\mathrm{SiO}_{2}$ as well as the high- $k$ oxides, have band gap values smaller than $9 \mathrm{eV}$, meaning that vacuum ultraviolet (VUV) radiation can create defects, for example, by photoemission or photoinjection of charge. Plasma-induced defect creation has been studied in great detail for the plasma processing of $\mathrm{SiO}_{2}$-based gate stacks ${ }^{299,300,346-349}$ and the influence of VUV exposure has also recently been studied for the high- $k$ oxide $\mathrm{HfO}_{2} \cdot{ }^{299,300,344,350-352}$ However, this damage mechanism has not really been highlighted for plasma-assisted ALD processes, for example, during the synthesis of metal oxides by plasma-assisted ALD itself or when depositing other materials (such as electrode materials) on top of high- $k$ oxides by plasma-assisted ALD. Note that, apart from the fact that the metal oxide film might itself be affected, the interfacial $\mathrm{SiO}_{x}$ layer, which is typically present (either unintentionally or prepared on purpose) between the metal oxide and the Si substrate, can also be affected. From experiments (see Fig. 14(a)), it has recently been demonstrated that the surface passivation of crystalline $\mathrm{Si}$ by as-deposited $\mathrm{Al}_{2} \mathrm{O}_{3}$ is strongly affected by defects generated by VUV photons from the $\mathrm{O}_{2}$ plasma (photon energy of $9.5 \mathrm{eV}$, see Fig. 6). ${ }^{43,303}$ To illustrate that VUV radiation is responsible for the degradation in surface passivation, a silicon wafer coated with thermal ALD-deposited $\mathrm{Al}_{2} \mathrm{O}_{3}$ (30 nm in thickness) was exposed to an $\mathrm{O}_{2}$ plasma through $5.0 \mathrm{~mm}$ quartz and $\mathrm{MgF}_{2}$ windows covering the sample which would either block or transmit the $9.5 \mathrm{eV}$ photons, respectively. The results, which are presented in Fig. 14(b), demonstrate that no degradation in lifetime is observed when the VUV radiation was blocked by the quartz window. However, for the exposure through the $\mathrm{MgF}_{2}$ window, the lifetime degraded with a rate equal to that obtained when no window was used (after correcting for the $\sim 60 \%$ transmittance of the $\mathrm{MgF}_{2}$ window at $130.5 \mathrm{~nm}$ wavelength). The photons emitted by the $\mathrm{O}_{2}$ plasma during plasma-assisted ALD induce a very high interface defect density $\left(D_{i t} \approx 10^{12} \mathrm{eV}^{-1} \mathrm{~cm}^{-2}\right.$ at the a)

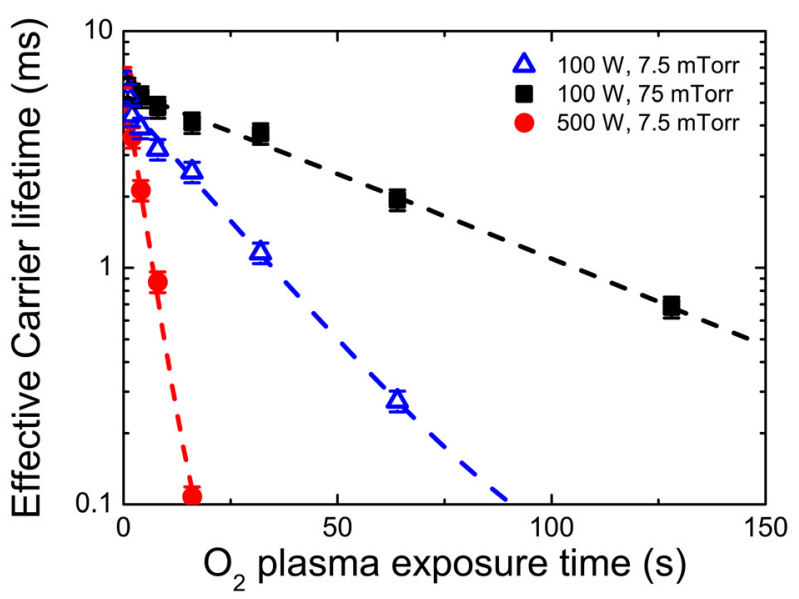

b)

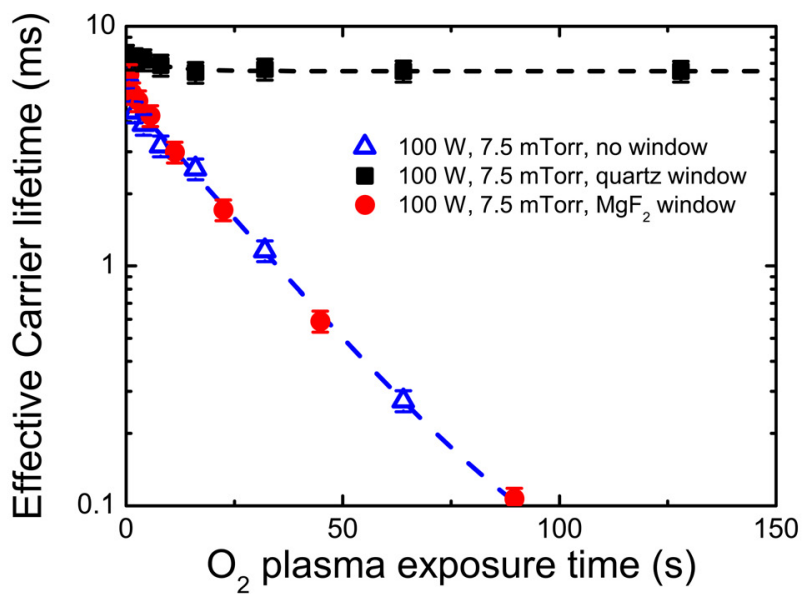

FIG. 14. (Color online) Experiments proving that VUV radiation from the plasma affects the surface passivation of crystalline $\mathrm{Si}$ by $\mathrm{Al}_{2} \mathrm{O}_{3}$ when deposited by plasma-assisted ALD (Refs. 43, 303). After annealing, the wafers were exposed to an $\mathrm{O}_{2}$ plasma for various exposure times. (a) The effective charge carrier lifetimes degraded for increasing exposure times at a rate which increased with increasing VUV radiation present in the plasma (higher intensity for higher power and/or lower pressure). (b) Results are also given for the situation in which the substrate is covered by quartz and $\mathrm{MgF}_{2}$ windows that respectively block and do not block the VUV photons of 9.5 eV. From H.B. Profijt et al., ECS Trans. 33, 61 (2010). Reproduced with permission of ECS—The Electrochemical Society.

midgap) such that extremely high surface recombination velocities of $10^{7} \mathrm{~cm} / \mathrm{s}$ were obtained. ${ }^{43}$ However, most of these surface defects can be removed by annealing the films for 10 min at $400{ }^{\circ} \mathrm{C}$ in $\mathrm{N}_{2}\left(D_{i t}\right.$ reduced to $\sim 10^{11} \mathrm{eV}^{-1}$ $\mathrm{cm}^{-2}$ ), such that excellent surface recombination velocities, as low as $1 \mathrm{~cm} / \mathrm{s}$, can be achieved on low-resistivity floatzone Si. These surface recombination velocities correspond to a surface passivation quality not yet paralleled by any other material. ${ }^{323}$ On the other hand, as-deposited $\mathrm{Al}_{2} \mathrm{O}_{3}$ synthesized by thermal ALD affords reasonably low surface recombination velocities, as the films are not exposed to VUV radiation from a plasma (despite this fact, the level of surface passivation after annealing is not as good as for $\mathrm{Al}_{2} \mathrm{O}_{3}$ synthesized with by plasma-assisted ALD). ${ }^{43}$ Furthermore, it has been demonstrated that the level of surface passivation by asdeposited $\mathrm{Al}_{2} \mathrm{O}_{3}$ synthesized by plasma-assisted ALD can be increased by decreasing the length of the plasma exposure 
step, in this case, by using slightly sub-saturated ALD conditions. $^{43}$

The aforementioned challenges for plasma-assisted ALD are inherent to the plasma-surface interaction that takes place during the plasma step. To assess their possible impact on the potential applications of the plasma-assisted ALD method, a deeper investigation of the underlying surface processes, including the plasma-surface interaction, is required in order to establish whether they lead to problems for the specific applications considered. Another class of challenges is related to the development of equipment and the industrial scale-up of the process. The use of plasma steps during ALD cycles requires more complex equipment than that used for thermal ALD. Unless this additional complexity is compensated for by the significant advantages of plasma-assisted ALD, thermal ALD will be the method of choice. For research and development (R\&D), the interest in plasma-assisted ALD equipment is hardly or not affected, as R\&D equipment is required to directly compare the results obtained by plasma and thermal ALD. This is evidenced by the fact that several combined plasma and thermal ALD tools have recently been introduced onto the market. However, for industrial scale-up the situation is different. Here, plasma-assisted ALD will only be adopted when it provides major benefits over thermal ALD and when alternative deposition techniques are not available for the specific applications envisioned. The latter situation is currently prominent in the field of crystalline silicon photovoltaics, where mainly thermal ALD is currently considered by equipment manufacturers for the scale-up of $\mathrm{Al}_{2} \mathrm{O}_{3}$ deposition, ${ }^{18,353-355}$ despite the fact that plasma-assisted ALD can provide significant benefits over thermal ALD in this case. ${ }^{356}$

\section{SELECTED APPLICATIONS}

In the literature a number of applications have been suggested for thin films synthesized by plasma-assisted ALD. In the semiconductor industry these applications vary from the so-called "back-end-of-line," the level in IC fabrication where individual device components are interconnected, to the so-called "front-end-of-line," the level where the individual device components are created in and on the silicon substrate. Over the past few years, the application of the films as barrier and protective layers has gained significant interest.

\section{A. Back-end-of-line processing}

Although the first time that a plasma was used in an ALD process dates back to 1991, the research on plasma-assisted ALD primarily started around 2000, when major thin film challenges in the back-end-of-line processing were foreseen. At that time, the replacement of $\mathrm{Al}$ by $\mathrm{Cu}$ as the interconnect material was imminent and plasma-assisted ALD processes for the deposition of $\mathrm{Ta}$ and $\mathrm{Ti}$ liners were developed. ${ }^{206}$ Such liner materials became necessary to prevent $\mathrm{Cu}$ diffusion into the low- $k$ dielectric and to promote the adhesion of $\mathrm{Cu}$ to the diffusion barrier layer. ${ }^{357}$ For this application, typically a stack of materials, such as TaN/Ta or TiN/Ti, needs to be employed and these materials need to be deposited in the trenches and vias before filling them with $\mathrm{Cu}$. Therefore, in addition to the good barrier and adhesion properties, other requirements for the liner materials include a high conformality of the films in nanoscale structures, a deposition temperature compatible with back-end-of-line processing $\left(\leq 400{ }^{\circ} \mathrm{C}\right)$, as well as a high chemical and thermal stability. Also the resistivity should be low to keep the total resistance of the interconnects as low as possible and to allow for metal layers to be connected through the barrier layers. In particular cases, a low-resistivity barrier and adhesion layer could also simultaneously act as a seed-layer for the electrochemical deposition process of $\mathrm{Cu}$. ${ }^{161,166,180-183,220,240}$

Triggered by these challenges, Rossnagel and co-workers at IBM developed plasma-assisted ALD processes of Ta and Ti using the metal halides $\mathrm{TaCl}_{5}$ and $\mathrm{TiCl}_{4}$ as precursors and an $\mathrm{H}_{2}$ plasma as a reducing agent. ${ }^{206}$ As mentioned in Sec. IV, no thermal ALD processes exist for these metals, but the deposition of $\mathrm{Ta}$ and $\mathrm{Ti}$ films by plasma-assisted ALD was successful (see Fig. 15). As a follow-up of this work, the IBM group, as well as others, also developed plasma-assisted ALD processes for other liner materials, including the metal-nitrides $\mathrm{TaN}$ and TiN. The development of these processes was intended to facilitate the switching from metal halide precursors to metal-organic precursors (e.g. $\mathrm{Ta}\left(\mathrm{NMe}_{2}\right)_{5}, \mathrm{Ta}\left(\mathrm{N}^{t} \mathrm{Bu}\right)\left(\mathrm{NEt}_{2}\right)_{3}, \mathrm{Ti}\left(\mathrm{NMe}_{2}\right)_{4}$ to name a few) due to compatibility issues of the former, caused by halide impurities in the films. The plasmas employed were typically generated in $\mathrm{H}_{2}, \mathrm{H}_{2} / \mathrm{N}_{2}$ and $\mathrm{NH}_{3}$. Research on a combined $\mathrm{Cu}$ diffusion barrier and $\mathrm{Cu}$ seed layer triggered the development of plasma-assisted processes of refractory metals, most prominently $\mathrm{Ru}$, e.g. from $\mathrm{Ru}\left(\mathrm{Cp}^{\mathrm{Et}}\right)_{2}$ as the precursor and an $\mathrm{NH}_{3}$ plasma as the reactant. ${ }^{165-174}$ A comprehensive overview of the metal and metal nitride films deposited by (plasma-assisted) ALD for $\mathrm{Cu}$ interconnect applications can be found in the review paper by Kim. ${ }^{328}$

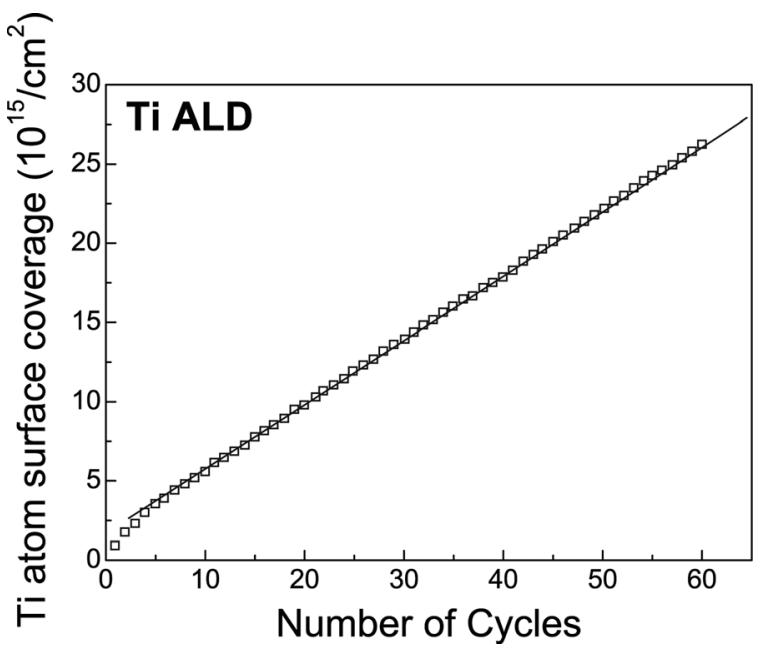

FIG. 15. Surface coverage of Ti atoms as a function of the number of ALD cycles, as measured by a quartz crystal microbalance at room temperature (Ref. 232). The precursor employed was $\mathrm{TiCl}_{4}$ and the reactant was an $\mathrm{H}_{2}$ plasma. For deposition on the as-received crystal, the growth showed a linear trend after $\sim 5$ cycles. Reprinted with permission from H. Kim et al., J. Vac. Sci. Technol. A 20, 802 (2002). Copyright 2002 American Vacuum Society. 
The suitability of plasma-assisted ALD-deposited Ta, TaN, Ti, and TiN films as diffusion barriers was investigated and reported in a number of articles. ${ }^{175,204,219,222,225,226}$ In an early report, Kim et al. demonstrated that the barrier films should preferably be amorphous, in order to avoid $\mathrm{Cu}$ leakage along the grain boundaries. ${ }^{226,357}$ They demonstrated that plasma-assisted ALD Ta films showed superior $\mathrm{Cu}$ diffusion barrier properties compared to their PVD counterpart, especially for thicknesses below $10 \mathrm{~nm}$, due to the amorphous structure of the films. ${ }^{204}$ For TaN films deposited by plasma-assisted ALD and PVD, a similar performance was found with both materials basically showing the same barrier failure temperatures as a function of thickness. ${ }^{219}$ These results are summarized in Fig. 16. For a process involving the metal-organic precursor $\mathrm{Ta}\left(\mathrm{NMe}_{2}\right)_{5}$ and a $\mathrm{N}_{2}$ plasma, it was demonstrated that TaN films of only $0.6 \mathrm{~nm}$ thick possessed a barrier failure temperature of $>800{ }^{\circ} \mathrm{C} .{ }^{226}$ This temperature is one of the higher values reported with the enhancement in diffusion barrier properties being mostly attributed to an increased nitrogen content in the film.

Another interesting issue addressed by Kim et al. is the fact that the barrier material should not penetrate into the porous low- $k$ dielectric layer. Therefore, penetration of $\mathrm{TaN}$ during deposition with thermal and plasma-assisted ALD using $\mathrm{Ta}\left(\mathrm{NMe}_{2}\right)_{5}$ as the precursor and $\mathrm{NH}_{3}$ or an $\mathrm{H}_{2} / \mathrm{N}_{2}$ plasma as reactants was investigated. ${ }^{357}$ For the thermal ALD case, the TaN layer penetrated the porous dielectric material as both the precursor as the reactant species were able to enter the pores and participate in the ALD growth process. However, for the plasma-assisted case, no evidence of film growth was found deep in the pores. While the precursor is able to travel a significant distance into the pores, the plasma radicals cannot, as they will eventually recombine after undergoing several surface collisions. ${ }^{357}$

Despite these efforts in the early 2000s, the interest and research on plasma-assisted (and thermal) ALD on liner

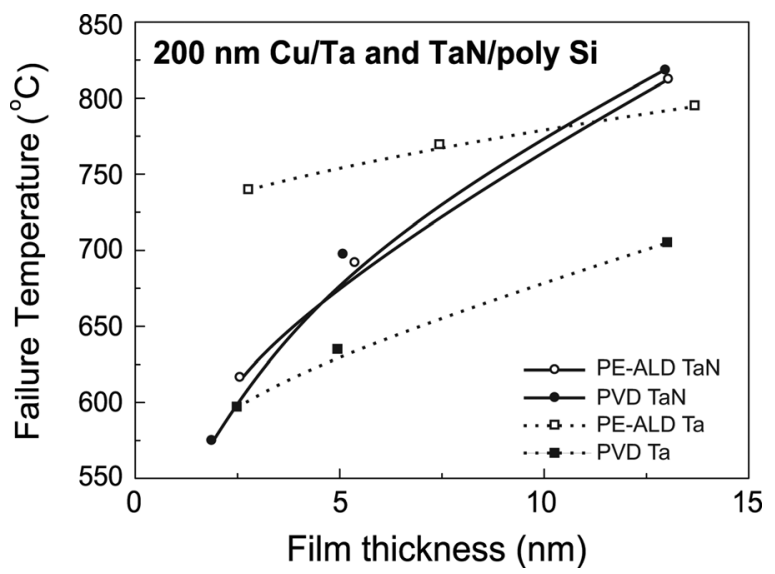

FIg. 16. Barrier failure temperatures for $\mathrm{TaN}$ and Ta films deposited by PVD and plasma-assisted ALD (Refs. 204, 219). After deposition the TaN and Ta layers were capped by $200 \mathrm{~nm}$ thick $\mathrm{Cu}$ films using the PVD technique. Barrier failure temperatures were determined by monitoring the disappearance of the $\mathrm{Cu}$ (111) peak by X-ray diffraction measurements. The ALD films were deposited using an $\mathrm{H}_{2} / \mathrm{N}_{2}$ plasma for TaN and an $\mathrm{H}_{2}$ plasma for Ta. From H. Kim et al., J. Appl. Phys. 95, 5848 (2004). Reprinted with permission. Copyright 2004, American Institute of Physics. materials declined after several years. The reason was that continuous improvements in PVD technology for $\mathrm{Cu}$ interconnects, for example by advances in ionized PVD, reduced the need for the adaption of a completely new film technology in the back-end-of-line processing. However, the research on ALD materials for back-end-of-line processing is currently increasing again, as it is inevitable that new thin film technologies will need to be implemented to deal with the challenges presented by future technology nodes. ${ }^{13,357}$

\section{B. Front-end-of-line processing}

\section{High-k dielectric layers}

Since the advent of Moore's law, the downscaling of CMOS transistors requires a continuous decrease in the thickness of the gate dielectric. By the end of the 1990s, it was realized that the required thickness of the standard $\mathrm{SiO}_{2}$ layer would eventually be too thin to prevent large leakage currents. ${ }^{358}$ This led to an increase in interest, within the semiconductor industry, in ALD of dielectric thin films as a viable alternative to growing $\mathrm{SiO}_{2}$ by thermal oxidation. It resulted in the screening of all kinds of high- $k$ dielectrics, especially $\mathrm{HfO}_{2}$ and $\mathrm{ZrO}_{2}$, and associated ALD processes to find a material with a physically higher thickness but a lower equivalent oxide thickness (EOT). Eventually it led to the implementation of Hfbased oxides deposited by ALD in the $45 \mathrm{~nm}$ technology node in 2007. ${ }^{12,359}$ In addition to thermal ALD processes, it also resulted in many investigations of plasma-assisted ALD processes for high- $k$ oxides, again putting a considerable effort into $\mathrm{HfO}_{2}$ and related oxides. For example, Park et al. demonstrated that a plasma step can be beneficial as it can result in $\mathrm{HfO}_{2}$ films with a higher density, a lower impurity level and a higher interface quality. ${ }^{135}$ The films were deposited from $\mathrm{Hf}(\mathrm{NEtMe})_{4}$ with an $\mathrm{O}_{2}$ plasma as the reactant. Compared to thermally-deposited layers, the interface layer was thicker $(2.0$ $\mathrm{nm}$ versus $1.5 \mathrm{~nm}$ ), but because it consisted of $\mathrm{Hf}-\mathrm{Si}-\mathrm{O}$ mixed with $\mathrm{SiO}_{2}$, the total film had a higher $k$-value than the thermal ALD layer with a $\mathrm{SiO}_{2}$ interface layer. Moreover, the leakage current density of the plasma deposited samples was three times lower than that for the thermally-deposited samples, but the fixed oxide charge density was higher.

The fact that the availability of a plasma source also offers the possibility of using plasmas in situ before, during or after deposition was also exploited. In a number of studies, it was demonstrated that a thin $\mathrm{SiO}_{2}$ layer grown by an $\mathrm{O}_{2}$ plasma pretreatment can retard the formation of a Hf-silicate interface layer, resulting in films with improved $k$-values and related electrical properties. ${ }^{122,130,132}$ The use of a $\mathrm{CF}_{4}$ plasma for $60 \mathrm{~s}$ was also proven to be beneficial prior to the deposition process. ${ }^{141}$ Maeng et al. reported interface defect passivation by $\mathrm{Si}-\mathrm{F}$ bonds resulting in a decrease in the flatband voltage and a lower leakage current density. The deposition of $\mathrm{HfO}_{2}$ on a $1.0 \mathrm{~nm}$ thick plasma-nitrided $\mathrm{HfO}_{2}$ or $\mathrm{Al}_{2} \mathrm{O}_{3}$ layer was found to result in a thinner interfacial layer, a lower EOT, a lower leakage current density, and a reduced charge defect density. ${ }^{129}$

Exploring variations in plasma composition, Lee et al. reported a lower fixed oxide charge density for $\mathrm{HfO}_{2}$ when 

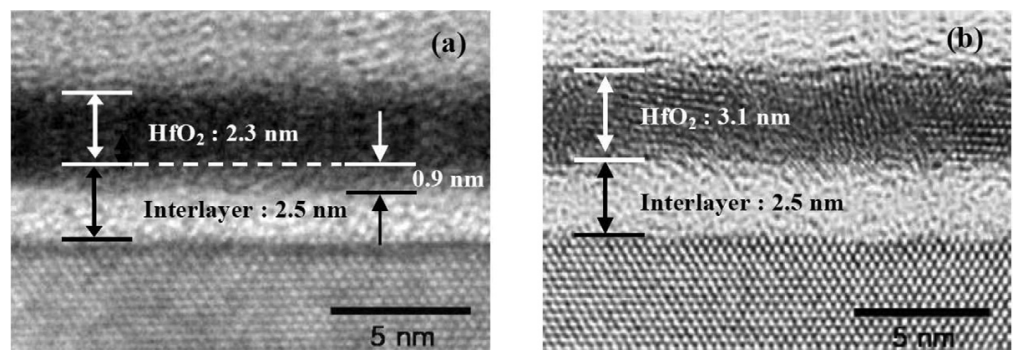

FIG. 17. Cross-sectional high-resolution transmission electron microscopy (HRTEM) images of as-grown $\mathrm{HfO}_{2}$ films deposited by (a) remote-plasma ALD and (b) direct-plasma ALD (Refs. 124, 125). The films were deposited on $\mathrm{Si}$ at a deposition temperature of $250{ }^{\circ} \mathrm{C}$ using $\mathrm{Hf}\left(\mathrm{NEt}_{2}\right)_{4}$ as the precursor and an $\mathrm{O}_{2}$ plasma as the reactant. A gradual transition from the interface layer to the $\mathrm{HfO}_{2}$ layer can be observed for the remote-plasma ALD film, whereas the film deposited using a direct-plasma shows an abrupt transition. The film deposited using a direct-plasma was partially crystallized, whereas using a remote plasma afforded an amorphous film. From J. Kim et al., Appl. Phys. Lett. 87, 53108 (2005). Reprinted with permission. Copyright 2005, American Institute of Physics.

using a $\mathrm{N}_{2} \mathrm{O}$ plasma instead of an $\mathrm{O}_{2}$ plasma. ${ }^{134}$ Maeng et al. observed a slightly higher fixed oxide charge density and interface state charge density when using a $\mathrm{N}_{2} / \mathrm{O}_{2}$ plasma. ${ }^{134,140}$ It was also shown that the use of a $\mathrm{N}_{2} \mathrm{O}$ plasma resulted in randomly oriented polycrystalline films, instead of amorphous films obtained with $\mathrm{N}_{2} \mathrm{O}$ gas. Also, the growth per cycle was higher. ${ }^{134}$ Maeng et al. also reported two different experiments in which a $\mathrm{HfO}_{x} \mathrm{~N}_{y}$ layer was incorporated within an $\mathrm{HfO}_{2}$ film by varying the plasma composition during the ALD process. ${ }^{116,143}$ In this case the precursor was $\mathrm{Hf}\left(\mathrm{NMe}_{2}\right)_{4}$, whereas the reactant was varied from an $\mathrm{O}_{2}$ plasma to an $\mathrm{H}_{2}$ plasma or an $\mathrm{O}_{2} / \mathrm{N}_{2}$ plasma. The films possessed a higher $k$-value, a lower interface defect density $D_{\text {it }}$ and a lower or comparable leakage current density. The latter was attributed to the presence of $\mathrm{N}-\mathrm{H}$ bonds, which block leakage paths and suppress conduction band lowering and reduce trap sites. ${ }^{116}$ Besides the plasma composition, the reactor choice can also influence the material properties, as already mentioned in Sec. V. Kim et al. reported polycrystalline $\mathrm{HfO}_{2}$ films deposited from $\mathrm{Hf}\left(\mathrm{NEt}_{2}\right)_{4}$ and an $\mathrm{O}_{2}$ plasma in a direct plasma reactor compared to amorphous films obtained with the same ALD chemistry in a remote plasma (See Fig. 17). ${ }^{123,125}$ In addition to better dielectric properties, MOSFET devices that were prepared using remote-plasma ALD $\mathrm{HfO}_{2}$ showed better interface properties and a lower fixed oxide charge density. The difference in material properties was attributed to the increased physical reactivity of the direct plasma, in terms of ion bombardment (see Sec. V). On the other hand, a beneficial effect of some (mild) ion bombardment was also demonstrated in a recent study. $\mathrm{HfO}_{2}$ was deposited using $\mathrm{Hf}(\mathrm{NEtMe})_{4}$ and an $\mathrm{O}_{2}$ plasma in a capacitively-coupled remote plasma reactor (see Sec. III) in which the grid between the driven electrode and the substrate carrier was biased. Films deposited with a $30 \mathrm{~W}$ bias power resulted in films with a lower EOT and a higher breakdown electric field than those in an unbiased situation. ${ }^{138}$

Although the plasma-assisted ALD processes to Hf-based and the many other high- $k$ oxides investigated are currently not considered for adaptation into process flows for advanced gate stacks, there are still many research efforts on plasma-assisted ALD of high- $k$ oxides ongoing. Several other applications also exist for which high- $k$ and other oxides deposited by plasma-assisted ALD are interesting candidates. In particular, the manufacture of high-density capacitors, for which ultrahigh- $k$ oxides (e.g. $\mathrm{SrTiO}_{3}$ (Refs. 195-198)) are being considered, ${ }^{327}$ might require energyenhanced ALD processes as certain classes of precursors do not react with $\mathrm{H}_{2} \mathrm{O}$ under ALD conditions (see Sec. IV). ${ }^{360}$

\section{Spacer-defined double patterning}

As discussed in the previous sections, plasma-assisted ALD is generally able to deposit thin films at lower temperatures than thermal ALD. In several cases, films of reasonably high quality can even be deposited at temperatures of $100{ }^{\circ} \mathrm{C}$ and lower. This merit of plasma-assisted ALD has recently led to a development of high interest to the semiconductor industry. In order to keep up with the future demands of miniaturization, extreme-UV lithography (13.5 nm wavelength) is being developed. However, methods such as double exposure and double patterning ${ }^{361,362}$ are being adopted in the interim to extend the versatility of current lithography methods (193 nm wavelength) while still allowing for smaller structures to be defined. Recently an alternative form of double patterning, requiring only one lithography step instead of two, has been developed. This spaced-defined double-patterning method, which is currently being introduced in DRAM manufacturing for the fabrication of the next generation of logic devices, employs a low temperature plasma-assisted ALD step. ${ }^{13,321,363}$

In spacer-defined double patterning, a photoresist layer is deposited and patterned on top of the target layer, as shown in Fig. 18. Then, a highly conformal $\mathrm{SiO}_{2}$ spacer layer is deposited directly onto the photoresist pattern. This requires a low temperature plasma-assisted ALD process, as the photoresist is temperature-sensitive. Next, the structure is anisotropically etched and the photoresist is removed, resulting in a patterned layer with narrow spacer features. These then function as a mask for the second anisotropic etching step, in which the pattern is transferred to the target layer. Finally, the $\mathrm{SiO}_{2}$ masking material can be removed. Obviously, the deposition of $\sim 20 \mathrm{~nm}$ thick $\mathrm{SiO}_{2}$ layers with excellent uniformity and deposition temperatures $<100{ }^{\circ} \mathrm{C}$ is key in this process. Plasma-assisted ALD is well-suited for this application and is, therefore, an enabling technology for the 


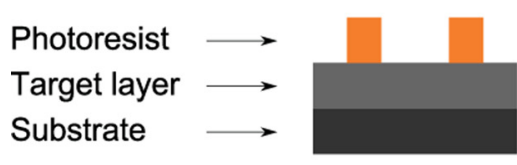

(a) Patterned photoresist

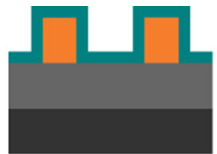

(b) Spacer deposition

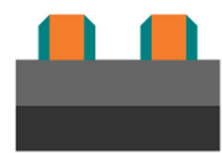

(c) Anisotropic etch step

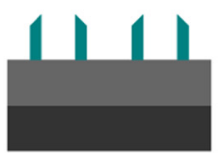

(d) Photoresist removal

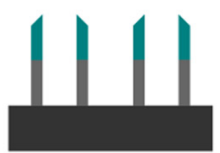

(e) Anisotropic etch step

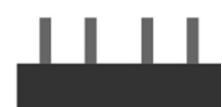

(f) Spacer removal

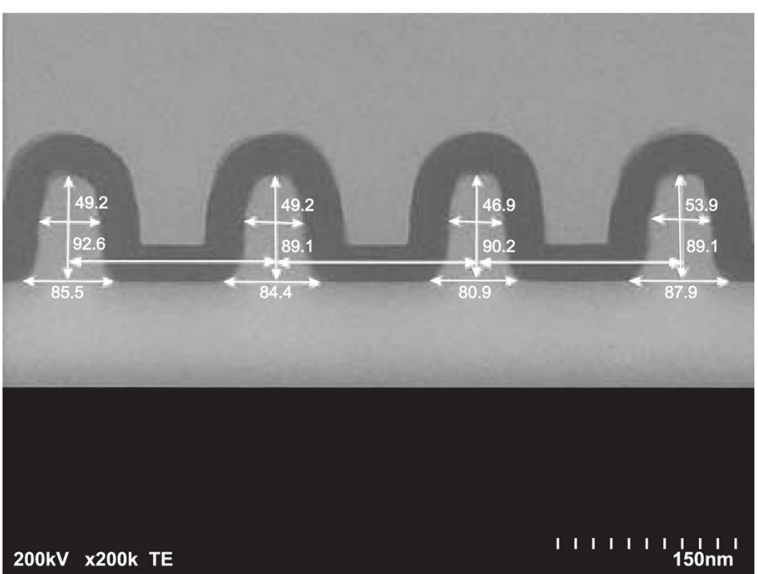

(g)

FIG. 18. (Color online) The spacer-defined double patterning process (Ref. 321), in which (a) a photoresist layer is deposited on top of the target layer (i.e. the layer to be patterned) and patterned by UV exposure and photoresist development. In the next step (b) a $\mathrm{SiO}_{2}$ spacer layer is deposited at a low temperature using plasma-assisted ALD, after which an anisotropic etch is carried out. Subsequently, the photoresist is removed in step (d) after which the pattern can be transferred into the target layer. Finally, in step (f) the $\mathrm{SiO}_{2}$ spacers are removed, after which narrow features at half-pitch are left. Between steps (a) and (b), an optional plasma-treatment can be carried out in order to additionally reduce the feature thickness of the photo resist. In (g) a scanning-electron microscopy image is shown, illustrating a photoresist pattern covered by a conformal $\mathrm{SiO}_{2}$ spacer layer (corresponding to the situation in (b)). Courtesy of ASM International N.V.

spacer-defined double patterning method. Several lowtemperature plasma-assisted ALD processes of $\mathrm{SiO}_{2}$ have recently been reported. ${ }^{184,186,187}$ In the literature, a successful spacer-defined double patterning process was demonstrated for $32 \mathrm{~nm}$ half-pitch polysilicon lines. ${ }^{321}$ It has also been reported that predeposition plasma treatments are useful for further widening of the space between lines and/or to reform the resist shape. Spacer-defined double patterning does not suffer from overlay issues, which is common for the double exposure technique. High throughputs can be achieved in mini-batch systems which are essentially multisingle-wafer systems. ${ }^{13}$

\section{Encapsulation}

Another promising application of plasma-assisted ALD processes is the encapsulation of polymeric and/or organic devices by thin films. It has been demonstrated that metal oxide films (e.g. $\mathrm{Al}_{2} \mathrm{O}_{3}$ and $\mathrm{TiO}_{2}$ ) prepared by plasmaassisted ALD can serve as good barrier layers against $\mathrm{H}_{2} \mathrm{O}$ and $\mathrm{O}_{2}$ permeation. ${ }^{38,39,54,251,256}$ For $\mathrm{Al}_{2} \mathrm{O}_{3}$ it was reported that the material can provide very low water vapor transmission rates for the encapsulation of organic LEDs while also significantly reducing the pinhole density. ${ }^{38,39,54}$ The advantage of ALD processes for this application is that dense, high quality thin films can be prepared that outperform films prepared by other vapor phase deposition methods (such as PECVD and PVD) even when those layers are much thicker. ${ }^{54,364,365}$ The main advantage of the plasma-based process is that short cycle times can be maintained at low substrate temperatures, including room temperature. Moreover, Langereis et al. reported the striking result that, for $\mathrm{Al}_{2} \mathrm{O}_{3}$ films deposited by remote plasma-assisted ALD, the best barrier performance was obtained for films deposited at room temperature (see Fig. 19). ${ }^{54}$

A related application of low temperature ALD-synthesized films is the protection of high-precision and high-purity metal parts against corrosion by water (liquid or vapor), acidic, basic or saline solutions, or organic solvents. ${ }^{366-369}$ For this application, ultra-thin, dense, and defect-free coatings are also desired and, in most cases, they need to be deposited at reduced substrate temperatures to maintain the mechanical properties of the substrates and to reduce the possibility of premature surface oxidation. $\mathrm{Al}_{2} \mathrm{O}_{3}$ is again among the most important candidate materials, although for the final application a stack of materials might be required. A recent study revealed that plasma-assisted ALD with an $\mathrm{O}_{2}$ plasma produced $\mathrm{Al}_{2} \mathrm{O}_{3}$ encapsulation layers that showed a better film nucleation and lower porosity than films deposited by thermal ALD using $\mathrm{H}_{2} \mathrm{O}$ vapor. ${ }^{65}$ For this application, but also for the application of $\mathrm{Al}_{2} \mathrm{O}_{3}$ as an $\mathrm{H}_{2} \mathrm{O}$ and $\mathrm{O}_{2}$ barrier, the advantage of plasma-assisted ALD over thermal ALD was most prominent for the thinnest films $(\sim 10 \mathrm{~nm})$ deposited at room temperature. Considering the growing importance of thin film encapsulation and the increasing number of applications of temperature sensitive materials, 


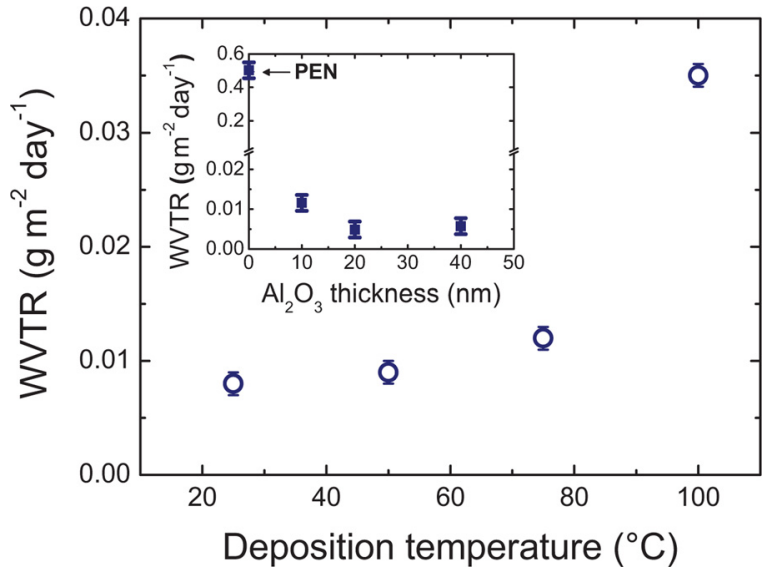

FIG. 19. (Color online) Water vapor transmission rate (WVTR) of a $20 \mathrm{~nm}$ thick $\mathrm{Al}_{2} \mathrm{O}_{3}$ films on poly(2,6-ethylenenaphthalate) (PEN) substrates as a function of the deposition temperature (Ref. 54). The $\mathrm{Al}_{2} \mathrm{O}_{3}$ films were deposited by plasma-assisted ALD using $\mathrm{AlMe}_{3}$ as the precursor and an $\mathrm{O}_{2}$ plasma as the reactant. The inset shows the WVTR as a function of the film thickness for a film deposited at room temperature. The WVTR values were determined using a standard calcium test (Ref. 378) and include water permeation through pinholes which are possibly present. From E. Langereis et al., Appl. Phys. Lett. 89, 081915 (2006). Reprinted with permission. Copyright 2006, American Institute of Physics.

plasma-assisted ALD has the potential to become a prominent technology in this field.

\section{CONCLUDING REMARKS AND OUTLOOK}

With the growing need for high quality ultra-thin and conformal films, in and outside the semiconductor industry, the number of applications of ALD will grow substantially in the next decade. As a consequence, the requirements on process conditions and material properties will increase and diversify, requiring new experimental approaches and a variety of ALD equipment configurations. As plasma-assisted ALD can provide some unique merits over the thermal ALD method, it is expected that the interest in this method will also keep growing considerably. This increase in interest is already currently manifested by the number of ALD equipment manufacturers providing dedicated plasma-assisted ALD tools, which has increased significantly in the last few years. The demand for plasma-assisted ALD equipment from industrial R\&D laboratories has, in particular, appeared to be high. It is likely that this is fueled by the fact that industrial laboratories are particularly focused on equipment that provides a high degree of flexibility in combination with a robustness of the equipment and processes. In this respect, plasma-based techniques have been well-accepted in thin film and device manufacturing. Nevertheless, plasmaassisted ALD also faces several challenges. In order to address the question whether and when aspects inherent to the plasma-based process will provide principal limitations for certain applications, a deeper understanding of film growth by plasma-assisted ALD is required. Therefore, more insight into the underlying surface reactions and the role of the plasma-surface interaction needs to be obtained. This is quite a challenging task, but, consequently, also an appealing one considering the complexity of plasma processes. Also of vital importance is that plasma-assisted ALD equipment for high volume manufacturing will be developed and implemented. In the case where (multiple) single wafer reactors are used, the implementation of a plasma source is relatively easy. ${ }^{13}$ Recently, however, the first results were presented on plasma-assisted ALD an inline spatial ALD system ${ }^{66}$ while also the first results obtained in a multiwafer ALD batch reactor equipped with plasma source were presented. ${ }^{370}$ Furthermore, in 2007 a patent was filed on roll-to-roll ALD using an atmospheric plasma ${ }^{371}$ by FujiFilm Manufacturing Europe. ${ }^{372}$ Generally for plasma-assisted ALD, it would be best to focus initially on applications for which no alternative deposition techniques exist, or on applications for which the merits of plasma-assisted ALD are substantial and critical. Once established, the method will certainly find more applications and plasma-assisted ALD will complement existing thin film manufacturing techniques.

\section{ACKNOWLEDGMENTS}

The current and past ALD team members of the Eindhoven University are thanked for their contribution to the measurements and the many fruitful discussions. This work was supported financially by the Dutch Technology Foundation STW (Thin Film Nanomanufacturing (TFN) programme) and by the NanoNextNL programme.

${ }^{1}$ S. M. George, A. W. Ott, and J. W. Klaus, J. Phys. Chem. 100, 13121 (1996).

${ }^{2}$ S. M. George, Chem. Rev. 110, 111 (2010).

${ }^{3}$ C. H. L. Goodman and M. V. Pessa, J. Appl. Phys. 60, R65 (1986).

${ }^{4}$ M. Leskela and M. Ritala, J. Phys. IV 9, Pr8/837 (1999).

${ }^{5}$ M. Leskela and M. Ritala, Thin Solid Films 409, 138 (2002).

${ }^{6}$ L. Niinisto, M. Ritala, and M. Leskela, Mater. Sci. Eng. B 41, 23 (1996).

${ }^{7}$ R. L. Puurunen, J. Appl. Phys. 97, 121301 (2005).

${ }^{8}$ M. Ritala and M. Leskela, Nanotechnology 10, 19 (1999).

${ }^{9}$ T. Suntola, Mater. Sci. Rep. 4, 261 (1989).

${ }^{10}$ S. Haukka, E. L. Lakooma, and T. Suntola, Stud. Surf. Sci. Catal. 120A, 715 (1999).

${ }^{11}$ T. Suntola and J. Antson, U.S. patent 4,058, 430 (15 November 1977).

${ }^{12}$ International Technology Roadmap for Semiconductors, http://www.itrs. net, (May 31, 2011).

${ }^{13}$ M. Verghese, J. W. Maes, and N. Kobayashi, Atomic layer deposition goes mainstream in $22 \mathrm{~nm}$ logic technologies, http://www.solid-state.com (November, 2010).

${ }^{14}$ Intel website, http://www.intel.com (May 31, 2011).

${ }^{15}$ W. M. M. Kessels, S. E. Potts, H. B. Profijt, and M. C. M. van de Sanden, in Atomic Layer Deposition of Nanostructures Materials, edited by M. Knez and N. Pinna (Wiley VCH, New York, 2011)

${ }^{16}$ ASM International website, http://www.asm.com (May 31, 2011).

${ }^{17}$ Oxford Instruments website, http://www.oxford-instruments.com (May 31, 2011).

${ }^{18}$ Beneq website, http://www.beneq.com (May 31, 2011).

${ }^{19}$ Cambridge NanoTech website, http://www.cambridgenanotech.com (May 31, 2011).

${ }^{20}$ Applied Materials website, http://www.appliedmaterials.com (May 31, 2011).

${ }^{21}$ Tokyo Electron Limited website, http://www.tel.com/ (May 31, 2011).

${ }^{22}$ Picosun website, http://www.picosun.com (May 31, 2011).

${ }^{23}$ Web of Knowledge, http://apps.isiknowlegde.com (May 31, 2011).

${ }^{24}$ A. Niskanen, T. Hatanpaa, K. Arstila, M. Leskela, and M. Ritala, Chem. Vap. Deposition 13, 408 (2007).

${ }^{25}$ C. W. Jeong, B. I. Lee, and S. K. Joo, Mater. Sci. Eng. C 16, 59 (2001).

${ }^{26}$ C. W. Jeong, J. S. Lee, and S. K. Joo, Jpn. J. Appl. Phys., Part 1 40, 285 (2001).

${ }^{27}$ B. H. Kim, W. S. Jeon, S. H. Jung, and B. T. Ahn, Electrochem. SolidState Lett. 8, G294 (2005). 
${ }^{28}$ J. Koo, S. Kim, S. Jeon, H. Jeon, Y. Kim, and Y. Won, J. Korean Phys. Soc. 48, 131 (2006).

${ }^{29}$ M. T. Seman, D. N. Richards, P. Rowlette, and C. A. Wolden, Chem. Vap. Deposition 14, 296 (2008).

${ }^{30}$ J. W. Lim and S. J. Yun, Jpn. J. Appl. Phys., Part 2 42, L663 (2003).

${ }^{31}$ S. W. Choi, C. M. Jang, D. Y. Kim, J. S. Ha, H. S. Park, W. Koh, and C. S. Lee, J. Korean Phys. Soc. 42, S975 (2003).

${ }^{32}$ J. W. Lim and S. J. Yun, Electrochem. Solid-State Lett. 7, F45 (2004).

${ }^{33}$ P. K. Park and S. W. Kang, Appl. Phys. Lett. 89, 192905 (2006).

${ }^{34}$ P. K. Park, E. S. Cha, and S. W. Kang, Appl. Phys. Lett. 90, 232906 (2007).

${ }^{35}$ J. W. Lim, J. B. Koo, S. J. Yun, and H. T. Kim, Electrochem. Solid-State Lett. 10, J136 (2007).

${ }^{36}$ K. Y. Park, H. I. Cho, H. C. Choi, Y. H. Bae, C. S. Lee, J. L. Lee, and J. H. Lee, Jpn. J. Appl. Phys., Part 2 43, L1433 (2004).

${ }^{37}$ S. M. Yoon, S. H. K. Park, C. W. Byun, S. H. Yang, and C. S. Hwang, J. Electrochem. Soc. 157, H727 (2010).

${ }^{38}$ S. J. Yun, Y. W. Ko, and J. W. Lim, Appl. Phys. Lett. 85, 4896 (2004).

${ }^{39}$ W. S. Kim, D. Y. Moon, B. W. Kang, J. W. Park, and J. G. Park, J. Korean Phys. Soc. 55, 55 (2009).

${ }^{40}$ A. Niskanen, K. Arstila, M. Ritala, and M. Leskela, J. Electrochem. Soc. 152, F90 (2005).

${ }^{41}$ M. Caymax, G. Brammertz, A. Delabie, S. Sioncke, D. Lin, M. Scarrozza, G. Pourtois, W. E. Wang, M. Meuris, and M. Heyns, Microelectron. Eng. 86, 1529 (2009).

${ }^{42}$ J. Dendooven, D. Deduytsche, J. Musschoot, R. L. Vanmeirhaeghe, and C. Detavernier, J. Electrochem. Soc. 157, G111 (2010).

${ }^{43}$ G. Dingemans, N. M. Terlinden, D. Pierreux, H. B. Profijt, M. C. M. Van de Sanden, and W. M. M. Kessels, Electrochem. Solid-State Lett. 14, H1 (2010).

${ }^{44}$ G. Dingemans, R. Seguin, P. Engelhart, M. C. M. van de Sanden, and W. M. M. Kessels, Phys. Status Solidi (RRL) 4, 10 (2010).

${ }^{45}$ J. J. H. Gielis, P. M. Gevers, I. M. P. Aarts, M. C. M. van de Sanden, and W. M. M. Kessels, J. Vac. Sci. Technol. A 26, 1519 (2008).

${ }^{46}$ S. B. S. Heil, P. Kudlacek, E. Langereis, R. Engeln, M. C. M. van de Sanden, and W. M. M. Kessels, Appl. Phys. Lett. 89, 131505 (2006).

${ }^{47}$ S. B. S. Heil, J. L. van Hemmen, M. C. M. van de Sanden, and W. M. M. Kessels, J. Appl. Phys. 103, 103302 (2008).

${ }^{48}$ B. Hoex, S. B. S. Heil, E. Langereis, M. C. M. van de Sanden, and W. M. M. Kessels, Appl. Phys. Lett. 89, 042112 (2006).

${ }^{49}$ B. Hoex, J. Schmidt, R. Bock, P. P. Altermatt, M. C. M. van de Sanden, and W. M. M. Kessels, Appl. Phys. Lett. 91, 112107 (2007).

${ }^{50}$ B. Hoex, J. Schmidt, P. Pohl, M. C. M. van de Sanden, and W. M. M. Kessels, J. Appl. Phys. 104, 044903 (2008).

${ }^{51}$ D. Hoogeland, K. B. Jinesh, F. Roozeboom, W. F. A. Besling, M. C. M. van de Sanden, and W. M. M. Kessels, J. Appl. Phys. 106, 114107 (2009).

${ }^{52}$ H. Kim, S. Woo, J. Lee, H. Lee, and H. Jeon, J. Phys. D 43, 505301 (2010).

${ }^{53}$ Y. Kim, S. Woo, H. Kim, J. Lee, H. Kim, H. Lee, and H. Jeona, J. Mater. Res. 25, 1898 (2010).

${ }^{54}$ E. Langereis, M. Creatore, S. B. S. Heil, M. C. M. Van de Sanden, and W. M. M. Kessels, Appl. Phys. Lett. 89, 081915 (2006).

${ }^{55}$ E. Langereis, J. Keijmel, M. C. M. Van de Sanden, and W. M. M. Kessels, Appl. Phys. Lett. 92, 231904 (2008).

${ }^{56}$ S. E. Potts, W. Keuning, E. Langereis, G. Dingemans, M. C. M. van de Sanden, and W. M. M. Kessels, J. Electrochem. Soc. 157, P66 (2010).

${ }^{57}$ V. R. Rai, V. Vandalon, and S. Agarwal, Langmuir 26, 13732 (2010).

${ }^{58}$ S. Sioncke, A. Delabie, G. Brammertz, T. Conard, A. Franquet, M. Caymax, A. Urbanzcyk, M. Heyns, M. Meuris, J. L. van Hemmen, W. Keuning, and W. M. M. Kessels, J. Electrochem. Soc. 156, H255 (2009).

${ }^{59}$ N. M. Terlinden, G. Dingemans, M. C. M. van de Sanden, and W. M. M. Kessels, Appl. Phys. Lett. 96, 112101 (2010).

${ }^{60}$ J. L. Van Hemmen, S. B. S. Heil, J. H. Klootwijk, F. Roozeboom, C. J. Hodson, M. C. M. Van de Sanden, and W. M. M. Kessels, J. Electrochem. Soc. 154, G165 (2007).

${ }^{61}$ H. S. Yun and K. H. Kim, J. Korean Phys. Soc. 54, 707 (2009).

${ }^{62}$ T. O. Kaariainen and D. C. Cameron, Plasma Processes Polym. 6, S237 (2009).

${ }^{63}$ K. Lambert, J. Dendooven, C. Detavernier, and Z. Hens, Chem. Mater. 23, 126 (2011).

${ }^{64}$ K. B. Jinesh, J. L. van Hemmen, M. C. M. van de Sanden, F. Roozeboom, J. H. Klootwijk, W. F. A. Besling, and W. M. M. Kessels, J. Electrochem. Soc. 158, G21 (2011).
${ }^{65}$ S. E. Potts, L. Schmalz, M. Fenker, B. Diaz, J. Swiatowska, V. Maurice, A. Seyeux, P. Marcus, G. Radnoczi, L. Toth, and W. M. M. Kessels, J. Electrochem. Soc. 158, C132 (2011).

${ }^{66}$ P. Poodt, B. Kniknie, A. Branca, H. Winands, and F. Roozeboom, Phys. Status Solidi (RRL) 5, 165 (2011).

${ }^{67}$ O. M. Nayfeh, T. Marr, and M. Dubey, IEEE Electron. Dev. Lett. 32, 473 (2011).

${ }^{68}$ A. Ali, H. S. Madan, A. P. Kirk, D. A. Zhao, D. A. Mourey, M. K. Hudait, R. M. Wallace, T. N. Jackson, B. R. Bennett, J. B. Boos, and S. Datta, Appl. Phys. Lett. 97, 143502 (2010).

${ }^{69}$ Y. H. Kim, J. Moon, C. H. Chung, S. J. Yun, D. J. Park, J. W. Lim, Y. H. Song, and J. H. Lee, IEEE Electron. Dev. Lett. 27, 896 (2006).

${ }^{70}$ D. J. Park, J. W. Lim, and B. O. Park, Solid-State Electron. 54, 323 (2010).

${ }^{71}$ Y. H. Kim, C. Y. Sohn, J. W. Lim, S. J. Yun, C. S. Hwang, C. H. Chung, Y. W. Ko, and J. H. Lee, IEEE Electron. Dev. Lett. 25, 550 (2004).

${ }^{72}$ J. Moon, Y. H. Kim, D. J. Park, C. H. Chung, S. Y. Kang, and J. H. Lee, Solid-State Electron. 54, 1326 (2010).

${ }^{73}$ S. Lee and H. Jeon, Electron. Mater. Lett. 3, 17 (2007).

${ }^{74}$ Y. J. Lee and S. W. Kang, Thin Solid Films 446, 227 (2004).

${ }^{75}$ Y. J. Lee, J. Cryst. Growth 266, 568 (2004).

${ }^{76}$ M. Bosund, P. Mattila, A. Aierken, T. Hakkarainen, H. Koskenvaara, M. Sopanen, V. M. Airaksinen, and H. Lipsanen, Appl. Surf. Sci. 256, 7434 (2010).

${ }^{77}$ M. Bosund, T. Sajavaara, M. Laitinen, T. Huhtio, M. Putkonen, V. M. Airaksinen, and H. Lipsanen, Appl. Surf. Sci. 257, 7827 (2011).

${ }^{78}$ K. H. Kim, N. W. Kwak, and S. H. Lee, Electron. Mater. Lett. 5, 83 (2009).

${ }^{79}$ J. W. Lim and S. J. Yun, Electrochem. Solid-State Lett. 7, H33 (2004).

${ }^{80}$ J. W. Lim, S. J. Yun, and J. H. Lee, Electrochem. Solid-State Lett. 8, F25 (2005).

${ }^{81}$ J. W. Lim, S. J. Yun, and J. H. Lee, Electrochem. Solid-State Lett. 9, F8 (2006).

${ }^{82}$ J. W. Lim, S. J. Yun, and H. T. Kim, J. Electrochem. Soc. 154, G239 (2007).

${ }^{83}$ J. W. Lim, S. J. Yun, and H. T. Kim, Jpn. J. Appl. Phys. 47, 6934 (2008).

${ }^{84}$ J. W. Lim, S. J. Yun, and S. H. Lee, J. Korean Phys. Soc. 56, 96 (2010).

${ }^{85}$ G. J. Choi, S. K. Kim, S. J. Won, H. J. Kim, and C. S. Hwang, J. Electrochem. Soc. 156, G138 (2009).

${ }^{86}$ H. B. R. Lee, J. Kim, H. Kim, W. H. Kim, J. W. Lee, and I. Hwang, J. Korean Phys. Soc. 56, 104 (2010).

${ }^{87}$ J. M. Kim, H. B. R. Lee, C. Lansalot, C. Dussarrat, J. Gatineau, and H. Kim, Jpn. J. Appl. Phys. 49, 05FA10 (2010).

${ }^{88}$ K. Kim, K. Lee, S. Han, W. Jeong, and H. Jeon, J. Electrochem. Soc. 154, H177 (2007).

${ }^{89}$ K. Kim, K. Lee, S. Han, T. Park, Y. Lee, J. Kim, S. Yeom, and H. Jeon, Jpn. J. Appl. Phys., Part 2 46, L173 (2007).

${ }^{90}$ H. B. R. Lee and H. Kim, Electrochem. Solid-State Lett. 9, G323 (2006).

${ }^{91}$ H. B. R. Lee, J. Y. Son, and H. Kim, Appl. Phys. Lett. 90, 213509 (2007).

${ }^{92}$ K. Lee, K. Kim, T. Park, H. Jeon, Y. Lee, J. Kim, and S. Yeom, J. Electrochem. Soc. 154, H899 (2007).

${ }^{93}$ K. Lee, K. Kim, H. Jeon, Y. Lee, J. Kim, and S. Yeom, J. Korean Phys. Soc. 50, 1141 (2007).

${ }^{94}$ M. E. Donders, H. C. M. Knoops, M. C. M. van de Sanden, W. M. M. Kessels, and P. H. L. Notten, J. Electrochem. Soc. 158, G92 (2011).

${ }^{95}$ H. B. R. Lee, G. H. Gu, J. Y. Son, C. G. Park, and H. Kim, Small 4, 2247 (2008).

${ }^{96}$ H. B. R. Lee and H. Kim, J. Cryst. Growth 312, 2215 (2010).

${ }^{97}$ L. Wu and E. Eisenbraun, J. Vac. Sci. Technol. B 25, 2581 (2007).

${ }^{98} \mathrm{~L}$. Wu and E. Eisenbraun, Electrochem. Solid-State Lett. 11, H107 (2008).

${ }^{99}$ L. Wu and E. Eisenbraun, J. Electrochem. Soc. 156, H734 (2009).

${ }^{100}$ A. Niskanen, A. Rahtu, T. Sajavaara, K. Arstila, M. Ritala, and M. Leskela, J. Electrochem. Soc. 152, G25 (2005).

${ }^{101}$ D. Y. Moon, W. S. Kim, T. S. Kim, B. W. Kang, J. W. Park, S. J. Yeom, and J. H. Kim, J. Korean Phys. Soc. 54, 1330 (2009).

${ }^{102}$ C. Jezewski, W. A. Lanford, C. J. Wiegand, J. P. Singh, P. I. Wang, J. J. Senkevich, and T. M. Lu, J. Electrochem. Soc. 152, C60 (2005).

${ }^{103}$ D. Y. Moon, D. S. Han, S. Y. Shin, J. W. Park, B. M. Kim, and J. H. Kim, Thin Solid Films 519, 3636 (2011).

${ }^{104}$ T. T. Van and J. P. Chang, Appl. Surf. Sci. 246, 250 (2005). 
${ }^{105}$ G. X. Liu, F. K. Shan, W. J. Lee, G. H. Lee, I. S. Kim, and B. C. Shin, Integr. Ferroelectr. 85, 155 (2006).

${ }^{106}$ G. X. Liu, F. K. Shan, W. J. Lee, B. C. Shin, S. C. Kim, H. S. Kim, and C. R. Cho, Integr. Ferroelectr. 94, 11 (2007).

${ }^{107}$ N. J. Seong, S. G. Yoon, and W. J. Lee, Appl. Phys. Lett. 87, 082909 (2005).

${ }^{108}$ N. J. Seong, E. T. Kim, and S. G. Yoon, Integr. Ferroelectr. 74, 181 (2005).

${ }^{109}$ F. K. Shan, G. X. Liu, W. J. Lee, G. H. Lee, I. S. Kim, and B. C. Shin, J. Appl. Phys. 98, 023504 (2005).

${ }^{110}$ F. K. Shan, G. X. Liu, W. J. Lee, G. H. Lee, I. S. Kim, and B. C. Shin, Integr. Ferroelectr. 80, 197 (2006).

${ }^{111}$ M. De Keijser and C. Van Opdorp, Appl. Phys. Lett. 58, 1187 (1991).

${ }^{112}$ G. X. Liu, F. K. Shan, J. J. Park, W. J. Lee, G. H. Lee, I. S. Kim, B. C. Shin, and S. G. Yoon, J. Electroceram. 17, 145 (2006).

${ }^{113}$ J. Lee, S. Choi, C. Lee, Y. Kang, and D. Kim, Appl. Surf. Sci. 253, 3969 (2007).

${ }^{114}$ B. J. Choi, S. Choi, T. Eom, S. W. Ryu, D. Y. Cho, J. Heo, H. J. Kim, C. S. Hwang, Y. J. Kim, and S. K. Hong, Chem. Mater. 21, 2386 (2009).

${ }^{115}$ S. Consiglio, W. X. Zeng, N. Berliner, and E. T. Eisenbraun, J. Electrochem. Soc. 155, H196 (2008).

${ }^{116}$ W. J. Maeng, G. H. Gu, C. G. Park, K. Lee, T. Lee, and H. Kim, J. Electrochem. Soc. 156, G109 (2009).

${ }^{117}$ E. J. Kim and D. H. Kim, Electrochem. Solid-State Lett. 9, C123 (2006).

${ }^{118}$ W. Jeong, Y. Ko, S. Bang, S. Lee, and H. Jeon, J. Korean Phys. Soc. 56, 905 (2010).

${ }^{119}$ J. Choi, S. Kim, J. Kim, H. Kang, H. Jeon, and C. Bae, J. Vac. Sci. Technol. A 24, 900 (2006).

${ }^{120}$ S. Choi, J. Koo, H. Jeon, and Y. Kim, J. Korean. Phys. Soc. 44, 35 (2004).

${ }^{121}$ H. Hong, S. Kim, S. Woo, H. Kim, H. Kim, W. Jeong, S. Jeon, S. Bang, S. Lfe, and H. Jeon, J. Korean Phys. Soc. 52, 1114 (2008).

${ }^{122}$ H. Kang, S. Kim, J. Choi, J. Kim, H. Jeon, and C. Bae, Electrochem. Solid-State Lett. 9, G211 (2006).

${ }^{123}$ I. Kim, S. Kuk, S. Kim, J. Kim, H. Jeon, M. H. Cho, and K. B. Chung, Appl. Phys. Lett. 90, 222101 (2007).

${ }^{124}$ J. Kim, S. Kim, H. Kang, J. Choi, H. Jeon, M. Cho, K. Chung, S. Back, K. Yoo, and C. Bae, J. Appl. Phys. 98, 094509 (2005).

${ }^{125}$ J. Kim, S. Kim, H. Jeon, M. H. Cho, K. B. Chung, and C. Bae, Appl. Phys. Lett. 87, 053108 (2005).

${ }^{126}$ S. Kim, J. Kim, J. Choi, H. S. Kang, H. Jeon, and C. Bae, J. Vac. Sci. Technol. B 24, 1088 (2006).

${ }^{127}$ S. Kim, J. Kim, J. Choi, H. Kang, H. Jeon, W. Cho, K. S. An, T. M. Chung, Y. Kim, and C. Bae, Electrochem. Solid-State Lett. 9, G200 (2006).

${ }^{128}$ S. Kim, S. Woo, H. Kim, W. Jeong, T. Park, H. Kim, S. B. Kim, and H. Jeon, J. Vac. Sci. Technol. B 25, 1922 (2007).

${ }^{129}$ S. Kim, S. Woo, H. Hong, H. Kim, H. Jeon, and C. Bae, J. Electrochem. Soc. 154, H97 (2007).

${ }^{130}$ S. Kim, S. Woo, H. Kim, I. Kim, K. Lee, W. Jeong, T. Park, and H. Jeon, J. Korean Phys. Soc. 52, 1103 (2008).

${ }^{131}$ Y. Won, S. Park, J. Koo, S. Kim, J. Kim, and H. Jeon, Appl. Phys. Lett. 87, 262901 (2005).

${ }^{132}$ S. Woo, H. Hong, S. Kim, H. Kim, J. Kim, H. Jeon, C. Bae, T. Okada, K. Sawada, and M. Ishida, Jpn. J. Appl. Phys. 47, 6196 (2008).

${ }^{133}$ Y. C. Byun, C. H. An, J. Y. Choi, C. Y. Kim, M. H. Cho, and H. Kim, J. Electrochem. Soc. 158, G141 (2011).

${ }^{134}$ Y. Lee, S. Kim, J. Koo, I. Kim, J. Choi, H. Jeon, and Y. Won, J. Electrochem. Soc. 153, G353 (2006).

${ }^{135}$ P. K. Park, J. S. Roh, B. H. Choi, and S. W. Kang, Electrochem. SolidState Lett. 9, F34 (2006).

${ }^{136}$ S. B. S. Heil, J. L. van Hemmen, C. J. Hodson, N. Singh, J. H. Klootwijk, F. Roozeboom, M. C. M. van de Sanden, and W. M. M. Kessels, J. Vac. Sci. Technol. A 25, 1357 (2007).

${ }^{137}$ J. Joo and S. M. Rossnagel, J. Korean Phys. Soc. 54, 1048 (2009).

${ }^{138}$ H. Kim, S. Woo, J. Lee, Y. Kim, H. Lee, I. J. Choi, Y. D. Kim, C. W. Chung, and H. Jeon, J. Electrochem. Soc. 158, H21 (2011).

${ }^{139}$ W. S. Kim, S. K. Park, D. Y. Moon, T. S. Kim, B. W. Kang, J. K. Seo, H. D. Kim, and J. W. Park, J. Korean. Phys. Soc. 53, 3334 (2008).

${ }^{140}$ W. J. Maeng and H. Kim, J. Electrochem. Soc. 155, H267 (2008).

${ }^{141}$ W. J. Maeng, J. Y. Son, and H. Kim, J. Electrochem. Soc. 156, G33 (2009).

${ }^{142}$ W. J. Maeng, W. H. Kim, J. H. Koo, S. J. Lim, C. S. Lee, T. Lee, and H. Kim, Appl. Phys. Lett. 96 (2010).
${ }^{143}$ W. J. Maeng and H. Kim, Appl. Phys. Lett. 91, 092901 (2007).

${ }^{144}$ H. Jeon and Y. Won, Appl. Phys. Lett. 93, 124104 (2008).

${ }^{145}$ S. X. Lao, R. M. Martin, and J. P. Chang, J. Vac. Sci. Technol. A 23, 488 (2005).

${ }^{146}$ W. J. Maeng and H. Kim, J. Appl. Phys. 104, 064111 (2008).

${ }^{147}$ H. Kim, S. Kim, S. Woo, H. Y. Chung, H. Kim, J. Park, and H. Jeon, J. Electrochem. Soc. 155, G299 (2008).

${ }^{148}$ J. R. Liu, R. M. Martin, and J. P. Chang, J. Vac. Sci. Technol. A 26, 1251 (2008).

${ }^{149}$ D. K. Joo, J. S. Park, and S. W. Kang, Electrochem. Solid-State Lett. 12, H77 (2009).

${ }^{150}$ S. W. Kim, S. H. Kwon, S. J. Jeong, J. S. Park, and S. W. Kang, Electrochem. Solid-State Lett. 11, H303 (2008).

${ }^{151}$ B. Y. Kim, M. G. Ko, E. J. Lee, M. S. Hong, Y. J. Jeon, and J. W. Park, J. Korean Phys. Soc. 49, 1303 (2006).

${ }^{152}$ E. J. Lee, M. G. Ko, B. Y. Kim, S. K. Park, H. D. Kim, and J. W. Park, J. Korean Phys. Soc. 49, 1243 (2006).

${ }^{153}$ H. Kim, S. Woo, J. Lee, H. Kim, Y. Kim, H. Lee, and H. Jeon, J. Electrochem. Soc. 157, H479 (2010).

${ }^{154}$ W. H. Kim, W. J. Maeng, K. J. Moon, J. M. Myoung, and H. Kim, Thin Solid Films 519, 362 (2010).

${ }^{155}$ W. S. Kim, S. K. Park, D. Y. Moon, B. W. Kang, H. D. Kim, and J. W. Park, Thin Solid Films 517, 3900 (2009).

${ }^{156}$ J. Hinz, A. J. Bauer, and L. Frey, Semicond. Sci. Technol. 25, 045009 (2010).

${ }^{157}$ J. Hinz, A. J. Bauer, T. Thiede, R. A. Fischer, and L. Frey, Semicond. Sci. Technol. 25, 075009 (2010).

${ }^{158}$ H. B. R. Lee, S. H. Bang, W. H. Kim, G. H. Gu, Y. K. Lee, T. M. Chung, C. G. Kim, C. G. Park, and H. Kim, Jpn. J. Appl. Phys. 49, 05FA11 (2010).

${ }^{159}$ K. M. Lee, C. Y. Kim, C. K. Choi, S. W. Yun, J. B. Ha, J. H. Lee, and J. Y. Lee, J. Korean Phys. Soc. 55, 1153 (2009).

${ }^{160}$ J. H. Lee, I. N. Lund, E. T. Eisenbraun, and R. E. Geer, Nanotechnology 22, 085603 (2011).

${ }^{161}$ N. E. Lay, G. A. T. Eyck, D. J. Duquette, and T. M. Lu, Electrochem. Solid-State Lett. 10, D13 (2007).

${ }^{162}$ G. A. Ten Eyck, J. J. Senkevich, F. Tang, D. L. Liu, S. Pimanpang, T. Karaback, G. C. Wang, T. M. Lu, C. Jezewski, and W. A. Lanford, Chem. Vap. Deposition 11, 60 (2005).

${ }^{163}$ G. A. Ten Eyck, S. Pimanpang, J. S. Juneja, H. Bakhru, T. M. Lu, and G. C. Wang, Chem. Vap. Deposition 13, 307 (2007).

${ }^{164}$ H. C. M. Knoops, A. J. M. Mackus, M. E. Donders, M. C. M. van de Sanden, P. H. L. Notten, and W. M. M. Kessels, Electrochem. Solid-State Lett. 12, G34 (2009).

${ }^{165}$ M. G. Ko, W. S. Kim, S. K. Park, H. D. Kim, and J. W. Park, J. Korean Phys. Soc. 53, 2123 (2008).

${ }^{166}$ O. K. Kwon, S. H. Kwon, H. S. Park, and S. W. Kang, J. Electrochem. Soc. 151, C753 (2004).

${ }^{167}$ O. K. Kwon, S. H. Kwon, H. S. Park, and S. W. Kang, Electrochem. Solid-State Lett. 7, C46 (2004).

${ }^{168}$ S. H. Kwon, O. K. Kwon, J. H. Kim, H. R. Oh, K. H. Kim, and S. W. Kang, J. Electrochem. Soc. 155, H296 (2008).

${ }^{169}$ S. S. Yim, M. S. Lee, K. S. Kim, and K. B. Kim, Appl. Phys. Lett. 89 (2006).

${ }^{170}$ S. S. Yim, D. J. Lee, K. S. Kim, M. S. Lee, S. H. Kim, and K. B. Kim, Electrochem. Solid-State Lett. 11, K89 (2008).

${ }^{171}$ J. Musschoot, Q. Xie, D. Deduytsche, K. De Keyser, D. Longrie, J. Haemers, S. Van den Berghe, R. L. Van Meirhaeghe, J. D'Haen, and C. Detavernier, Microelectron. Eng. 87, 1879 (2010).

${ }^{172}$ B. H. Choi, Y. H. Lim, J. H. Lee, Y. B. Kim, H. N. Lee, and H. K. Lee, Microelectron. Eng. 87, 1391 (2010).

${ }^{173}$ S. J. Park, W. H. Kim, H. B. R. Lee, W. J. Maeng, and H. Kim, Microelectron. Eng. 85, 39 (2008).

${ }^{174}$ Q. Xie, Y. L. Jiang, J. Musschoot, D. Deduytsche, C. Detavernier, R. L. Van Meirhaeghe, S. Van den Berghe, G. P. Ru, B. Z. Li, and X. P. Qu, Thin Solid Films 517, 4689 (2009).

${ }^{175}$ S. W. Kim, S. H. Kwon, S. J. Jeong, and S. W. Kang, J. Electrochem. Soc. 155, H885 (2008).

${ }^{176}$ S. H. Kwon, O. K. Kwon, J. S. Min, and S. W. Kang, J. Electrochem. Soc. 153, G578 (2006).

${ }^{177}$ S. J. Jeong, D. I. Kim, S. O. Kim, T. H. Han, J. D. Kwon, J. S. Park, and S. H. Kwon, J. Nanosci. Nanotechnol. 11, 671 (2011).

${ }^{178}$ C. C. Chang and F. M. Pan, J. Electrochem. Soc. 158, G97 (2011). 
${ }^{179}$ N. Leick, R. O. F. Verkuijlen, E. Langereis, S. Rushworth, F. Roozeboom, M. C. M. van de Sanden, and W. M. M. Kessels, J. Vac. Sci. Technol. A 29, 021016 (2011).

${ }^{180}$ D. Greenslit, T. Chakraborty, and E. Eisenbraun, J. Vac. Sci. Technol. B 27, 631 (2009).

${ }^{181}$ S. Kumar, D. Greenslit, T. Chakraborty, and E. T. Eisenbraun, J. Vac. Sci. Technol. A 27, 572 (2009).

${ }^{182}$ T. K. Eom, S. H. Kim, K. S. Park, S. Kim, and H. Kim, Electrochem. Solid-State Lett. 14, D10 (2011).

${ }^{183}$ W. Sari, T. K. Eom, S. H. Kim, and H. Kim, J. Electrochem. Soc. 158, D42 (2011).

${ }^{184}$ T. Murata, Y. Miyagawa, Y. Nishida, Y. Yamamoto, T. Yamashita, M. Matsuura, K. Asai, and H. Miyatake, Jpn. J. Appl. Phys. 49, 04 DB11 (2010).

${ }^{185}$ S. J. Won, S. Suh, M. S. Huh, and H. J. Kim, IEEE Electron. Dev. Lett. 31, 857 (2010).

${ }^{186}$ A. Kobayashi, N. Tsuji, A. Fukazawa, and N. Kobayashi, "Temperature dependence of GPC with PE-ALD SiO," in Book of Abstracts, 10th International Conference on Atomic Layer Deposition, Seoul, Korea, 20 June 2010.

${ }^{187}$ J. W. Lim, S. J. Yun, and J. H. Lee, ETRI J. 27, 118 (2005).

${ }^{188}$ Y. B. Jiang, N. G. Liu, H. Gerung, J. L. Cecchi, and C. J. Brinker, J. Am. Chem. Soc. 128, 11018 (2006).

${ }^{189}$ A. Cacciato, L. Breuil, H. Dekker, M. Zahid, G. S. Kar, J. L. Everaert, G. Schoofs, X. Shi, G. Van den Bosch, M. Jurczak, I. Debusschere, J. Van Houdt, A. Cockburn, L. Date, L. Q. Xa, M. Le, and W. Lee, Electrochem. Solid State Lett. 14, H271 (2011).

${ }^{190}$ G. Choi, L. Satyanarayana, and J. Park, Appl. Surf. Sci. 252, 7878 (2006).

${ }^{191}$ D. H. Kim, W. S. Kim, S. B. Lee, and S. H. Hong, Sens. Actuators B 147, 653 (2010).

${ }^{192}$ W. Lee, K. Hong, Y. Park, N. H. Kim, Y. Choi, and J. Park, Electron. Lett. 41, 475 (2005).

${ }^{193}$ W. Lee, Y. Choi, K. Hong, N. H. Kim, Y. Park, and J. Park, J. Korean Phys. Soc. 46, L756 (2005).

${ }^{194}$ D. H. Kim, J. H. Kwon, M. Kim, and S. H. Hong, J. Cryst. Growth 322, 33 (2011).

${ }^{195}$ E. Langereis, R. Roijmans, F. Roozeboom, M. C. M. van de Sanden, and W. M. M. Kessels, J. Electrochem. Soc. 158, G34 (2011).

${ }^{196}$ J. H. Ahn, J. Y. Kim, and S. W. Kang, Appl. Phys. Lett. 91, 062910 (2007).

${ }^{197}$ J. H. Ahn, S. W. Kang, J. Y. Kim, J. H. Kim, and J. S. Roh, J. Electrochem. Soc. 155, G185 (2008).

${ }^{198}$ J. H. Ahn, J. Y. Kim, J. H. Kim, J. S. Roh, and S. W. Kang, Electrochem. Solid-State Lett. 12, G5 (2009).

${ }^{199}$ J. H. Lee, Y. J. Cho, Y. S. Min, D. Kim, and S. W. Rhee, J. Vac. Sci. Technol. A 20, 1828 (2002).

${ }^{200}$ W. J. Lee, I. K. You, S. O. Ryu, B. G. Yu, K. I. Cho, S. G. Yoon, and C. S. Lee, Jpn. J. Appl. Phys., Part 1 40, 6941 (2001).

${ }^{201}$ W. C. Shin, S. O. Ryu, I. K. You, B. G. Yu, W. J. Lee, K. J. Choi, and S. G. Yoon, J. Electrochem. Soc. 151, C292 (2004).

${ }^{202}$ W. J. Lee, W. C. Shin, B. G. Chae, S. O. Ryu, I. K. You, S. M. Cho, B. G. Yu, and B. C. Shin, Integr. Ferroelectr. 46, 275 (2002).

${ }^{203}$ W. C. Shin, S. O. Ryu, I. K. You, S. M. Yoon, S. M. Cho, N. Y. Lee, K. D. Kim, B. G. Yu, W. J. Lee, K. J. Choi, and S. G. Yoon, Electrochem. Solid-State Lett. 7, F31 (2004).

${ }^{204}$ H. Kim, C. Cabral, C. Lavoie, and S. M. Rossnagel, J. Vac. Sci. Technol. B 20, 1321 (2002).

${ }^{205}$ H. Kim and S. M. Rossnagel, Thin Solid Films 441, 311 (2003).

${ }^{206}$ S. M. Rossnagel, A. Sherman, and F. Turner, J. Vac. Sci. Technol. B 18, 2016 (2000).

${ }^{207}$ W. J. Maeng, S. J. Park, and H. Kim, J. Vac. Sci. Technol. B 24, 2276 (2006).

${ }^{208}$ W. J. Maeng and H. Kim, Electrochem. Solid-State Lett. 9, G191 (2006).

${ }^{209}$ W. J. Maeng, J. W. Lee, J. M. Myoung, and H. Kim, Jpn. J. Appl. Phys., Part 1 46, 3224 (2007).

${ }^{210}$ A. Niskanen, U. Kreissig, M. Leskela, and M. Ritala, Chem. Mater. 19, 2316 (2007).

${ }^{211}$ D. F. Gu, J. Li, S. K. Dey, H. De Waard, and S. Marcus, J. Vac. Sci. Technol. B 24, 2230 (2006).

${ }^{212}$ C. Hossbach, S. Teichert, J. Thomas, L. Wilde, H. Wojcik, D. Schmidt, B. Adolphi, M. Bertram, U. Muhle, M. Albert, S. Menzel, B. Hintze, and J. W. Bartha, J. Electrochem. Soc. 156, H852 (2009).
${ }^{213}$ M. K. Song and S. W. Rhee, Chem. Vap. Deposition 14, 334 (2008).

${ }^{214}$ M. K. Song and S. W. Rhee, J. Electrochem. Soc. 155, H823 (2008).

${ }^{215}$ G. H. Cho and S. W. Rhee, Electrochem. Solid-State Lett. 13, H426 (2010).

${ }^{216}$ T. J. Park, J. H. Kim, J. H. Jang, K. D. Na, C. S. Hwang, J. H. Kim, G. M. Kim, J. H. Choi, K. J. Choi, and J. H. Jeong, Appl. Phys. Lett. 91, 252106 (2007).

${ }^{217}$ Q. Xie, D. Deduytsche, J. Musschoot, R. L. Van Meirhaeghe, C. Detavernier, S. F. Ding, and X. P. Qu, Microelectron. Eng. 88, 646 (2011).

${ }^{218}$ H. Kim, A. J. Kellock, and S. M. Rossnagel, J. Appl. Phys. 92, 7080 (2002).

${ }^{219}$ H. Kim, C. Lavoie, M. Copel, V. Narayanan, D. G. Park, and S. M. Rossnagel, J. Appl. Phys. 95, 5848 (2004).

${ }^{220}$ C. C. Chang, F. M. Pan, and C. W. Chen, J. Electrochem. Soc. 157, G62 (2010).

${ }^{221}$ H. S. Chung, J. D. Kwon, and S. W. Kang, J. Electrochem. Soc. 153, C751 (2006).

${ }^{222}$ H. C. M. Knoops, L. Baggetto, E. Langereis, M. C. M. van de Sanden, J. H. Klootwijk, F. Roozeboom, R. A. H. Niessen, P. H. L. Notten, and W. M. M. Kessels, J. Electrochem. Soc. 155, G287 (2008).

${ }^{223}$ E. Langereis, H. C. M. Knoops, A. J. M. Mackus, F. Roozeboom, M. C. M. Van de Sanden, and W. M. M. Kessels, J. Appl. Phys. 102, 083517 (2007).

${ }^{224}$ A. Furuya, H. Tsuda, and S. Ogawa, J. Vac. Sci. Technol. B 23, 979 (2005).

${ }^{225}$ Q. Xie, J. Musschoot, C. Detavernier, D. Deduytsche, R. L. Van Meirhaeghe, S. Van den Berghe, Y. L. Jiang, G. P. Ru, B. Z. Li, and X. P. Qu, Microelectron. Eng. 85, 2059 (2008).

${ }^{226}$ H. Kim, C. Detavernier, O. Van der Straten, S. M. Rossnagel, A. J. Kellock, and D. G. Park, J. Appl. Phys. 98, 014308 (2005).

${ }^{227}$ J. S. Park, M. J. Lee, C. S. Lee, and S. W. Kang, Electrochem. Solid-State Lett. 4, C17 (2001).

${ }^{228}$ J. S. Park, H. S. Park, and S. W. Kang, J. Electrochem. Soc. 149, C28 (2002).

${ }^{229}$ J. Y. Kim, K. W. Lee, H. O. Park, Y. D. Kim, H. Jeon, and Y. Kim, J. Korean Phys. Soc. 45, 1069 (2004).

${ }^{230}$ D. K. Kim, B. H. Kim, H. G. Woo, D. H. Kim, and H. K. Shin, J. Nanosci. Nanotechnol. 6, 3392 (2006).

${ }^{231}$ R. Sreenivasan, T. Sugawara, K. C. Saraswat, and P. C. McIntyre, Appl. Phys. Lett. 90, 102101 (2007).

${ }^{232}$ H. Kim and S. M. Rossnagel, J. Vac. Sci. Technol. A 20, 802 (2002).

${ }^{233}$ K. E. Elers, J. Winkler, K. Weeks, and S. Marcus, J. Electrochem. Soc. 152, G589 (2005).

${ }^{234}$ J. D. Kwon and J. S. Park, J. Korean. Phys. Soc. 57, 806 (2010).

${ }^{235}$ J. S. Park, S. W. Kang, and H. Kim, J. Vac. Sci. Technol. B 24, 1327 (2006).

${ }^{236}$ S. B. S. Heil, E. Langereis, A. Kemmeren, F. Roozeboom, M. C. M. van de Sanden, and W. M. M. Kessels, J. Vac. Sci. Technol. A 23, L5 (2005).

${ }^{237}$ S. B. S. Heil, E. Langereis, F. Roozeboom, M. C. M. Van de Sanden, and W. M. M. Kessels, J. Electrochem. Soc. 153, G956 (2006).

${ }^{238}$ E. Langereis, S. B. S. Heil, M. C. M. Van de Sanden, and W. M. M. Kessels, J. Appl. Phys. 100, 023534 (2006).

${ }^{239}$ F. Greer, D. Fraser, J. W. Coburn, and D. B. Graves, J. Vac. Sci. Technol. A 21, 96 (2003).

${ }^{240}$ P. Caubet, T. Blomberg, R. Benaboud, C. Wyon, E. Blanquet, J. P. Gonchond, M. Juhel, P. Bouvet, M. Gros-Jean, J. Michailos, C. Richard, and B. Iteprat, J. Electrochem. Soc. 155, H625 (2008).

${ }^{241}$ J. Y. Kim, Y. Kim, and H. Jeon, Jpn. J. Appl. Phys., Part 2 42, L414 (2003).

${ }^{242}$ D. H. Kim, Y. J. Kima, J. H. Park, and J. H. Kim, Mater. Sci. Eng. C 24, 289 (2004).

${ }^{243}$ J. Y. Kim, S. Seo, D. Y. Kim, H. Jeon, and Y. Kim, J. Vac. Sci. Technol. A 22, 8 (2004).

${ }^{244}$ J. Y. Kim, D. Y. Kim, H. O. Park, and H. T. Jeon, J. Electrochem. Soc. 152, G29 (2005).

${ }^{245}$ J. Y. Kim, D. Y. Kim, H. O. Park, and H. Jeon, J. Korean. Phys. Soc. 45 , 1639 (2004).

${ }^{246}$ N. G. Kubala, P. C. Rowlette, and C. A. Wolden, J. Phys. Chem. C 113, 16307 (2009).

${ }^{247}$ N. G. Kubala and C. A. Wolden, Thin Solid Films 518, 6733 (2010).

${ }^{248}$ A. Sarkar, S. E. Potts, S. A. Rushworth, F. Roozeboom, M. C. M. van de Sanden, and W. M. M. Kessels, ECS Trans. 33, 385 (2010). 
${ }^{249}$ G. X. Liu, F. K. Shan, W. J. Lee, and B. C. Shin, J. Korean. Phys. Soc. 50, 1827 (2007).

${ }^{250}$ J. J. Park, W. J. Lee, G. H. Lee, I. S. Kim, B. C. Shin, and S. G. Yoon, Integr. Ferroelectr. 68, 129 (2004).

${ }^{251}$ B. W. Kang, W. S. Kim, C. M. Hwang, D. Y. Moon, J. J. Kim, J. G. Park, and J. W. Park, Jpn. J. Appl. Phys. 49, 08JG05 (2010).

${ }^{252}$ C. S. Lee, J. Kim, J. Y. Son, W. Choi, and H. Kim, Appl. Catal. B 91, 628 (2009).

${ }^{253}$ C. S. Lee, J. Kim, G. H. Gu, D. H. Jo, C. G. Park, W. Choi, and H. Kim, Thin Solid Films 518, 4757 (2010).

${ }^{254}$ Q. Xie, J. Musschoot, D. Deduytsche, R. L. Van Meirhaeghe, C. Detavernier, S. Van den Berghe, Y. L. Jiang, G. P. Ru, B. Z. Li, and X. P. Qu, J. Electrochem. Soc. 155, H688 (2008).

${ }^{255}$ J. H. Kim, W. J. Lee, and S. G. Yoon, Integr. Ferroelectr. 68, 63 (2004).

${ }^{256}$ W. S. Kim, M. G. Ko, T. S. Kim, S. K. Park, Y. K. Moon, S. H. Lee, J. G. Park, and J. W. Park, J. Nanosci. Nanotechnol. 8, 4726 (2008).

${ }^{257}$ Y. K. Moon, S. H. Kim, D. Y. Moon, W. S. Kim, and J. W. Park, J. Korean Phys. Soc. 51, 1732 (2007).

${ }^{258}$ H. Y. Jeong, Y. I. Kim, J. Y. Lee, and S. Y. Choi, Nanotechnology 21, 115203 (2010).

${ }^{259}$ S. J. Won, S. Suh, S. W. Lee, G. J. Choi, C. S. Hwang, and H. J. Kim, Electrochem. Solid-State Lett. 13, G13 (2010).

${ }^{260}$ V. R. Rai and S. Agarwal, J. Phys. Chem. C 113, 12962 (2009).

${ }^{261}$ A. Niskanen, K. Arstila, M. Leskela, and M. Ritala, Chem. Vap. Deposition 13, 152 (2007).

${ }^{262}$ H. Y. Jeong, J. Y. Lee, M. K. Ryu, and S. Y. Choi, Phys. Status Solidi (RRL) 4, 28 (2010).

${ }^{263}$ S. Kim, S. L. Brown, S. M. Rossnagel, J. Bruley, M. Copel, M. J. P. Hopstaken, V. Narayanan, and M. M. Frank, J. Appl. Phys. 107, 054102 (2010).

${ }^{264}$ J. W. Park, D. Lee, H. Kwon, S. Yoo, and J. Huh, IEEE Electron. Dev. Lett. 30, 739 (2009).

${ }^{265}$ J. W. Park, D. Y. Lee, H. Kwon, and S. Yoo, IEEE Electron. Dev. Lett. 30, 362 (2009).

${ }^{266}$ W. S. Yang and S. W. Kang, Thin Solid Films 500, 231 (2006).

${ }^{267}$ Y. J. Lee and S. W. Kang, Appl. Phys. Lett. 86, 071919 (2005).

${ }^{268}$ Y. J. Lee and S. W. Kang, Electrochem. Solid-State Lett. 6, C70 (2003).

${ }^{269}$ J. S. Park and S. W. Kang, Electrochem. Solid-State Lett. 7, C87 (2004).

${ }^{270}$ J. W. Lim, S. J. Yun, and J. H. Kim, ETRI J. 31, 675 (2009).

${ }^{271}$ J. Musschoot, D. Deduytsche, H. Poelman, J. Haemers, R. L. Van Meirhaeghe, S. Van den Berghe, and C. Detavernier, J. Electrochem. Soc. 156, 122 (2009).

${ }^{272}$ D. H. Kim, Y. J. Kim, Y. S. Song, B. T. Lee, J. H. Kim, S. Suh, and R. Gordon, J. Electrochem. Soc. 150, C740 (2003).

${ }^{273}$ Y. T. Kim and J. H. Park, Phys. Status Solidi A 202, R164 (2005).

${ }^{274}$ H. S. Sim, S. I. Kim, H. Jeon, and Y. T. Kim, Jpn. J. Appl. Phys., Part 1 42, 6359 (2003).

${ }^{275}$ T. T. Van and J. P. Chang, Surf. Sci. 596, 1 (2005).

${ }^{276}$ J. Hoang, T. T. Van, M. Sawkar-Mathur, B. Hoex, M. C. M. van de Sanden, W. M. M. Kessels, R. Ostroumov, K. L. Wang, J. R. Bargar, and J. P. Chang, J. Appl. Phys. 101, 123116 (2007).

${ }^{277}$ T. T. Van and J. P. Chang, Appl. Phys. Lett. 87, 011907 (2005).

${ }^{278}$ T. T. Van, J. R. Bargar, and J. P. Chang, J. Appl. Phys. 100, 023115 (2006).

${ }^{279}$ T. T. Van, J. Hoang, R. Ostroumov, K. L. Wang, J. R. Bargar, J. Lu, H. O. Blom, and J. P. Chang, J. Appl. Phys. 100, 073512 (2006).

${ }^{280}$ S. H. K. Park, C. S. Hwang, H. S. Kwack, J. H. Lee, and H. Y. Chu, Electrochem. Solid-State Lett. 9, G299 (2006).

${ }^{281}$ C. R. Kim, C. M. Shin, J. Y. Lee, J. H. Heo, T. M. Lee, J. H. Park, H. Ryu, C. S. Son, and J. H. Chang, Current Appl. Phys. 10, S294 (2010).

${ }^{282}$ S. J. Lim, J. M. Kim, D. Kim, C. Lee, J. S. Park, and H. Kim, Electrochem. Solid-State Lett. 13, H151 (2010).

${ }^{283}$ D. Kim, H. Kang, J. M. Kim, and H. Kim, Appl. Surf. Sci. 257, 3776 (2011).

${ }^{284}$ D. A. Mourey, D. L. A. Zhao, and T. N. Jackson, IEEE Electron. Dev. Lett. 31, 326 (2010).

${ }^{285}$ D. A. Mourey, D. A. L. Zhao, J. Sun, and T. N. Jackson, IEEE Trans. Electron Devices 57, 530 (2010).

${ }^{286}$ D. L. Zhao, D. A. Mourey, and T. N. Jackson, IEEE Electron. Dev. Lett. 31, 323 (2010).

${ }^{287}$ P. C. Rowlette, C. G. Allen, O. B. Bromley, and C. A. Wolden, J. Vac. Sci. Technol. A 27, 761 (2009).

${ }^{288}$ P. C. Rowlette, C. G. Allen, O. B. Bromley, A. E. Dubetz, and C. A. Wolden, Chem. Vap. Deposition 15, 15 (2009).
${ }^{289}$ J. Y. Kim, S. H. Kim, H. Seo, J. H. Kim, and H. Jeon, Electrochem. Solid-State Lett. 8, G82 (2005).

${ }^{290}$ Y. Kim, J. Koo, J. W. Han, S. Choi, H. Jeon, and C. G. Park, J. Appl. Phys. 92, 5443 (2002).

${ }^{291}$ S. J. Yun, J. W. Lim, and J. H. Lee, Electrochem. Solid-State Lett. 7, F81 (2004).

${ }^{292}$ S. J. Yun, J. B. Koo, J. W. Lim, and S. H. Kim, Electrochem. Solid-State Lett. 10, H90 (2007).

${ }^{293}$ S. J. Yun, J. W. Lim, and J. H. Lee, Electrochem. Solid-State Lett. 8, F47 (2005).

${ }^{294}$ J. Koo, Y. Kim, and H. Jeon, Jpn. J. Appl. Phys., Part 1 41, 3043 (2002).

${ }^{295}$ Y. Tak and K. Yong, Surf. Rev. Lett. 12, 215 (2005).

${ }^{296}$ S. Cho, K. Lee, P. Song, H. Jeon, and Y. Kim, Jpn. J. Appl. Phys., Part 1 46, 4085 (2007)

${ }^{297}$ S. E. Potts, C. J. Carmalt, C. S. Blackman, F. Abou-Chahine, N. Leick, W. M. M. Kessels, H. O. Davies, and P. N. Heys, Inorg. Chim. Acta 363, 1077 (2010).

${ }^{298}$ A. Sherman, Patent No. US 5916365 (1996).

${ }^{299}$ M. A. Lieberman and A. J. Lichtenberg, Principles of Plasma Discharges and Materials Processing, 2nd ed. (John Wiley \& Sons, New York, 2005).

${ }^{300}$ A. Grill, Cold Plasmas in Materials Fabrication: From Fundamentals to Applications (Wiley-IEEE Press, New York, 1994).

${ }^{301}$ S. B. S. Heil, F. Roozeboom, M. C. M. van de Sanden, and W. M. M. Kessels, J. Vac. Sci. Technol. A 26, 472 (2008).

${ }^{302}$ A. J. M. Mackus, S. B. S. Heil, E. Langereis, H. C. M. Knoops, M. C. M. Van de Sanden, and W. M. M. Kessels, J. Vac. Sci. Technol. A 28, 77 (2010).

${ }^{303}$ H. B. Profijt, P. Kudlacek, M. C. M. Van de Sanden, and W. M. M. Kessels, J. Electrochem. Soc. 158, G88 (2011).

${ }^{304}$ H. C. M. Knoops, E. Langereis, M. C. M. van de Sanden, and W. M. M. Kessels, J. Electrochem. Soc. 157, G241 (2010).

${ }^{305}$ J. C. Greaves and J. W. Linnett, Trans. Faraday Soc. 55, 1346 (1959).

${ }^{306}$ B. J. Wood and H. Wise, J. Appl. Chem. 65, 1976 (1961).

${ }^{307}$ Y. C. Kim and M. Boudart, Langmuir 7, 2999 (1991).

${ }^{308}$ A. D. Tserepi and T. A. Miller, J. Appl. Phys. 75, 7231 (1994).

${ }^{309}$ J. Abrefah and D. R. Olander, Surf. Sci. 209, 291 (1989).

${ }^{310}$ A. Bouchoule and P. Ranson, J. Vac. Sci. Technol. A 9, 317 (1991).

${ }^{311}$ S. F. Adams and T. A. Miller, Plasma Sources Sci. Technol. 9, 248 (2000).

${ }^{312}$ M. Mozetic and A. Zalar, Appl. Surf. Sci. 158, 263 (2000).

${ }^{313}$ H. C. M. Knoops, E. Langereis, M. C. M. van de Sanden, and W. M. M. Kessels, J. Vac. Sci. Technol. A. (to be published).

${ }^{314}$ J. T. Gudmundsson, I. G. Kouznetsov, K. K. Patel, and M. A. Lieberman, J. Phys. D 34, 1100 (2001).

${ }^{315}$ MKS website, http://www.mksinst.com (May 31, 2011).

${ }^{316}$ Advanced Energy website, http://www.advanced-energy.com/ (May 31, 2011).

${ }^{317}$ E. Kawamura, V. Vahedi, M. A. Lieberman, and C. K. Birdsall, Plasma Sources Sci. Technol. 8, R45 (1999).

${ }^{318}$ H. B. Profijt, M. C. M. van de Sanden, and W. M. M. Kessels (to be published).

${ }^{319}$ J. W. Lim, S. J. Yun, and J. H. Lee, Electrochem. Solid-State Lett. 7, F73 (2004).

${ }^{320}$ S. J. Yun, J. W. Lim, and J. H. Lee, Electrochem. Solid-State Lett. 7, C13 (2004).

${ }^{321}$ J. Beynet, P. Wong, A. Miller, S. Locorotondo, D. Vangoidsenhoven, T. H. Yoon, M. Demand, H. S. Park, T. Vandeweyer, H. Sprey, Y. M. Yoo, and M. Maenhoudt, Proc. SPIE 7520, 75201J (2009).

${ }^{322}$ M. D. Groner, F. H. Fabreguette, J. W. Elam, and S. M. George, Chem. Mater. 16, 639 (2004).

${ }^{323}$ G. Dingemans, M. C. M. van de Sanden, and W. M. M. Kessels, Electrochem. Solid-State Lett. 13, H76 (2010).

${ }^{324}$ P. Williams, A. Kingsley, T. Leese, Y. Otsuka, and K. Uotani, in Book of Abstracts, 8th International Conference on Atomic Layer Deposition, Bruges, Belgium, 7 February 2008.

${ }^{325}$ Q. Xie, Y. L. Jiang, C. Detavernier, D. Deduytsche, R. L. Van Meirhaeghe, G. P. Ru, B. Z. Li, and X. P. Qu, J. Appl. Phys. 102, 083521 (2007).

${ }^{326}$ R. Katamreddy, Z. Wang, V. Omarjee, P. Venkateswara Raoa, C. Dussarrat, and C. Blasco, ECS Trans. 25, 217 (2009).

${ }^{327}$ J. A. Kittl, K. Opsomer, M. Popovici, N. Menou, B. Kaczer, X. P. Wang, C. Adelmann, M. A. Pawlak, K. Tomida, A. Rothschild, B. Govoreanu, 
R. Degraeve, M. Schaekers, M. Zahid, A. Delabie, J. Meersschaut, W. Polspoel, S. Clima, G. Pourtois, W. Knaepen, C. Detavernier, V. V. Afanas'ev, T. Blomberg, D. Pierreux, J. Swerts, P. Fischer, J. W. Maes, D. Manger, W. Vandervorst, T. Conard, A. Franquet, P. Favia, H. Bender, B. Brijs, S. van Elshocht, M. Jurczak, J. Van Houdt, and D. J. Wouters, Microelectron. Eng. 86, 1789 (2009).

${ }^{328}$ H. Kim, J. Vac. Sci. Technol. B 21, 2231 (2003).

${ }^{329}$ M. Ritala, P. Kalsi, D. Riihela, K. Kukli, M. Leskela, and J. Jokinen, Chem. Mater. 11, 1712 (1999).

${ }^{330}$ B. B. Burton, A. R. Lavoie, and S. M. George, J. Electrochem. Soc. 155, D508 (2008).

${ }^{331}$ P. Alen, M. Juppo, M. Ritaka, T. Sajavaara, J. Keinonen, and M. Leskela, J. Electrochem. Soc. 148, G566 (2001).

${ }^{332}$ T. Aaltonen, "Atomic Layer Deposition of Noble Metal Thin Films," Ph.D. thesis, University of Helsinki, Finland, 2005.

${ }^{333}$ T. Aaltonen, M. Ritala, T. Sajavaara, J. Keinonen, and M. Leskela, Chem. Mater. 15, 1924 (2003).

${ }^{334}$ W. M. M. Kessels, H. C. M. Knoops, S. A. F. Dielissen, A. J. M. Mackus, and M. C. M. van de Sanden, Appl. Phys. Lett. 95, 013114 (2009).

${ }^{335}$ J. Hämäläinen, F. Munnik, M. Ritala, and M. Leskela, Chem. Mater. 20, 6840 (2008).

${ }^{336}$ J. Dendooven, D. Deduytsche, J. Musschoot, R. L. Vanmeirhaeghe, and C. Detavernier, J. Electrochem. Soc. 156, 63 (2009).

${ }^{337}$ W. M. M. Kessels, in Book of Abstracts, Baltic Conference on Atomic Layer Deposition 2006, Oslo, Norway, 19 June 2006.

${ }^{338}$ J. W. Elam, D. Routkevitch, P. P. Mardilovich, and S. M. George, Chem. Mater. 15, 3507 (2003).

${ }^{339}$ J. Y. Kim, J. H. Kim, J. H. Ahn, P. K. Park, and S. W. Kang, J. Electrochem. Soc. 154, H1008 (2007).

${ }^{340}$ O. S. Kwon, S. K. Kim, M. Cho, C. S. Hwang, and J. Jeong, J. Electrochem. Soc. 152, C229 (2005).

${ }^{341}$ H. C. M. Knoops, J. W. Elam, J. A. Libera, and W. M. M. Kessels, Chem. Mater. 23, 2381 (2011).

${ }^{342}$ S. T. Oyama, Cat. Rev. Sci. Eng. 42, 279 (2000).

${ }^{343}$ S. C. Ha, E. Choi, S. H. Kim, and J. S. Roh, Thin Solid Films 476, 252 (2005).

${ }^{344}$ H. Ren, Y. Nishi, and J. L. Shohet, Electrochem. Solid-State Lett. 14, H107 (2011).

${ }^{345}$ T. Takagi, J. Vac. Sci. Technol. A 2, 382 (1984).

${ }^{346}$ C. Cismaru and J. L. Shohet, Appl. Phys. Lett. 74, 2599 (1999).

${ }^{347}$ K. G. Druijf, J. M. M. Denijs, E. Vanderdrift, E. H. A. Granneman, and P. Balk, Appl. Phys. Lett. 65, 347 (1994).

${ }^{348}$ H. L. Hughes and J. M. Benedetto, IEEE Trans. Nucl. Sci. 50, 500 (2003).

${ }^{349}$ S. Samukawa, Y. Ishikawa, S. Kumagai, and N. Okigawa, Jpn. J. Appl. Phys., Part 2 40, L1346 (2001).

${ }^{350}$ J. L. Lauer, J. L. Shohet, and Y. Nishi, Appl. Phys. Lett. 94, 162907 (2009).
${ }^{351}$ H. Ren, S. L. Cheng, Y. Nishi, and J. L. Shohet, Appl. Phys. Lett. 96, 192904 (2010).

${ }^{352}$ G. S. Upadhyaya and J. L. Shohet, Appl. Phys. Lett. 90, 072904 (2007).

${ }^{353}$ Levitech website, http://www.levitech.nl (May 31, 2011).

${ }^{354}$ TNO website, http://www.tno.nl (May 31, 2011).

${ }^{355}$ SolayTec website, http://www.solaytec.com (May 31, 2011).

${ }^{356} \mathrm{G}$. Dingemans and W. M. M. Kessels, Proceedings of the 25 th EU PVSEC, Valencia, Spain, 6-10 September, 2010, p. 1083.

${ }^{357}$ H. Kim, Surf. Coat. Technol. 200, 3104 (2006).

${ }^{358}$ J. Robertson, Rep. Prog. Phys. 69, 327 (2005).

${ }^{359}$ J. H. Choi, Y. Mao, and J. P. Chang, Mater. Sci. Eng. R 72, 97 (2011).

${ }^{360}$ M. Vehkamaki, T. Hatanpaa, T. Hanninen, M. Ritala, and M. Leskela, Electrochem. Solid-State Lett. 2, 504 (1999).

${ }^{361}$ S. Owa, H. Nagasaka, K. Nakano, and Y. Ohmura, Proc. SPIE 6154, 615408 (2006).

${ }^{362}$ Y. Borodovky, Proc. SPIE 6153, 615301 (2006).

363"'Below 22 nm, Spacers Get Unconventional: Interview with ASM," http://www.solid-state.com (January 13, 2011).

${ }^{364}$ P. F. Carcia, R. S. Mclean, M. H. Reilly, M. D. Groner, and S. M. George, Appl. Phys. Lett. 89, 031915 (2006).

${ }^{365}$ S. H. K. Park, J. Oh, C. S. Hwang, J. I. Lee, Y. S. Yang, and H. Y. Chu, Electrochem. Solid-State Lett. 8, H21 (2005).

${ }^{366}$ X. Du, K. Zhang, K. Holland, T. Tombler, and M. Moskovits, Appl. Opt. 48, 6470 (2009)

${ }^{367}$ R. Matero, M. Ritala, M. Leskela, T. Salo, J. Aromaa, and O. Forsen, J. Phys. IV 9, 493 (1999).

${ }^{368}$ C. X. Shan, X. Hou, and K. L. Choy, Surf. Coat. Technol. 202, 2399 (2007).

${ }^{369}$ K. Sugioka, J. F. Fan, K. Toyoda, H. Waki, and H. Takai, J. Mater. Res. 7, 185 (1992)

${ }^{370}$ W. Lehnert, G. Ruhl, and A. Gschwandtner, "Plasma enhanced ALD of high k dielectrics in a batch system", in Book of Abstracts, Baltic ALD 2010 \& GerALD2, Hamburg, Germany, 16 September 2010.

${ }^{371} \mathrm{H}$. W. de Vries, WO patent 2007145513, 2007.

${ }^{372}$ FujiFilm Manufacturing Europe website, http://www.fujitilburg.nl (May 31, 2011).

${ }^{373}$ J. M. Ajello, S. K. Srivastava, and Y. L. Yung, Phys. Rev. A 25, 2485 (1982).

${ }^{374}$ A. C. Fozza, A. Kruse, A. Hollander, A. Ricard, and M. R. Wertheimer, J. Vac. Sci. Technol. A 16, 72 (1998).

${ }^{375}$ R. Henck, C. Fuchs, and E. Fogarassy, J. Appl. Phys. 79, 2259 (1996).

${ }^{376}$ J. A. Young, C. P. Malone, P. V. Johnson, J. M. Ajello, X. Liu, and I. Kanik, J. Phys. B 43, 135201 (2010).

${ }^{377}$ Z. Lianzhu, Z. Shuxia, and M. Xiulan, Plasma Sci. Technol. 10, 455 (2008).

${ }^{378}$ P. C. P. Bouten, G. Nisato, P. J. Slikkerveer, H. F. van Tongeren, H. E. Itzhak, and P. van der Sluis, U.S. patent 6,993,956, 2006. 